\title{
A Multidimensional Approach to Understanding Gender and Health among Middle-Aged and Older Adults
}

\author{
Rebecca K. Delaney
}

Follow this and additional works at: https://researchrepository.wvu.edu/etd

\section{Recommended Citation}

Delaney, Rebecca K., "A Multidimensional Approach to Understanding Gender and Health among MiddleAged and Older Adults" (2017). Graduate Theses, Dissertations, and Problem Reports. 5466.

https://researchrepository.wvu.edu/etd/5466

This Dissertation is protected by copyright and/or related rights. It has been brought to you by the The Research Repository @ WVU with permission from the rights-holder(s). You are free to use this Dissertation in any way that is permitted by the copyright and related rights legislation that applies to your use. For other uses you must obtain permission from the rights-holder(s) directly, unless additional rights are indicated by a Creative Commons license in the record and/ or on the work itself. This Dissertation has been accepted for inclusion in WVU Graduate Theses, Dissertations, and Problem Reports collection by an authorized administrator of The Research Repository @ WVU.

For more information, please contact researchrepository@mail.wvu.edu. 
A Multidimensional Approach to Understanding Gender and Health among Middle-Aged and Older Adults

Rebecca K. Delaney, M.S.

Dissertation submitted to the Eberly College of Arts and Sciences at West Virginia University in partial fulfillment of the requirements for the degree of

Doctor of Philosophy In Psychology

JoNell Strough, Ph.D., Chair Julie Hicks Patrick, Ph.D. Nicholas Turiano, Ph.D. Kevin Larkin, Ph.D. Kristina Hash, Ph.D.

Department of Psychology Morgantown, West Virginia 2017

Keywords: gender, health, masculinity, femininity, midlife, older adults

Copyright 2017

[Rebecca Delaney] 


\section{ABSTRACT \\ A Multidimensional Approach to Understanding Gender and Health among}

\section{Middle-Aged and Older Adults}

\section{Rebecca Delaney}

"Women get sicker, men die quicker," is a statement used to describe how women suffer from more chronic health conditions, greater physical limitations, and report poorer health compared to men (Crimmins, Kim, \& Solé -Auró, 2011; Lochner \& Cox, 2010), whereas men have a shorter life expectancy compared to women (CDC, 2013). Although biological sex differences offer some explanation for why men and women differ in health and mortality, there is much left unexplained (Miller, 2014). Gender, a psychosocial construct that reflects attitudes, feelings, and behaviors prescribed by cultural expectations for men and women (Unger, 1979) has been highlighted as an important, yet understudied construct, that can influence sex differences in health (Courtenay, 2000; Evans, Frank, Oliffe, \& Gregory, 2011). The current study applied a multidimensional approach that tested how gender-typed traits (e.g., masculine and feminine traits) and behaviors (e.g., interdependence and health behaviors) related to three health outcomes (i.e., perceived health, physical functioning, and chronic health burden). The sample was comprised of 486 middle-aged and older adults (40-79 years old; $M_{\text {age }}=55.57$; 54.5\% female) recruited from Amazon's Mechanical Turk Program and the community (i.e., via social media). Findings indicated that although there were no main sex differences in health outcomes, gender-typed traits were differentially associated with behaviors (e.g., social support, health-risk behaviors) that are known to impact health. For example, men and women who reported greater endorsement of masculine traits reported significantly greater health-promoting behaviors, greater social support, less interdependent problem solving, and greater health-risk behaviors. Men and women who reported greater endorsement of feminine traits reported significantly greater health-promoting behaviors, greater social support, greater interdependent problem solving, and fewer health-risk behaviors. The findings provide a new perspective for understanding how gender may influence behaviors, which in turn can lead to varying health consequences. 


\section{ACKNOWLEDGEMENTS}

I would like to thank Dr. JoNell Strough, my academic advisor and dissertation chair, for her advice and support throughout this project. In addition, I am grateful for receiving the West Virginia University Foundation Distinguished Doctoral Scholarship which supported the research costs for my dissertation. I also appreciate the time and useful comments that my committee members, Dr. Julie Hicks Patrick, Dr. Nicholas Turiano, Dr. Kevin Larkin, and Dr. Kristina Hash, provided. Lastly, thank you to my family members, boyfriend, and friends who have been a huge source of support throughout my time in graduate school. 
TABLE OF CONTENTS

Page

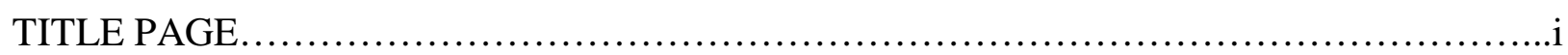

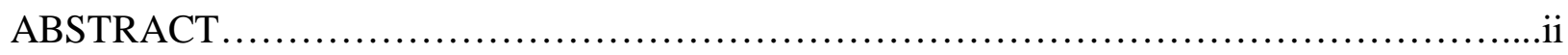

ACKNOWLEDGEMENTS ................................................................

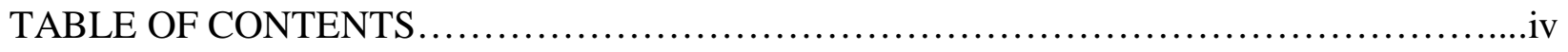

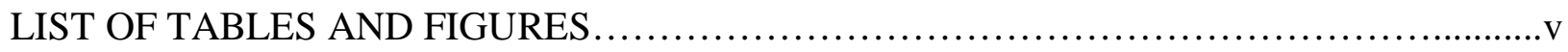

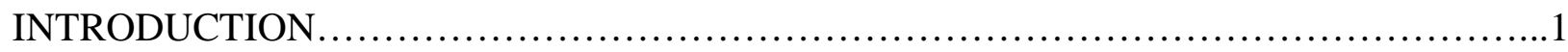

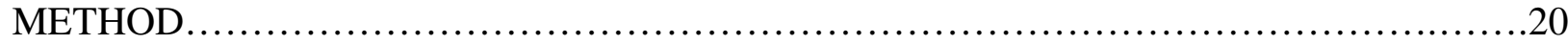



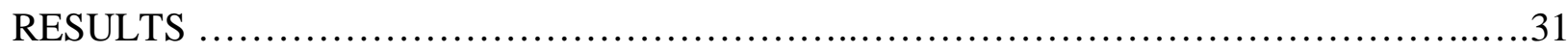

DISCUSSION ..................................................................40

LIMITATIONS AND FUTURE DIRECTIONS....................................48

CONCLUSION ...................................................................50

REFERENCES................................................................. 51

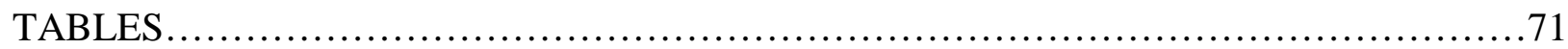

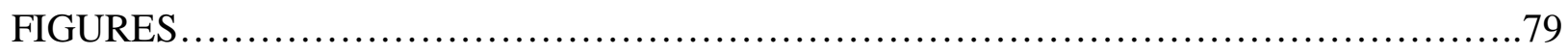






\section{LIST OF TABLES AND FIGURES}

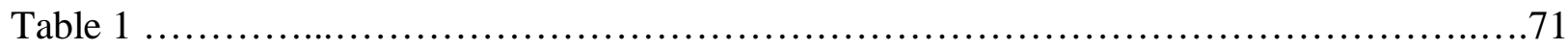

Bivariate Correlations for Full Sample

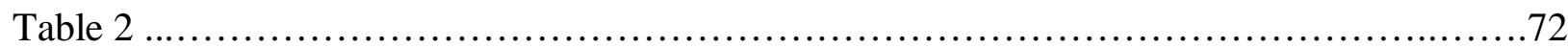

Bivariate Correlations for Men and Women Separately

Table 3 ......................................................................73

MANOVA: Multivariate Effects for Gender-Typed Traits and Behaviors

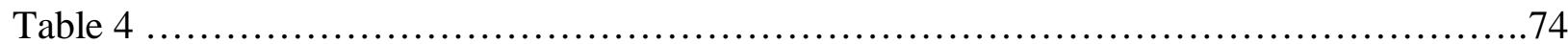

Main Effects of Self-Reported Sex on Variables of Interest (Univariate ANOVA)

Table 5 ......................................................................75

Main Effects of Age Group on Variables of Interest (Univariate ANOVA)



MANCOVA: Multivariate Effects for Health Outcomes

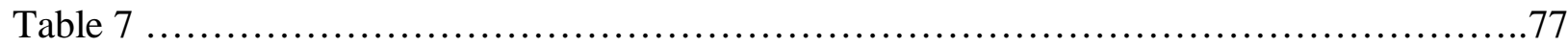

Main Effects of Self-Reported Sex on Health Outcomes (Univariate ANCOVA)

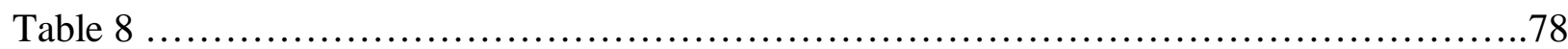

Main Effects of Age Group on Health Outcomes (Univariate ANCOVA)

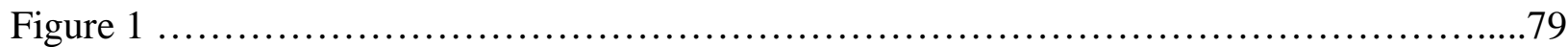

Conceptual multidimensional model of gender and health

Figure 2 .................................................................... 80

Originally proposed conceptual model testing aspects of "having” and “doing” gender

Figure 3 ..................................................................81

Exploratory conceptual model with behaviors as mediators between gender and health



Path analysis using original model to predict perceived health

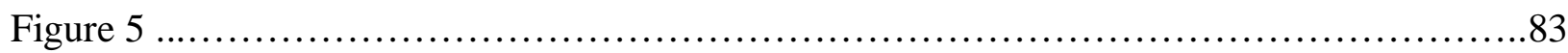

Path analysis using original model to predict physical functioning

Figure 6

Path analysis using original model to predict chronic health burden

Figure 7 .85

Path analysis using mediation model to predict perceived health 
Figure 8

Path analysis using mediation model to predict physical functioning

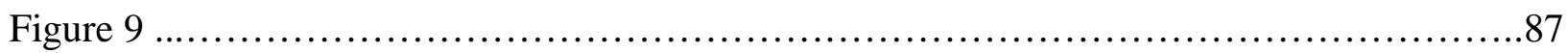

Path analysis using mediation model to predict chronic health burden 
MULTIDIMENSIONAL APPROACH TO GENDER AND HEALTH
A Multidimensional Approach to Understanding Gender and Health among Middle-Aged and Older Adults

\section{Introduction}

Chronic diseases have cost the United States upwards of \$555 billion in health care expenditures in 2011, which is expected to increase to $\$ 903$ billion in 2020 as the population of older adults rises (Centers for Disease Control and Prevention [CDC], 2013). The CDC has thus called for greater health promotion and intervention development to prevent future health care costs from escalating (Centers for Disease Control and Prevention [CDC], 2009). Identifying health factors that differ among Americans is one strategic starting point. The statement, “women get sicker, men die quicker” is one that describes important differences in men’s and women’s health. Women have multiple chronic conditions (Centers for Medicare and Medicaid Services, 2012; Lochner \& Cox, 2010) and suffer from more functional limitations in daily activities, such as climbing stairs, bathing, and getting dressed compared to men (Christensen, Doblhammer, Rau, \& Vaupel, 2009; Crimmins, Kim, \& Solé -Auró, 2011; Jagger et al., 2008; Schön \& Parker, 2008). Women also report poorer perceived health compared to men (Crimmins, et al., 2011; Read \& Gorman, 2010). Men, on the other hand, have a shorter life expectancy (Centers for Disease Control and Prevention [CDC], 2013; Minino, Heron, Murphy, \& Kocharek, 2007) and are more likely to die from the leading causes of death compared to women (e.g., heart disease, cancer; CDC, 2013; Minino et al., 2007). Behavioral differences also appear in that women engage in more health-promoting behaviors (e.g., seeking medical help and preventative health screenings) and men engage in more health-risk behaviors (e.g., smoking, drinking; Powell-Griner, Anderson, \& Murphy, 1997; Ratner, Bottorff, Johnson, \& 
MULTIDIMENSIONAL APPROACH TO GENDER AND HEALTH

Hayduk, 1994). Although biological factors (e.g., hormones) offer some explanation for sex differences in health, there is much left unexplained (Miller, 2014; Philips, 1974).

Researchers often cite gender as an important construct that can add to understanding health differences among men and women, yet little research has empirically investigated this notion (Berger, Addis, Green, Mackowiak, \& Goldberg, 2013; Courtenay, 1998; Courtenay, 2000; Evans, Frank, Oliffe, \& Gregory, 2011). Gender is a psychosocial construct that reflects attitudes, feelings, and behaviors prescribed by cultural expectations for men and women (Unger, 1979), whereas sex refers to biological characteristics (e.g., reproductive organs, chromosomes). Although conceptually distinct, biological sex and gender are often confounded, such as when gender is used as a proxy term for sex (see Miller, 2014). Recently, there have been calls from the National Institutes of Health and research journals to encourage scientists to make improvements in distinguishing between biological sex and gender in research studies (Clayton \& Tannenbaum, 2016; National Institutes of Health, 2015). Acknowledging sex and gender as two distinct constructs is thus important for moving forward to understand factors that relate to health.

One aim of the current study was to extend our knowledge about differences between men and women's health by testing a multidimensional model of gender in which indicators of “having gender” (i.e., intrapersonal factors and traits) and “doing gender” (i.e., external, social behaviors) were the focus (see Lemaster, Strough, Stoiko, \& DiDonato, 2015; West \& Zimmerman, 1987). The model considers the extent to which gender-typed traits and behaviors might help explain differences in men and women’s health as they age. Health becomes a prominent concern among middle-aged and older adults, as older age is associated with poorer self-rated health (Chen, Cohen, \& Kasen, 2007; Fylkesnes \& Førde, 1991; Shooshtari, Menec, \& Tate, 2007), a greater number of chronic conditions, and more functional limitations (e.g., Jette, 
MULTIDIMENSIONAL APPROACH TO GENDER AND HEALTH

1996; Kramarow, Lentzner, Rooks, Weeks, \& Saydah, 1999). The current study applied a multidimensional approach to gender and health by understanding how different facets of gender relate to various health outcomes among middle-aged and older adults.

In addition, the current study sought to recognize and study potential diversity within men and women (Annandale \& Hunt, 1990; Annandale \& Hunt, 2000; Rieker \& Bird, 2000). Research on health and health-related behaviors often uses comparative methodological design to assess sex differences. Women are seen as the ideal standard for health because compared to men they live longer and are less likely to suffer from the leading causes of death, such as heart disease and cancer (CDC, 2010; Department of Health and Human Services, 1996). This limits our understanding of variability within groups of men and women (see Annandale \& Hunt, 1990; Galdas, Cheater, \& Marshall, 2005). Not all men are the same, nor are all women. Furthermore, there may be relatively few or only small psychological differences between men and women (Hyde, 2005, 2007), thus it is important to address variability within each group. Individual differences are important to acknowledge in many domains, especially health care, to develop effective interventions (Addis \& Mahalik, 2003). Thus, the current study sought to identify associations between individual difference characteristics (e.g., gender-typed traits and behaviors) and health, including whether associations varied between and within aging men and women.

\section{Multidimensional Model of Gender and Health}

For the current study, a conceptual model was developed to show the potential way in which various dimensions of gender may relate to individual differences in health (see Figure 1). First, the model acknowledges that development is inherently embedded within a historical and sociocultural context (Baltes, 1987). This is an important consideration when examining gender and health because aspects such as availability of health care resources, quality of care, and 
MULTIDIMENSIONAL APPROACH TO GENDER AND HEALTH

societal views of aging and gender roles could impact individuals’ development. Furthermore, a person's position relative to other's in society based on the intersection of identities such as age and social class need to be considered when studying gender (Collins, 1990, 2000; Risman, 2004). Second, the model highlights the established association between age and biological sex with health (e.g., Chen et al., 2007; Crimmins et al., 2011; Fylkesnes \& Førde, 1991; Jette, 1996; Minino et al., 2007; Shooshtari et al., 2007). Although health can be examined in various ways, the proposed model features three measures of health status, which include: perceived health, functional limitations (e.g., difficulties with climbing stairs), and chronic health burden. These three measures of health were included due to strong associations found with morbidity and mortality (e.g., Benyamini, 2008; Lee, 2000; Millán-Calenti et al., 2010; Minino et al., 2007). Third, the model proposes that men and women can differ in endorsing various personality traits and beliefs which can be conceptualized as aspects of "having gender" (e.g., gender-typed traits, identity, and typicality). The aspects of "having gender," or traits, may then influence actions and behaviors related to “doing gender,” which prior research has shown to differ between men and women (e.g., interdependent strategies and health behaviors). Lastly, the model suggests that gender-typed characteristics and behaviors may account for sex differences in health. The following sections will highlight research surrounding these conceptual links to develop predictions for how multiple facets of gender will relate to health outcomes for men and women.

\section{The Role of Gender in Health}

What is gender? Gender has been previously studied as a bipolar construct in which individuals were identified as having stereotypical masculine or feminine traits (Constantinople, 1973). Theorists have highlighted, however, that traits can be endorsed simultaneously in that men and women may endorse traits stereotypically considered to be masculine and feminine (Bem, 1974). Gender has also been conceptualized as a multidimensional construct, in that 
MULTIDIMENSIONAL APPROACH TO GENDER AND HEALTH

gender can be examined through many factors such as personality traits, attitudes, and activities

(Ashmore, 1990; Huston, 1983; Lemaster, Delaney, \& Strough, 2015; Lemaster et al., 2015b;

Twenge, 1999). Facets of gender have been further distinguished as "having gender” (i.e., intrapersonal factors and traits) and “doing gender” (i.e., external gender-typed behaviors;

Lemaster et al., 2015b; West \& Zimmerman, 1987). In the current study, gender was examined as a multidimensional construct relating to health. Gender-typed characteristics including personality traits (e.g., masculine and feminine; Bem, 1974), gender identification (sense of belonging to gender group; Michaelieu, 1997), and gender typicality (exemplifying a 'typical' woman or man; Egan \& Perry, 2001) were measured as intrapersonal factors of "having gender.” In addition, interdependent strategies (e.g., utilizing others in decision situations, social support), health-risk (e.g., alcohol use), and health-promoting behaviors (e.g., preventative health care) were examined as indicators of “doing gender” as they are overt behaviors that tend to differ for men and women (Courtenay, 2000; Delaney, Turiano, \& Strough, 2016; Powell-Griner et al., 1997) and have been associated with masculinity and femininity (Annandale \& Hunt, 1990; Mahalik, Burns, \& Syzeks, 2007; Ruffing-Rahal, Barin, \& Combs, 1997). The following section will discuss how interdependent strategies and health behaviors can be conceptualized as an aspect of “doing gender.”

Effect of social roles on gender-typed traits, behaviors, and health. The larger sociocultural context in which men and women develop reinforces different social roles (Eagly \& Wood, 1999). Eagly’s (1987) social role theory, for example, acknowledges that historical differences in labor between men and women influence gender-typed traits and behaviors. Men are socially prescribed to be the "breadwinners" who work outside of the home, whereas women are socially prescribed to be the caregivers who maintain the household and care for children (Eagly, 1987; Eagly \& Wood, 1991). Although women entering the labor force have become 
MULTIDIMENSIONAL APPROACH TO GENDER AND HEALTH

more common since the second half of the $20^{\text {th }}$ century (Eagly, Eaton, Rose, Riger, \& McHugh, 2012), women still tend to maintain the caregiver role (Spence \& Helmreich, 2014). In accordance with these social roles, men are posited to adopt agentic traits and behaviors that match their breadwinner role (e.g., independence, skillfulness, competence). Women are posited to adopt communal traits and behaviors that match their caregiver role (e.g., friendly, interpersonally-oriented, selfless; Eagly \& Wood, 1991). Studies have used Bem’s (1974) Sex Role Inventory to identify whether stereotypical gender-typed traits (masculinity, femininity) align with the ideas from social role theory (Eagly, 1987). Indeed, research has found that men reported greater stereotypical masculine traits than women and women reported greater stereotypical feminine traits than men (Hyde \& Phillis, 1979; Kasen, Chen, Sneed, Crawford, \& Cohen, 2006; Lemaster et al., 2015a; Strough, Leszczynski, Neely, Flinn, \& Margrett, 2007).

Given that stereotypical gender-typed roles are posited to influence behaviors (Eagly, 1987), theorists have suggested that sex differences in health outcomes may be attributed to adopting stereotypical gender roles and traits (Hibbard \& Pope, 1983; Verbrugge, 1985). Differences exist in health behaviors, for instance, in that men report fewer health-promoting behaviors, and greater health-risk behaviors than women (Byrnes, Miller, \& Schaefer, 1999; Powell-Griner et al., 1997; Ratner et al., 1994). Men and masculinities literature often highlights that some men enact the stereotypical masculine gender role, defined by stoicism and invincibility, through health-risk behaviors because they assume they are strong and invulnerable from harm (Courtenay, 2000; Lohan, 2007; Nicholas, 2000). Relatedly, some men may avoid health care utilization (e.g., see physician, preventative screening), as this would be in conflict with the strong and invincible masculine gender role set by society (Addis \& Mahalik, 2003; Cameron \& Bernades, 1998). Corresponding with the stereotypical feminine role, women tend to be more interpersonally oriented by seeking advice when faced with decisions (Delaney, 
MULTIDIMENSIONAL APPROACH TO GENDER AND HEALTH

Strough, Parker, \& Bruine de Bruin, 2015) and seek social support more than men (Tamres, Janicki, \& Helgeson, 2002; Thoits, 1995). The current study assessed associations between gender-typed traits with interdependent and health behaviors to offer insight in the extent to which these behaviors represent aspects of "doing gender."

\section{“Having Gender:” Stereotypical Gender-Typed Traits and Health}

Research that has examined the association between stereotypical masculine and feminine gender-typed traits (i.e., aspects of "having gender”) with various subjective and objective health outcomes have yielded inconsistent findings for men and women (e.g., Annandale \& Hunt, 1990; Hunt, 2000; Hunt, Lewars, Emslie, \& Batty, 2007; Kaplan \& Marks, 1995). Potential problems in the existing literature will be highlighted in the following sections.

Women, gender, and health. One reason women live longer than men (CDC, 2013; Minino et al., 2007), may be that they endorse traits and exhibit behaviors that promote better health. Being expressive and interacting with others frequently corresponds to social roles prescribed to women (Eagly, Wood, \& Diekman, 2000) and have been posited to be defining feminine traits (Bem, 1974). These characteristics may help explain why women are more likely than men to report symptoms and seek help when encountering health problems (Corney, 1990; Husaini, Moore, \& Cain, 1994; McKay, Rutherford, Cacciola, \& Kabasakalian-McKay, 1996; Oliver, Pearson, Coe, \& Gunnell, 2005; Padesky \& Hammen, 1981). However, research that addresses this issue shows mixed results. Annandale and Hunt (1990) found that greater endorsement of feminine traits (measured by the BSRI) was associated with poorer self-rated health. Whereas a study with older women (65+ years old) found that greater endorsement of stereotypical feminine traits (measured by the BSRI) was associated with better self-rated health (Ruffing-Rahal et al., 1997). Other studies have not found significant associations between stereotypical feminine traits measured by the BSRI (Bem, 1974) and responses to health- 
MULTIDIMENSIONAL APPROACH TO GENDER AND HEALTH

threatening events (Kaplan \& Marks, 1995) or mortality risk due to chronic heart disease (Hunt et al., 2007). It is therefore not clear whether endorsing feminine traits have a significantly negative or more neutral effect on health outcomes for women.

Some personality traits stereotypically associated with men, such as dominance, are posited to be detrimental to men's health (Courtenay, 2000). Thus, it seems reasonable to expect that endorsement of stereotypical masculine traits would similarly have negative consequences for women's health. In contrast to this expectation, greater endorsement of masculine traits was associated with better self-rated health for women (Annandale \& Hunt, 1990). However, a follow-up study that utilized the same sample of women divided according to generation (young vs. older adult cohort), did not fully replicate this finding (Hunt, 2002). For the younger adult cohort of women (35 years old), greater endorsement of stereotypical masculine traits, as measured by the BSRI (Bem, 1974), was associated with lower malaise symptoms (e.g., nervousness, anxiety) but was not significant for the older cohort (55 years old; Hunt, 2002). Within the older cohort, greater masculinity scores were associated with a greater number of physical problems (e.g., headaches, cold/flu; Hunt, 2002), supporting that masculine traits can negatively affect health. Helgeson (1990) also found that post-myocardial infarction patients who endorsed more aggression and hostility, classified as undesirable masculine traits in the study, had more severe heart attacks. Because the studies used different health outcomes as dependent variables, it is difficult to determine whether stereotypical masculine traits have a significant effect on health across adulthood for women. Including assessments of both perceived health and physical symptoms for the same sample, as is done in the current study, may help obtain a better overall depiction of individuals’ health.

Men, gender, and health. For men, theorists have discussed the negative implications masculinity has for health (e.g., Evans et al., 2011). Some men may endorse masculine ideals 
MULTIDIMENSIONAL APPROACH TO GENDER AND HEALTH

corresponding to societal gender roles (e.g., dominance, invulnerability, emotional control), which may then negatively influence health (e.g., Courtenay, 1998; Courtenay, 2000). Empirical studies have found conflicting results when studying the association between stereotypical gender-typed traits (masculinity and femininity) and health factors among men. Helgeson (1990) found that post-myocardial infarction patients who endorsed more aggression and hostility, classified as undesirable masculine traits in the study, experienced more serious heart attacks. Conversely, when using the Bem Sex Role Inventory (BSRI; Bem, 1974) among a Scottish sample, greater endorsement of stereotypical masculine traits (e.g., self-sufficient, analytical) was associated with better self-rated health (Annandale \& Hunt, 1990). Yet, objective health measures such as blood pressure (Annandale \& Hunt, 1990) and mortality risk from chronic heart disease (Hunt et al., 2007) were not related to the stereotypical masculine traits measured by the BSRI. Research is thus scattered in that both significant positive and negative associations between masculinity and health factors have been found, whereas other results indicated no significant associations. The inconsistencies could be due to different measures of masculinity being used. For example, some of the undesirable masculine traits (e.g., hostility) have a strong connection to heart disease (Matthews \& Haynes, 1986), whereas other stereotypical masculine traits (e.g., independence) may not carry as strong of an influence on heart disease.

Caring about health and asking for help have been characterized as feminine attributes that positively influence health (Cameron \& Bernardes, 1998; Courtenay, 2000; Evans et al., 2011). For these reasons, it would be expected that greater endorsement of feminine traits would be associated with better health among men. Consistent with these expectations, greater endorsement of stereotypical feminine traits, as measured by the BSRI (e.g., yielding, loyal; Bem, 1974) was associated with greater concern about health-threatening events (Kaplan \& 


\section{MULTIDIMENSIONAL APPROACH TO GENDER AND HEALTH}

Marks, 1995) and lower mortality risk from chronic heart disease among men (Hunt et al., 2007). Thus, endorsement of feminine traits may be a protective factor for health among men.

Methodological considerations. Theorists argue that gender matters, but as the studies reviewed earlier indicate, the few studies that have examined gender have had mixed findings. Previous studies used a variety of health outcome measures, which could contribute to inconsistent results. In some studies, health outcomes were measured in relation to specific diseases (e.g., heart problems; Helgeson, 1990; Hunt et al., 2007), whereas others used count scores for psychological and physical symptoms (Annandale \& Hunt, 1990; Hunt, 2002). Being disease-specific and using count variables for symptoms ignores the severity of medical symptoms and chronic conditions. It is important to account and adjust for these differences because there is strong association between comorbidities and mortality risk in older adulthood (Charlson, Pompei, Ale, \& MacKensie, 1987; Concato, Horwitz, Feinstein, Elmore, \& Schiff, 1992). Previous studies also did not assess functional limitations, which are also related to mortality risk (Manton, 1988; Millán-Calenti et al., 2010). The current study adds to the literature by including a measure of comorbid chronic conditions and assessing functional limitations. In addition, perceived health was included as a measure of health to compare with previous research findings (e.g., Annandale \& Hunt, 1990).

The measurement of gender in previous research has focused on stereotypical masculine and feminine traits (e.g., Bem’s Sex Role Inventory, 1974), which is just one dimension of gender. Other measures of gender that might matter have not been thoroughly investigated yet. Broadening the measure of gender as a multidimensional construct may add to our understanding of gender and health.

Gender identification (i.e., identifying, psychologically connecting, and feeling positively associated with male/femaleness; Kulis, Marsiglia, \& Hecht, 2002; Michaelieu, 1997) and 
MULTIDIMENSIONAL APPROACH TO GENDER AND HEALTH

gender typicality (feeling like a typical woman or man; Egan \& Perry, 2001) are two other facets of gender that show differences between men and women (Lemaster et al., 2015a; Lemaster et al., 2015b). Men have reported greater gender identification and gender typicality than women (Lemaster et al., 2015a; Lemaster et al., 2015b). Gender identification has also been associated with men and women's reports of engaging in stereotypically gender-typed activities (e.g., hunting, babysitting; Lemaster et al., 2015b) and unhealthy behaviors—namely, less selfreported substance use for women (Mehta, Alfonso-Barry, Delaney, \& Ayotte, 2013). Because differences between men and women have been found with these constructs, considering these aspects of gender could offer a more nuanced approach to studying gender in relation to health outcomes.

\section{“Doing Gender”: Health Behaviors and Interdependence}

Drawing from social role theory (Eagly, 1987), men and women may engage in behaviors that conform to stereotypical depictions of masculinity (e.g., independence) and femininity (e.g., interpersonally-oriented). Thus, men and women may exhibit actions of “doing gender,” in which their strategies and behaviors match socially-prescribed gender roles (Lemaster et al., 2015b; West \& Zimmerman, 1987).

Health-risk and health-promoting behaviors. Health behaviors have been a predominant focus of aging literature as many deaths are due to unhealthy lifestyles (CDC, 2013). For example, seminal research studies (see Heidrich, 1998 for a review) on health-risk behaviors have shown that cigarette smoking and heavy drinking, predict higher rates of hospitalization (Palmore, 1970), greater functional limitations (Strawbridge, Camacho, Cohen, \& Kaplan, 1993), and greater mortality risk (e.g., Kaplan, Seeman, Cohen, Knudsen, \& Guralik, 1987; Klatsky, Armstrong, \& Friedman, 1992). Conversely, health-promoting behaviors (e.g., exercise and healthy eating), predict lower rates of hospitalization (Palmore, 1970), fewer 
MULTIDIMENSIONAL APPROACH TO GENDER AND HEALTH

functional limitations (Duffy \& MacDonald, 1990; Strawbridge et al., 1993), and lower mortality risk (Kaplan et al., 1987).

As mentioned previously, important sex differences in some health behaviors have been found. Men engage in more health-risk behaviors and women engage in more health-promoting behaviors (Powell-Griner et al., 1997; Ratner et al., 1994). More specifically, it is more common for men to engage in cigarette smoking, alcohol and drug use, reckless driving, and risky sexual activities (Byrnes et al., 1999). Theorists have attributed these differences to some men feeling pressure to enact masculine ideals set by societal gender roles, which in turn may relate to greater health-risk behaviors (e.g., Courtenay, 1998; 2000). Indeed, men who reported conforming to more traditional forms of masculinity (e.g., emotional control, self-reliance), reported greater health-risk behaviors (e.g., alcohol and tobacco use, seatbelt use) and fewer health-promoting behaviors (e.g., exercise, dietary habits; Mahalik et al., 2007).

Women, on the other hand, tend to engage in more responsible health behaviors such as seeking preventative health screenings and being aware of medical conditions more than men (Powell-Griner et al., 1997). Stereotypical feminine, communal traits have been associated with health behaviors among women. For example, Annandale and Hunt (1990) found that stereotypical feminine traits (measured by the BSRI) explained why women were more likely to visit their physician than men. In addition, older women (65+ years old), who endorsed greater feminine and masculine traits were more likely to report that they visited their physician and adhered to taking prescribed medications (Ruffing-Rahal et al., 1997).

Across various cultures women report better nutritional habits, interpersonal relations, and stress management than men (e.g., Hacıhasanoğlu, Yıldırım, Karakurt, \& Sağlam, 2011; Nassar \& Shaheen, 2014; Tirodimos, Georgouvia, Savvala, Karanika, \& Noukari, 2010). Stereotypical masculine and feminine traits have been associated with these health-promoting 
MULTIDIMENSIONAL APPROACH TO GENDER AND HEALTH

behaviors. Older women who endorsed both feminine and masculine traits were more likely to report better nutritional habits and more active composure (i.e., avoid stress and have strong interpersonal relations). However, no significant association between feminine and masculine traits with health-risk behaviors among older women were found (e.g., tobacco, alcohol, seatbelt use; Ruffing-Rahal et al., 1997).

The current study included health behaviors as aspects of “doing gender” to predict differences in perceived health, functional limitations, and chronic conditions among men and women. While associations between stereotypical gender-typed traits and health behaviors have been found (e.g., Mahalik et al., 2007; Ruffing-Rahal et al., 1997), this does not necessarily mean that all behaviors are driven by gender. There are biological differences that contribute to differences in men and women’s health behaviors, however, gender has recently been highlighted as a distinct factor that can also influence health and health-related behaviors (see infographic in Appendix A). Our conceptualization of health behaviors as “doing gender” is meant to guide analyses and build connections between gender and health behaviors, which are often theorized to be related within the literature, but few studies have empirically examined multiple aspects of gender and different behaviors. Identifying how gender-typed traits relate to health behaviors can also provide insight for developing strategies that can work to counteract gender stereotypes that may stifle particular health-promoting behaviors.

Interdependent strategies. Some researchers have studied help-seeking behaviors as a mechanism to explain differences between men and women in regards to health outcomes (Addis \& Mahalik, 2003; Galdas et al., 2005). For men, in particular, there can be a stigma associated with help-seeking as it can work in opposition to the masculine ideals of being strong and invulnerable to harm (Courtenay, 2000; Lohan, 2007; Nicholas, 2000). Related to seeking advice, help-seeking attitudes and behaviors address the likelihood that a person will visit a 
MULTIDIMENSIONAL APPROACH TO GENDER AND HEALTH

health care professional if they encounter physical or psychological health issues (Eriksson, Maclure, \& Kragstrup, 2004; Fischer \& Turner, 1970). Previous research has found that men were less likely than women to seek help for a variety of issues related to psychological and physical health such as depression, substance use, physical disabilities, and stress (Husaini et al., 1994; McKay et al., 1996; Oliver et al., 2005; Padesky \& Hammen, 1981). Because men are less likely than women to seek mental health services despite having similar emotional strains as women (see Addis \& Mahalik, 2003 for a review; Kessler \& McRae, 1981), most research has focused on different factors related to the likelihood that men seek psychological help (e.g., Levant, Wimer, Williams, Smalley, \& Noronha, 2009).

Although studying psychological help is important, it does not depict how individuals approach problems and decisions on a regular basis. Men may try to consistently uphold stereotypical masculine ideals (e.g., independence) throughout all behaviors. For example, men are less likely to utilize others when making decisions (i.e., be “dependent”; Delaney et al., 2016; Phillips, Pazienza, \& Ferrin, 1984), are less likely to seek social support (Tamres et al., 2002; Thoits, 1995), utilize fewer sources of social support (Gurung, Taylor, \& Seeman, 2003), and report less advice seeking than women (Delaney et al., 2016). Lesser reported advice seeking and perceived social support (i.e., perceptions that support is available, Barrera, 1986) have been related to increased mortality risk, poorer self-rated health, and greater disability for both men and women (Berkman, Glass, Brissette, \& Seeman, 2000; Delaney et al., 2016; Rowe \& Kahn, 1997; Uchino, 2009). The associations between interdependent strategies and health thus support the idea that men’s tendency to avoid interdependent strategies, such as seeking advice or social support, can have negative implications for health.

In the current study, interdependent problem-solving strategies and perceived social support were examined as an aspect of “doing gender” to help potentially explain differences in 
MULTIDIMENSIONAL APPROACH TO GENDER AND HEALTH

men's and women's health. The independent-interdependent problem-solving scale (Rubin, Watt, \& Ramelli, 2012) was used specifically to assess the extent to which individuals utilize others for advice and help with everyday problems and decisions, which is distinct from previous literature that focuses on seeking professional psychological help.

\section{Health Outcomes}

As mentioned previously, health can be measured by a variety of factors. Sex differences in health have been acknowledged prevalently in public health reports (Baker et al., 2014; CDC, 2013), with a large focus calling attention to differences in morbidity and mortality among men and women. For the purposes of the current study, health was measured by three factors: perceived health, functional limitations, and chronic health conditions, which have been found to differ for men and women. Women have been found to report poorer self-rated health than men within industrialized societies (Read \& Gorman, 2010) and across 13 relatively diverse countries (Crimmins et al., 2011). In addition, women have been found to suffer from more functional limitations (e.g., walking, climbing stairs) than men (Christensen et al., 2009; Crimmins et al., 2011; Jagger et al., 2008; Schön \& Parker 2008). Women are also more likely to have multiple chronic health conditions than men (Centers for Medicare and Medicaid Services, 2012). Men, however, experience a greater prevalence of chronic health conditions that are the top leading causes of death (e.g., heart disease, cancer, diabetes; Centers for Medicare and Medicaid Services, 2012; Lochner \& Cox, 2010; Minino et al., 2007). These three health indices were thus chosen for the known sex differences and for their associations with important health outcomes that will be discussed in the following sections.

Perceived health. First, perceived health is a subjective measure of health that requires individuals to assess and rate how they feel their current health status is (i.e., ranging from “poor” to “excellent”). Used extensively in previous research, perceived health has been 
MULTIDIMENSIONAL APPROACH TO GENDER AND HEALTH

associated with physical health (e.g., medical diagnoses and symptoms), functional limitations (i.e. difficulties with activities of daily living), and psychological health (e.g. depression; Pinquart, 2001). Perceived health has also been a robust predictor of morbidity and mortality (Benyamini, 2008; Idler \& Benyamini, 1997; Lee, 2000). Perceived health stands out from other objective indicators of health (e.g., blood pressure, diabetes), as it allows the individual to assess their overall health. That is, individuals take into account physical signs of health (e.g., medical diagnoses, physical functioning), comparisons of health (e.g., in light of age, compared to others), and culturally prescribed responses (e.g., their health situation compared to the "norm”; Jyhlä, 2009) when forming their responses to their current health status. Perceived health still independently predicts mortality risk even when a wide range of health indicators is included (see Idler \& Benyamini, 1997; Jyhlä, 2009). This suggests that perceived health incorporates information of which a collection of other health indicators cannot account for. These findings suggest the utility in assessing perceived health in the current study, as it can be an important indicator of various health outcomes and mortality.

Functional limitations. Second, functional limitations in completing activities of daily living correspond to difficulties with basic self-care activities that can limit independence (Foti \& Koketsu, 2008). Various activities can be measured to examine this such as bathing, eating, and getting dressed independently (Katz, 1983) or by examining types of mobility such as climbing, walking, and lifting (Fillenbaum, 1987). Difficulties with completing activities of daily living have been connected with nursing home admissions (Branch \& Jette, 1982; Gaugler, Duval, Anderson, \& Kane, 2007), paid home care (Garber, 1989; Soldo \& Manton, 1985), utilization of hospital services (Branch et al., 1981), and as a predictor of mortality (Manton, 1988; Millán-Calenti et al., 2010). Functional limitations in the current study focused on physical mobility (e.g., climbing stairs, walking), rather than routine activities of daily living (e.g., eating, 


\section{MULTIDIMENSIONAL APPROACH TO GENDER AND HEALTH}

bathing, dressing), as these tend to be less affected than by biased responses influenced by societal expectations of aging (Freedman \& Martin, 1998; Nagi, 1991; Verbrugge \& Jette, 1994).

Chronic health conditions. Lastly, chronic health burden was used as an additional indicator of health to help gauge comorbidity (i.e., more than one chronic condition) among adults. Some of the leading causes of death include chronic diseases and conditions such as heart disease, respiratory diseases, stroke, and diabetes (Minino et al., 2007; Thacker et al., 2006). Furthermore, chronic health conditions such as heart disease (Kozek, Owings, \& Hall, 2001) and diabetes (Rosenthal, Fajardo, Gilmore, Morley, \& Naliboff, 1998) relate to greater rates of hospitalization. Among older adults (aged 65 and older), there is a greater prevalence of comorbid conditions (Wolff, Starfield, \& Anderson, 2002) that should be accounted for given strong associations among comorbid conditions with mortality (Charlson et al., 1987; Concato et al., 1992), functional limitations (Cleary et al., 1991; Deyo, Cherkin, \& Ciol, 1992; Olomu, Corser, Stommel, Xie, \& Holmes-Rovner, 2012), surgical outcomes (Cleary et al., 1991), and length of hospitalization (Cleary et al., 1991; Deyo et al., 1992). The current study used a selfreport, comorbidity questionnaire that measures the sum of chronic health conditions while accounting for severity of conditions (e.g., AIDs scored higher in severity than diabetes) to gauge chronic burden. Although mortality could not be assessed within the scope of the current

study, accounting for the number and severity of chronic conditions (e.g., diabetes, lung problems, and stroke) provides an objective picture of adults' health conditions.

\section{Statement of the Problem}

In middle and older adulthood, chronic health burdens become prominent issues that can impede successful aging (National Academy on Aging Society, 1999). Men and women experience differences in morbidity and mortality that are partly due to biological factors, but biological factors do not fully account for health disparities (Miller, 2014; Philips, 1974). 
MULTIDIMENSIONAL APPROACH TO GENDER AND HEALTH

Although theorists have acknowledged that gender, as a distinct construct from sex, is a factor that may account for health inequalities among men and women, (Berger et al., 2013; Courtenay, 1998; Courtenay, 2000; Evans et al., 2011) the limited studies that have examined this have yielded inconsistent findings (e.g., Annandale \& Hunt, 1990, Hunt et al., 2007). Gender has mostly been examined through one dimension (i.e., stereotypical gender-typed traits) rather than a multidimensional construct that addresses how gender-typed traits ("having gender”) and behaviors (“doing gender”) impact health. The current study extended the measurement of gender by including assessments of gender identification and gender typicality in addition to stereotypical masculine and feminine traits. Furthermore, aspects of “doing gender” were assessed by interdependent strategies (e.g., advice seeking, social support), health-risk (e.g., alcohol use), and health-promoting behaviors (e.g., stress management) to add to our understanding of differences in men's and women’s health.

By applying a multidimensional model of gender to understand health, potential healthrisk factors for men and women can be identified. Interventions could then be developed to thwart gender-typed risk factors for men and women. The current study utilized a middle-aged and older adult sample in the US to test the extent to which aspects of "having gender" and “doing gender” were associated with health (i.e., perceived health, functional limitations, and chronic health conditions). It was expected that some facets of gender would be differentially related to men and women's health outcomes.

\section{Research Questions and Hypotheses}

Research Question 1. Do health indices (perceived health, chronic conditions, and functional limitations) vary for males and females? 
MULTIDIMENSIONAL APPROACH TO GENDER AND HEALTH

Hypothesis 1a. Based on previous findings, women will report poorer perceived health, more functional limitations, and more chronic conditions than men (Christensen et al., 2009, Crimmins, et al., 2011; Jagger et al., 2008; Read \& Gorman, 2010).

Research Question 2. Are aspects of "having gender” (i.e., masculine and feminine traits, gender typicality, and gender identification) significantly associated with different health indices (perceived health, functional limitations, chronic conditions)? Do associations vary by selfreported sex?

Rationale and Hypotheses 2a-3c. Stereotypical masculine traits have been theorized to have negative implications for health among men (see Courtenay, 2000; Evans et al., 2011), and have been associated with some negative health effects for both men (Helgeson, 1990) and women (Helgeson, 1990; Hunt, 2000). Stereotypical feminine traits have been associated with better health outcomes for men (Kaplan \& Marks, 1995; Hunt et al., 2007) and women (Ruffing-Rahal et al., 1997). It was hypothesized that men and women who endorsed greater masculine traits and fewer feminine traits would report poorer perceived health (Hypothesis 2a), greater functional limitations (Hypothesis 2b), and greater chronic health burden (Hypothesis 2c). Alternatively, because Annandale and Hunt (1990) found negative associations between feminine traits and perceived health for women and positive associations between masculine traits and perceived health for men, the alternative hypothesis that men and women who endorse greater masculine and fewer feminine traits would report better perceived health was tested (Alternative Hypothesis 2a).

Rationale and Hypotheses 2d-2f. Because women live longer than men (Minino et al., 2007) and greater gender identification has been associated with better self-rated health and less substance use (e.g., Mehta et al., 2013; Ruffing-Rahal et al., 1997) it was 
MULTIDIMENSIONAL APPROACH TO GENDER AND HEALTH

expected that, for women, greater gender identification and gender typicality would be associated with better perceived health (Hypothesis $2 \boldsymbol{d}$ ), fewer functional limitations (Hypothesis 2e), and less chronic burden (Hypothesis 2f). Conversely, it was expected that men who reported greater gender identification and typicality would report poorer perceived health (Hypothesis 2d), greater functional limitations (Hypothesis 2e), and greater chronic burden (Hypothesis 2f).

Research Question 3. Are aspects of “doing gender” (i.e., interdependent strategies, healthpromoting behaviors, health-risk behaviors) significantly associated with different health indices (perceived health, functional limitations, chronic conditions)? Do associations vary by selfreported sex?

Rationale and Hypotheses 3a-3c. Given previous research (e.g., Delaney et al., 2016; Powell-Griner et al., 1997; Ratner et al., 1994; Uchino, 2009), for men and women, lower endorsement of interdependent strategies, less perceived social support, lower health promotion, and greater health-risk behaviors would be associated with poorer perceived health (Hypothesis 3a), more functional limitations (Hypothesis $3 b$ ), and greater chronic health burden (Hypothesis 3c).

\section{Method}

\section{Participants}

Recruitment methods. Six hundred and fifty-two participants (91.2\% of total participants recruited) were recruited through Amazon’s Mechanical Turk program. An IP address restriction was implemented to confirm that participants were located in the United States. A series of human intelligence tasks (HITs) advertised the study for adults aged 40-59 years old and those who were at least 60 years old (i.e., the ages that typically distinguish middle and older adulthood; Erikson, 1980; McCormick, Kuo, \& Masten, 2011). The survey took 
MULTIDIMENSIONAL APPROACH TO GENDER AND HEALTH

approximately one hour to complete. After completing the survey, participants were required to enter a unique code within the Mechanical Turk HIT and were provided with \$2.50 in participant compensation, comparable to typical payment used within Mechanical Turk (Buhrmester, Kwang, \& Gosling, 2011). To reach the recruitment goal of 700 participants, a community sample of participants were also recruited for the study. A total of 63 participants (8.8\% of total) were recruited through advertisements on social network sites (i.e., Facebook) and via email for referrals from previous research studies. Participants who entered a unique code to signify study completion were entered in a drawing for a \$25 Amazon gift card. Out of participants who completed the study, one winner was chosen for each age group (i.e., 24 eligible middle-aged adults; 23 eligible older adults).

Mechanical Turk considerations. Amazon’s Mechanical Turk (“MTurk”) was developed as an online crowd sourcing system to connect workers to jobs or tasks identified as Human Intelligence Tasks (HITs). MTurk is now a popular source for researchers across various disciplines (e.g., psychologists, economists, consumer behaviorists) to gain access to a large, diverse participant pool for rapid and inexpensive online data collection (Berinsky, Huber, \& Lenz, 2012; Buhrmester et al., 2011; Mason \& Suri, 2012). The comparability of data from MTurk participants in relation to other samples has been questioned, but data analyzed from MTurk samples have shown acceptable validity and reliability (Berinsky et al., 2012; Buhrmester et al., 2011; Goodman, Cryder, \& Cheema, 2013; Mason \& Suri, 2012). Per Goodman and colleagues’ (2013) suggestion, Instructional Manipulation Checks (Oppenheimer, Meyvis, \& Davidenko, 2009) were built into the study to assess the attention of participants, such as instructing participants to select a specific response to a question.

Exclusion criteria. The MTurk and community-recruited sample were combined for a total of 715 participants recruited for the study, but some were excluded prior to data analysis. 


\section{MULTIDIMENSIONAL APPROACH TO GENDER AND HEALTH}

To be included, participants needed to complete the entire survey (excluding 106 participants), have only completed the study once (excluding an additional 13 participants), consistently reported their gender (excluding 1 additional participant), were at least 40 years old (excluding an additional 10 participants), reported a valid age that matched their birth year and age entered at later points in the survey (excluding an additional 20 participants), and passed five of seven attention check questions (excluding an additional 74 participants). The sample was then reduced to 491 participants.

Multivariate outliers were also identified among key variables included in the study. A linear regression was computed with the following predictors: age, sex, stereotypical masculine traits, stereotypical feminine traits, gender typicality, gender identification, interdependent problem solving, social support, health-promoting behaviors, health-risk behaviors, perceived health, functional limitations, and chronic health conditions with a random identification number as the outcome variable. The cutoff for Mahalanobis distance was 34.53 based on a chi-square table (13 degrees of freedom, $p=.001$ ). Participants identified as multivariate outliers were excluded from analyses, which excluded an additional 5 participants from the sample. The final sample included 486 participants. Comparisons between the community and MTurk sample are reported in Footnote 1. ${ }^{1}$ Participants who were excluded did not significantly differ from those included based on sex (male versus female; $\left.\chi^{2}(1)=0.97, p=.32\right)$, age $(F(1,666)=0.03, p=$ $.96)$, race $(F(1,666)=0.85, p=.36)$, education $(F(1,666)=1.26, p=.26)$, income $(F(1,666)=$

\footnotetext{
${ }^{1}$ The MTurk and community sample were assessed for significant differences among demographic and key study variables. Compared to the MTurk sample, the community sample was significantly more likely to be female $\left(\chi^{2}(1)=\right.$ 8.37, $p=.004)$, slightly older $(F(1,484)=6.14, p=.01)$, have more education $(F(1,484)=10.92, p=.001)$, report greater interdependent problem solving $(F(1,484)=4.37, p=.04)$, fewer health-risk behaviors $(F(1,484)=3.89, p=$ $.05)$, and a greater number of chronic health conditions $(F(1,484)=11.28, p=.001)$. The samples did not significantly differ by age, income, stereotypical traits (masculine and feminine), gender typicality, gender identification, health-promoting behaviors, social support, perceived health, or functional limitations.
} 
MULTIDIMENSIONAL APPROACH TO GENDER AND HEALTH

$1.40, p=.24)$, or marital status $(F(1,666)=0.66, p=.42)$. Differences and similarities in other variables are described in Footnote $2 .^{2}$

Power. Guidelines were followed by Bentler and Chou (1987) to reach the minimum sample size necessary for structural equation modeling. Five participants were required per each estimated parameter. In the largest model, there were 46 estimated parameters (including covariances and covariates), thus at least 230 participants were required for analyses. For testing multi-group differences between men and women, and for middle-aged and older adults, a sample size of 460 participants was needed for each analysis. The final sample of 486 participants met these requirements.

Final sample. The final sample consisted of slightly more females ( $n=265,54.5 \%)$ than males ( $n=221,45.5 \%)$. Age was measured and entered as a continuous variable in primary analyses (range $=40-79$ years old, $M_{\text {age }}=55.57 \mathrm{yrs}, S D=9.63$ ), but to equalize representation by age participants were recruited by age group in which middle-aged adults were between 40-59 years old ( $\left.n=250 ; 51.4 \% ; M_{\text {age }}=47.41 \mathrm{yrs}, S D=5.47\right)$ and older adults were at least 60 years old ( $n=236 ; 48.6 \% ; M_{\text {age }}=64.21$ yrs, $\left.S D=3.73\right)$.

Race and marital status. The majority of the sample identified as White or Caucasian (n $=430 ; 88.5 \%), 5.6 \%$ as Black $(n=27), 3.1 \%$ as Asian $(n=15), 2.1 \%$ as bi-racial $(n=10)$, and $.4 \%$ as American Indian or Alaskan Native $(n=2)$. One participant preferred not to answer $(.2 \%)$ and one additional participant indicated “other” (.2\%). Most participants indicated that they were

\footnotetext{
${ }^{2}$ Compared to excluded participants, those included in the study reported greater gender identification $(F(1,633)=$ $14.65, p=.001)$, less interdependent problem solving $(F(1,624)=3.93, p=.05)$, fewer health-risk behaviors, $(F(1,616)=14.46, p<.001)$, fewer chronic health conditions $(F(1,616)=4.60, p=.03)$, and better physical functioning $(F(1,616)=23.38, p<.001)$. No significant differences were found for stereotypical traits (masculine and feminine), gender typicality, health-promoting behaviors, social support, or perceived health.
} 
MULTIDIMENSIONAL APPROACH TO GENDER AND HEALTH

married (55.3\%; $n=269), 18.1 \%$ were never married $(n=88), 15 \%$ were divorced $(n=73), 6 \%$ were not married but living with a partner $(n=29)$, and 5.6\% were widowed $(n=27)$.

Education. The sample consisted of individuals from diverse educational backgrounds including, .2\% who did not complete high school $(n=1), 11.7 \%$ who completed high school or their GED ( $n=57), 20.4 \%$ who completed some college coursework but did not received a degree $(n=99), 12.8 \%$ with an Associate's degree $(n=62), 38.7 \%$ with a Bachelor's degree $(n=$ 188), $12.3 \%$ with a Master's degree ( $n=60), 2.1 \%$ with a professional degree (e.g., MD, DDS; $n$ $=10)$, and $1.9 \%$ with a doctoral degree $(n=9)$.

Employment status and income. The majority of the sample were employed full time $(51.9 \% ; n=252)$, while $14.8 \%$ were employed part time $(n=72), 14.1 \%$ were fully retired $(n=$ 69), 7.2\% were partially retired $(n=35), 3.5 \%$ indicated "other” ( $n=17), 3.3 \%$ were unable to work ( $n=16)$, and $.4 \%$ indicated student status $(n=2)$. Participants’ estimated gross income (e.g., wages, social security, earning, etc.) included a range of levels, with 9.5\% reported making less than $\$ 10,000(n=46), 14.2 \%$ reported between $\$ 10,000-\$ 19,000(n=69), 13.4 \%$ between $\$ 20,000-\$ 29,000(n=65), 13 \%$ between $\$ 30,000-\$ 39,000(n=63), 12.8 \%$ between $\$ 40,000$ $\$ 49,000(n=62), 10.5 \%$ between $\$ 50,000-\$ 59,000(n=51), 8.6 \%$ between $\$ 60,000-\$ 69,000(n$ $=42), 16.7 \% \$ 70,000$ or more $(n=81)$, and $1.4 \%$ preferred to not answer $(n=7)$.

\section{Procedure}

Participants recruited from Amazon’s Mechanical Turk program and the community were directed to complete the measures through the online survey program, SurveyMonkey. After agreeing to participate, participants were then presented with a series of questionnaires to complete and then compensation was provided. Measures were presented to participants in the order shown in the following section. 
MULTIDIMENSIONAL APPROACH TO GENDER AND HEALTH

Demographic information. Participants were asked to provide basic demographic

information (Appendix B) including their age, year of birth (to confirm age), marital status, race and ethnicity, highest level of education, employment status, and income level. ${ }^{3}$ Income $(M=$ 4.56, $S D=2.29)$ and education $(M=4.33, S D=1.40)$ were used as control variables in the main analyses with health indices. Based on a scale from 1 (earning less than $\$ 10,000$ per year) to 8 (earning greater than $\$ 70,000$ per year), participants earned approximately $\$ 40,000$ on average per year. Similarly, for education, participants reported on a scale from 1 (not completing high school) to 8 (doctoral degree). The mean of education indicated that participants obtained an associate's degree, on average. In addition, participants were asked to report their sex based on their birth certificate as being male or female, the gender they identified with, and sexual orientation. Allowing participants to report their sex, gender identity, and sexual orientation acknowledges that these are separate constructs and can vary among men and women. For the purposes of the current study, sex was used in analyses to test differences among men and women.

Gender typicality. An adapted version of Egan and Perry’s (2001) Gender Typicality Scale (Appendix C) assessed men and women’s ratings of how much they felt they represented his/her own gender group. The 6-item scale was originally developed for children, but has more recently been adapted for adults and has had acceptable internal consistency ( $\alpha \mathrm{s}=.84-.89$; Lemaster \& Strough, 2014; Lemaster et al., 2015a). The adapted version changes the terms from "boys"/ "girls” to “men”/ "women.” Participants were asked to rate on a 1 (very untrue for me) to 4 (very true for me) scale how much they felt each statement represented them. An example item

\footnotetext{
${ }^{3}$ To avoid losing data for advanced analyses (SEM models), the median income based on the sample (4, between \$30,000- \$39,000) was imputed for the seven participants who chose "prefer not to answer," for their income level. Results did not significantly differ when the median income was entered for the missing ("prefer not to answer”) responses, thus all reported analyses used the income variable with median entered.
} 
MULTIDIMENSIONAL APPROACH TO GENDER AND HEALTH

is, "I feel like I fit in with other men/women." A mean score was computed across all items $(M=$ 2.86, $S D=0.64$, range $=1-4$ ), with higher scores indicating greater gender typicality. The scale had acceptable internal consistency $(\alpha=.87)$.

Interdependent problem solving. To measure the extent to which participants engaged in more individualistic or interdependent strategies, Rubin, Watt, and Ramelli’s (2012) Independent-Interdependent Problem-Solving scale (IIPSS; Appendix D) was used. The 10-item scale asked participants to rate on a 7-point Likert-type scale from 1 (strongly disagree) to 7 (strongly agree) how much they agreed or disagreed with each statement. Sample items included: "I prefer to make decisions on my own, rather than with other people," "I like to get advice from my friends and family when deciding how to solve my personal problems," and "I prefer to consult with others before making an important decision.” Items 1, 3, 8, and 9 were reversed scored so that higher scores indicated greater interdependent problem solving. The interdependent problem solving scale $(M=3.71, S D=1.06$, range $=1$ - 7) was found to have acceptable internal consistency $(\alpha=.91)$.

Perceived health (Lawton, Moss, Fulcomer, \& Kleban, 1982). Participants were asked to rate how they perceived their present health on a four-item scale (Appendix E). One item asked, "How would you rate your overall health at the present time?” and participants chose from 1 (excellent) to 4 (poor) how they perceived their health. Two items asked participants to rate from 1 (better) to 3 (not as good) how they perceived their health compared to three years ago and compared to others their age. For the final item, participants rated from 1 (not at all) to 3 (a great deal) whether they believed their health problems prevented them from engaging in activities. Items were reversed scored and a sum score was computed for the scale $(M=9.49, S D=2.08$, range $=4$ - 13). Higher scores indicated better perceived health. The perceived health scale had acceptable internal consistency $(\alpha=.79)$. 
MULTIDIMENSIONAL APPROACH TO GENDER AND HEALTH

Bem Sex Role Inventory (BSRI). To be consistent with previous studies that have examined gender and health (e.g., Hunt, 2000; Hunt et al., 2007), the 60-item Bem Sex Role Inventory (Bem, 1974; Appendix F) was used to measure the extent to which participants saw stereotypical masculine (e.g., forceful, dominant) and feminine (e.g., affectionate, understanding) personality traits as characteristic of themselves. Participants were presented with a list of traits (20 stereotypically masculine, 20 stereotypically feminine, and 20 neutral) and were asked to rate on a scale of 1 (never or almost never true) to 7 (almost always true) the extent to which each trait described them. Neutral items were included in the original measure as they represented desirable traits for both men and women. For the purposes of the current study, neutral items were not scored. To reflect that men and women can simultaneously endorse stereotypical masculine and feminine traits, trait scores were computed based on the mean of masculine items $(M=4.61, S D=0.84$, range $=1.9-6.8)$ and feminine items $(M=4.54, S D=0.81$, range $=1.8-$ 6.7; see Lemaster et al., 2015a) rather than Bem’s (1981) method of categorization into groups (i.e., feminine, masculine, androgynous, undifferentiated). Higher scores indicated greater endorsement of the stereotypical gender-typed traits. Both masculine $(\alpha=.88)$ and feminine $(\alpha=$ .87) traits had acceptable internal consistency.

The BSRI is one of the most widely used measures of masculine and feminine traits, but it should be noted that it has also had critiques against it over the years since its development (Hoffman \& Borders, 2001). Studies have found, however, that the BSRI can be valid measure of masculinity and femininity (Holt \& Ellis, 1998), but acknowledge that the magnitude of differences in ratings among men and women has reduced (Holt \& Ellis, 1998; Twenge, 1997).

Health-Promoting Life Style Profile II (HPLP). The Health-Promoting Life Style Profile (Walker, Sechrist, \& Pender, 1995; Appendix G) is a 52-item questionnaire that was used to assess self-report health-promoting behaviors. Participants rated from 1 (never) to 4 


\section{MULTIDIMENSIONAL APPROACH TO GENDER AND HEALTH}

(routinely) how often they engaged in different health-promoting behaviors. Six subscale scores were obtained to assess: health responsibility (e.g., "report any unusual signs or symptoms to a physician or other health professional"), physical activity (e.g., "follow a planned exercise program"), nutrition (e.g., choose a diet low in fat, saturated fat, and cholesterol"), spiritual growth (e.g., "believe that my life has purpose”), interpersonal relations (e.g., “maintain meaningful and fulfilling relationships with others"), and stress management (e.g., "take some time for relaxation each day"). The six subscale scores were used to compute a composite for health-promoting behaviors. A mean score was computed for the composite $(M=2.56, S D=$ 0.50 , range $=1.3-4.0)$ in which higher scores indicated greater health-promoting lifestyle behaviors. Internal consistency for subscales ranged between Cronbach's alphas of .77 to .88 and the overall internal consistency was .95. For alphas for each subscale see Appendix G.

Gender identification. Michaelieu’s (1997) Gender Identification Scale (Appendix H) was used to assess the extent to which participants identified with and valued being a member of the larger group that corresponded to their self-reported sex. Participants were presented with 13 items and indicated how much they agreed with each statement $(1=$ strongly disagree to $5=$ strongly agree). Some sample items are, "being a male/female is an important part of who I am," "in general, most people respect males/females," and "usually I identify with males/females more than females/male." Items were sex-specific and were worded according to participants' reported sex at the beginning of the survey (i.e. men answered questions about males). A mean score was computed across all items $(M=3.52, S D=0.45$, range $=1.9-4.4)$ and higher scores indicated greater gender identification. Internal consistency was $\alpha=.60$.

Health Survey. Originally developed for the Medical Outcomes Study for RAND (Ware \& Sherbourne, 1992), the RAND 36-item Health Survey 1.0 (Appendix I) assessed various indicators of quality of life for individuals. The survey consisted of seven subscales with 


\section{MULTIDIMENSIONAL APPROACH TO GENDER AND HEALTH}

example items/questions in parentheses as follows: physical functioning (10 items; “health limits my ability to climb one flight of stairs"), bodily pain (2 items; "how much body pain have you experienced in the past 4 weeks?”), role limitations due to physical health problems (4 items; “accomplished less than you would like as a result of physical health”), role limitations due to personal or emotional problems (3 items; “didn’t do work or other activities as carefully as usual as a result of emotional problems”), emotional well-being (5 items; “have you been a happy person?”), social functioning (2 items; “To what extent has your physical health/emotional problems interfered with normal social activities with family, friends, neighbors, or groups?”), energy/fatigue (4 items; “did you feel full of pep?”), and general health (5 items; “I am as healthy as anybody I know”). The physical functioning subscale was the only measure used in analyses to represent functional limitations. Items were re-coded to be on a scale from 0 to 100 such that a higher score represented more favorable health. Items were then averaged for each subscale. When reporting results, higher scores represented "better" physical functioning and lower scores represented "limited" physical functioning. The physical functioning scale $(M=$ 80.14, $S D=24.53$, range $=5-100)$ had internal consistency $(\alpha=.93)$. See Appendix I for more details about item scoring and internal consistency for each subscale.

Social support. The Medical Outcomes Study (MOS) Social Support Survey (Sherbourne \& Stewart, 1991; Appendix J) is a 19-item measure that identified participants' perceptions of available social support. The measure utilized a multidimensional approach by assessing various functions of social support, which included the following subscales: emotional/informational (e.g., "someone to give you advice about a crisis”), tangible (e.g., “someone to help with daily chores if you were sick”), affectionate (e.g., "someone who shows you love and affection"), and positive social interaction (e.g., "someone to have a good time with”). Participants rated on a 5-point Likert scale (1 = none of the time to $5=$ all of the time), 
MULTIDIMENSIONAL APPROACH TO GENDER AND HEALTH

how often they perceived each type of support was available to them. A mean score was computed across all 19 items to compute an overall support index $(M=3.71, S D=1.06$, range $=$ 1- 5). Higher scores indicated greater perceived social support and the social support scale had internal consistency $(\alpha=.98)$.

Chronic health burden. The Self-Administered Comorbidity Questionnaire (SCQ; Katz, Chang, Sangha, Fossel, \& Bates, 1996) is a 19-item measure that assessed the types of chronic health conditions participants had (Appendix K). The measure was adapted from the validated Charlson Comorbidity index (Charlson et al., 1987; Quan et al., 2011) to improve efficiency of collecting comorbidity information through self-report instead of relying on medical record extraction. The measure accounted for comorbidities (i.e., based on number of chronic conditions) and utilize weighted severity scores for health conditions. Participants used a "yes, no” format to indicate whether they had certain chronic conditions, such as asthma, diabetes, congestive heart failure, or lung problems. A weighted scoring method from the Charlson index (Charlson et al., 1987) was used where each health condition was assigned a score of 1, 2, 3, or 6 according to the likelihood someone will die from the condition. For example, conditions such as congestive heart failure was scored as 1 point, diabetes was scored as 2 points, and AIDS was scored as 6 points. Higher sum scores reflected a greater risk of dying. In the results, higher scores represent greater chronic health burden and lower scores represent less chronic health burden $(M=0.80, S D=1.59$, range $=0-9)$.

Health-risk behaviors. The 6-item health and safety subscale of the Domain Specific Risk Taking scale (DOSPERT; Blais \& Weber, 2006) assessed the likelihood (1 = very unlikely to $5=$ very likely) that participants engaged in different risky behaviors (Appendix L). Example items included: "drinking heavily at a social function" and "sunbathing without sunscreen." 
MULTIDIMENSIONAL APPROACH TO GENDER AND HEALTH

Items were summed in which higher scores indicated greater risk-taking behaviors $(M=1.96, S D$ $=0.75$, range $=1-4.8)$. The health $/$ safety subscale had acceptable internal consistency $(\alpha=.71)$.

\section{Results}

Missing Data. Only participants who completed all measures were included in analyses therefore there were no missing data used in analyses.

\section{Preliminary Analyses}

Descriptive statistics. Descriptive statistics were conducted for the following key study variables: stereotypical masculine traits, stereotypical feminine traits, gender typicality, gender identification, interdependent problem solving, social support, health-promoting behaviors, and health-risk behaviors. Table 4 includes descriptive statistics for the overall sample and for men and women separately.

Skewness. Skewness was examined among key study variables. Social support and physical functioning were negatively skewed, whereas health-risk behaviors and chronic health burden were positively skewed. These variables were transformed with a square root transformation. When transformed variables were included in main analyses instead of untransformed variables the results did not significantly change. For this reason, the raw variables without transformations were reported in the results.

Correlations. Correlations for all key study variables from the entire sample (see Table 1) and separately by men and women (see Table 2) were computed.

MANOVA. As an exploratory analysis, a multivariate analysis of variance (MANOVA) was conducted to assess differences in gender-typed traits and behaviors by reported sex (men and women) and age group (middle-aged and older adults; see Table 3). Sex and age group were entered as independent variables, and stereotypical masculine traits, stereotypical feminine traits, gender typicality, gender identification, interdependent problem-solving, social support, health- 
MULTIDIMENSIONAL APPROACH TO GENDER AND HEALTH

promoting behaviors, and health-risk behaviors were entered as dependent variables. The interaction of sex and age group was also tested (Table 3). Significant multivariate main effects were found for sex and age group, but the sex by age group interaction was not significant.

For exploratory purposes, univariate main effects of sex (see Table 4) and age group (see Table 5) were examined. Men significantly reported greater masculine traits and health-risk behaviors than women. Women significantly reported greater feminine traits, social support, and health-promoting behaviors than men. No significant sex differences were found in gender typicality, gender identification, or interdependent problem solving.

Middle-aged adults significantly reported less gender typicality, fewer health-promoting behaviors, and greater health-risk behaviors than older adults. No significant age differences were found in masculine traits, feminine traits, gender identification, interdependent problem solving, or social support.

\section{Research Question 1: Differences in Health among Men and Women}

The objective of Research Question 1 was to test sex differences in the main health indices (perceived health, physical functioning, and chronic health burden). For Hypothesis 1a, it was expected that women would report significantly worse perceived health, limited physical functioning, and greater chronic health burden than men.

Hypothesis 1a: Sex differences in health. A multivariate analysis of covariance (MANCOVA) was conducted to address Hypothesis 1a (see Table 6). Self-reported sex $(0=$ male, 1 = female) and age group ( 0 = middle-aged adults, $1=$ older adults $)$ were entered as independent variables. Education and income were included as covariates based on significant correlations with health indices (see Table 1). An interaction term for sex by age group was entered as part of an exploratory analysis to test whether age moderated the association between sex and health. 
MULTIDIMENSIONAL APPROACH TO GENDER AND HEALTH

Multivariate main effects were significant for age group, but sex and the sex by age group interaction effects were not significant (see Table 6) ${ }^{4}$ Next, the univariate main effects of sex were examined to assess Hypotheses 1a. Hypothesis 1a, that women would report poorer selfrated health, limited physical functioning, and greater chronic health burden than men was not supported. There were no significant differences between men's and women's health, when controlling for education and income (see Table 7). ${ }^{5}$

For exploratory purposes, univariate main effects were also examined for age group (see Table 8). Middle-aged adults reported significantly less chronic health burden and better physical functioning compared to older adults. No significant differences between middle-aged and older adults' perceived health were found.

\section{Research Questions 2 and 3: Gender-Typed Psychological and Behavioral Health Model}

The objective of Research Questions 2 and 3 was to examine whether gender-typed traits (i.e. masculine and feminine traits, gender typicality, and gender identification) and behaviors (i.e., interdependent strategies, social support, health-promoting and health-risk behaviors) predicted three main health outcomes (perceived health, physical functioning, and chronic health burden). In addition, potential differences by sex (male, female) and age group (middle-aged, older adults) in regards to associations between variables of interest and health outcomes were assessed. The following were hypothesized:

(1) For men and women, greater endorsement of masculine traits and lower endorsement of feminine traits will be associated with poorer perceived health (Hypothesis 2a), better

\footnotetext{
${ }^{4}$ Significant multivariate effects were found for income as a covariate, but not education.

${ }^{5}$ Without the covariates, univariate main effects indicated that men $(M=82.97, S D=22.03)$ had significantly better physical functioning than women $(M=77.79, S D=26.24 ; F(1,486)=7.06, p=.01)$.
} 
MULTIDIMENSIONAL APPROACH TO GENDER AND HEALTH

perceived health (Alternative Hypothesis 2a), limited physical functioning (Hypothesis 2b), and greater chronic health burden (Hypothesis 2c).

(2) For women, greater gender typicality and greater gender identification will be associated with better perceived health (Hypothesis 2d), better physical functioning (Hypothesis 2e), and less chronic health burden (Hypothesis 2f).

(3) Conversely, for men, greater gender typicality and greater gender identification will be associated with poorer perceived health (Hypothesis 2d), limited physical functioning (Hypothesis 2e), and greater chronic health burden (Hypothesis 2f).

(4) For men and women, lower endorsement of interdependent strategies, less perceived social support, fewer health promoting-behaviors, and greater health-risk behaviors will be associated with poorer perceived health (Hypothesis 3a), limited physical functioning (Hypothesis 3b), and greater chronic health burden (Hypothesis 3c).

\section{Plan of Analysis}

To address Research Questions 2 and 3, and corresponding hypotheses, three path analyses were computed using the IBM SPSS Amos program in which each index of health (i.e., perceived health, physical functioning, and chronic health burden) was tested separately as the outcome variable. Gender-typed traits and behaviors were entered as predictors. Relevant covariates (e.g., age (continuous), education, and income) that were significantly associated with health, based on correlations (see Table 1), were included in the models. Researchers suggest various cut-offs for model fit (see Hooper, Coughlan, \& Mullen, 2008; Hu \& Bentler, 1999), but for the purpose of the current study, acceptable model fit was based on index ranges: $\chi^{2} / d f \leq 3.2$, CFI .90 - .99, and RMSEA .05 - .08 (Little, 2013), to provide flexibility if the models did not reach stringent cut-offs for each index. Stringent criterion has been identified as CFI > .95 and RMSEA < .06 (Hu \& Bentler, 1999). 


\section{MULTIDIMENSIONAL APPROACH TO GENDER AND HEALTH}

The following steps were taken for each model: (1) the originally proposed model was tested with gender-typed traits and behaviors simultaneously predicting each health outcome (see Figure 2), (2) an exploratory mediation model with behaviors entered as mediators between gender-typed traits and health was then tested (see Figure 3), (3) the best-fitting model (original or mediation) was then used to test multi-group differences by sex (male, female) and by age group (middle-aged and older adult), and (4) if no significant multi-group differences were found, the best-fitting model with paths constrained to be equal was used to assess relevant hypotheses.

Perceived health. The first path analysis included perceived health as the outcome variable to test Hypotheses 2a (and Alternative 2a), 2d, and 3a. Gender-typed traits and behaviors were simultaneously entered as predictors (see Figure 4). Sex, age, education, and income were added as covariates. After covarying conceptually-relevant indicators and measurement error terms, the model was an acceptable fit to the data based on less stringent criterion, $\chi^{2}(27)=105.95, R^{2}=.23, \mathrm{CMIN} / \mathrm{df}=3.92 ; \mathrm{CFI}=.94 ; \mathrm{RMSEA}=.08$ [90\% CI; .06, .09].

A conceptual model was then tested using self-reported behaviors as mediating variables as an exploratory analysis to potentially improve model fit. The model with behavioral indictors as mediators did achieve acceptable model fit, $\chi^{2}(29)=88.99, R^{2}=.25$, CMIN/df $=3.07$; CFI $=$ $.95 ;$ RMSEA $=.07$ [90\% CI; .05, .08]. The mediation model fit was a significant improvement compared to the original model ${ }^{6}$ and was used to test multi-group differences.

\footnotetext{
${ }^{6}$ A lower AIC (Akaike Information Criteria) indicates the best-fitting model (Akaike, 1974). For each of the following models, the mediation models had smaller values compared to the original models and thus provided a better fit to the data than the original models.

Model 1 (Perceived health): Mediation model AIC= $238.99<$ Original model AIC= 261.82

Model 2 (Physical functioning): Mediation model AIC= $238.85<$ Original model AIC= 268.83

Model 3 (Chronic health burden): Mediation model AIC= $242.10<$ Original model AIC= 272.21
} 
MULTIDIMENSIONAL APPROACH TO GENDER AND HEALTH

Two separate multi-group analyses were conducted with the mediation model to test significant differences in path values by sex (males and females) and age group (middle-aged and older adults). Path values were constrained to be equal and then compared to an unconstrained model where path values were allowed to vary by sex and age group. No significant differences were found between the two models by sex or age group, thus men and women, $\Delta \chi^{2}(27)=28.63, p=.38$ and middle-aged and older adults had similar path values overall, $\Delta \chi^{2}(27)=31.54, p=.25$.

Because there were no significant differences in the models for men and women, or middle-aged and older adults, the mediation model was used where path values were constrained to be equal to assess Hypotheses 2a (and Alternative 2a), 2d, and 3a. Age, sex, education, and income were included as covariates. Path estimates were examined to determine whether hypotheses were supported. See Figure 7 for the final model with path estimates.

Hypotheses 2a (and Alternative Hypothesis 2a) and 2d were not supported as there were no significant associations between gender-typed traits (masculine and feminine traits, gender typicality, gender identification) and perceived health. Hypothesis 3a was not fully supported, as interdependent strategies, social support, and health-risk behaviors were not significantly associated with perceived health. However, consistent with Hypothesis 3a, reporting engagement in more health-promoting behaviors was associated with better perceived health.

Physical functioning. The second path analysis included physical functioning as the outcome variable to test Hypotheses 2b, 2e, and 3b (see Figure 5). Physical functioning was coded such that higher scores indicated better physical functioning and lower scores indicated limited physical functioning. Gender-typed traits and behaviors were included as predictors of physical functioning. Sex, age, education, and income were added as covariates. After covarying conceptually relevant indicators and measurement error terms, the model reached acceptable fit 
MULTIDIMENSIONAL APPROACH TO GENDER AND HEALTH

to the data based on less stringent criterion, $\chi^{2}(31)=122.83, R^{2}=.18, \mathrm{CMIN} / \mathrm{df}=3.96$; $\mathrm{CFI}=$ $.92 ;$ RMSEA $=.08$ [90\% CI; .06, .09].

A conceptual model was then tested with self-reported behaviors as mediating variables as an exploratory analysis to potentially improve model fit. The model with behavioral indictors as mediators did achieve acceptable model fit, $\chi^{2}(27)=84.85, R^{2}=.19$, CMIN/df $=3.14$; CFI = $.95 ;$ RMSEA = .07 [90\% CI; .05, .08]. The mediation model fit was a significant improvement compared to the original model ${ }^{6}$ and was used to test multi-group differences.

Two separate multi-group analyses were conducted with the mediation model to test significant differences in path values by sex (males and females) and age group (middle-aged and older adults). Path values were constrained to be equal and then compared to an unconstrained model where path values were allowed to vary by sex and age group. No significant differences were found between the two models by sex or age group. Men and women, $\Delta \chi^{2}(27)=28.55, p=.38$ and middle-aged and older adults, had similar path values overall, $\Delta \chi^{2}(27)=25.42, p=.55$.

Because there were no significant differences in the models for men and women, or middle-aged and older adults, the mediation model was used where path values were constrained to be equal to assess Hypotheses 2b, 2e, and 3b. Age, sex, education, and income were included as covariates. Path estimates were then examined to determine whether Hypotheses 2b, 2e, and 3b were supported. See Figure 8 for the final model with path estimates.

Hypotheses 2b and 2e were not supported as there were no significant associations between gender-typed traits (masculine and feminine traits, gender typicality, gender identification) and physical functioning. Hypothesis 3a was partially supported as greater perceived social support and health-promoting behaviors were associated with better physical 
MULTIDIMENSIONAL APPROACH TO GENDER AND HEALTH

functioning. However, in contrast to Hypothesis 3a, interdependent strategies and health-risk behaviors were not significantly associated with physical functioning.

Chronic health burden. The third path analysis included chronic health burden as the outcome variable to test Hypotheses 2c, 2f, and 3c (see Figure 6). Gender-typed traits and behaviors were simultaneously entered as predictors. Sex, age, education, and income were entered as covariates. After covarying conceptually relevant indicators and measurement error terms, the model adequately fit the data based on less stringent criterion, $\chi^{2}(31)=126.21, R^{2}=$ $.07, \mathrm{CMIN} / \mathrm{df}=4.07 ; \mathrm{CFI}=.92 ; \mathrm{RMSEA}=.08$ [90\% CI; .07, .09].

A conceptual model was then tested with self-reported behaviors as mediating variables as an exploratory analysis to potentially improve model fit. The model with behavioral indictors as mediators did achieve acceptable model fit, $\chi^{2}(28)=90.10, R^{2}=.07$, CMIN/df $=3.21$; CFI $=$ $.95 ;$ RMSEA = .07 [90\% CI; .05, .08]. The mediation model fit was a significant improvement compared to the original model ${ }^{6}$ and was used to test multi-group differences.

Two separate multi-group analyses were conducted with the mediation model to test significant differences in path values by sex (male, female) and age group (middle-aged and older adults). Path values were constrained to be equal and then compared to an unconstrained model where path values were allowed to vary by sex and age group. No significant differences were found between the two models by sex or age group, thus men and women, $\Delta \chi^{2}(27)=20.98$, $p=.79$ and middle-aged and older adults had similar path values overall, $\Delta \chi^{2}(27)=26.70, p=$ .48.

Because there were no significant differences in the models for men and women, or middle-aged and older adults, the mediation model was used where path values were constrained to be equal to assess Hypotheses 2c, 2f, and 3c. Age, sex, education, and income were included 
MULTIDIMENSIONAL APPROACH TO GENDER AND HEALTH

as covariates. Path estimates were examined to determine whether Hypotheses 2c, 2f, and 3c were supported. See Figure 9 for the final model with path estimates.

Hypotheses 2c and $2 \mathrm{f}$ were not supported as there were no significant associations between gender-typed traits (masculine and feminine traits, gender typicality, gender identification) and chronic health burden. Hypothesis 3c was not fully supported, as interdependent strategies, health-promoting, and health-risk behaviors were not significantly associated with chronic health burden. However, as expected for Hypothesis 3c, reporting greater perceived social support was associated with less chronic health burden.

\section{Testing Associations between Gender-Typed Traits and Behaviors}

The initially proposed analyses tested gender-typed traits (e.g., masculine and feminine traits) and behaviors (e.g., health-promoting behavior) directly predicting health (Figures 4 - 6). Exploratory models that tested behaviors as mediating variables between gender-typed traits and health, however, had better model fit to the data, suggesting the importance of examining pathways between gender-typed traits and behaviors. The following sections will describe the significant pathways between stereotypical masculine and feminine traits, gender typicality, and gender identification with interdependent strategies, social support, health-promoting and healthrisk behaviors (see Figures 7 - 9).

Interdependent strategies. For men and women, greater gender typicality and greater endorsement of stereotypical feminine traits were associated with greater interdependent problem solving. In contrast, greater endorsement of stereotypical masculine traits was associated with less interdependent problem solving. Gender identification was not significantly related to interdependent strategies. 
MULTIDIMENSIONAL APPROACH TO GENDER AND HEALTH

Social support. For men and women, greater gender typicality, greater gender identification, greater endorsement of masculine and feminine traits were all associated with greater perceived social support.

Health-promoting behaviors. For men and women, greater gender typicality, greater endorsement of stereotypical masculine and feminine traits were associated with greater healthpromoting behaviors. Gender identification was not significantly related to health-promoting behaviors.

Health-risk behaviors. For men and women, greater gender identification and feminine traits were associated with fewer health-risk behaviors. In contrast, greater endorsement of masculine traits was associated with greater health-risk behaviors. Gender typicality was not significantly related to health-risk behaviors.

\section{Discussion}

\section{Applying the Multidimensional Model of Gender and Health}

The main aim of the current study was to apply a multidimensional approach to understanding how gender may contribute to differences in health among men and women. The conceptual model that guided the study was largely based on expected differences in men's and women’s health (e.g., Crimmins et al., 2011; Lochner \& Cox, 2010; Read \& Gorman, 2010), however, significant differences between men's and women's health was not found in the current study. This could be due to the sample being comprised of relatively healthy individuals, thus decreasing the amount of variability to predict in the health outcomes. For example, physical functioning and chronic burden scores were significantly skewed, in that average physical functioning was 80 out of 100 (100 indicated no physical limitations) and most reported no chronic health conditions (71\% of sample). There were also no direct associations between gender-typed traits and health indices, however, significant associations between aspects of 
MULTIDIMENSIONAL APPROACH TO GENDER AND HEALTH

interdependence and health behaviors and health were found. In the current study, for example, greater social support and health-promoting behaviors were related to better physical functioning. The model was also partially supported in that men and women did differ in some aspects of "having gender" (i.e., stereotypical masculine and feminine traits) and "doing gender" (i.e., social support, health behaviors). Furthermore, significant associations between gendertyped traits and behaviors were found, providing some insight into how gender may function in relation to health. The following sections discuss the implications of gender-typed traits in relation to behaviors known to impact health.

\section{Men and Women Endorse Stereotypical Gender-Typed Traits}

In accordance with previous literature and social role theory (e.g., Eagly, 1987; Lemaster et al., 2015a; Strough et al., 2007), current findings did indicate sex differences in gender-typed traits. Men and women develop within a larger sociocultural context that reinforces different social roles for men and women, largely due to historical differences in labor (Eagly, 1987; Eagly \& Wood, 1999). That is, men are socially prescribed to being "breadwinners" and are posited to adopt agentic, masculine traits and behaviors (e.g., independence, skillfulness, risk taking). Whereas women are socially prescribed to be caregivers and are posited to adopt communal, feminine traits and behaviors (e.g., friendly, interpersonally-oriented, selfless; Eagly, 1987; Eagly \& Wood, 1991). In accord with socially prescribed roles, in the current study, men reported greater stereotypical masculine traits than women and women reported greater stereotypical feminine traits than men. Gender identification and gender typicality were also assessed to expand the conceptualization of gender, but no differences were found between men and women despite previous research finding that men report greater gender typicality and gender identification than women (Lemaster et al., 2015a; Lemaster \& Strough, 2014). Men and 
MULTIDIMENSIONAL APPROACH TO GENDER AND HEALTH

women in the current study equally perceived themselves as belonging to their respective gender group.

Although men and women did not significantly differ in gender typicality and identification, significant associations between stereotypical traits with gender typicality and gender identification variables were different for men and women. For men, masculine and feminine traits were positively related to gender typicality but only masculine traits were positively related to gender identification. For women, however, only feminine traits were significantly related, in a positive association, to gender typicality and identification. This suggests that although men and women did not significantly differ in their perceptions of belonging to their gender group, the meaning of belongingness may be different (e.g., for men, gender typicality related to masculinity and femininity, but for women it was only femininity). For men, examining item-level associations between feminine traits and gender typicality showed strong, positive correlations between the feminine characteristics of "understanding” and “loves children” with the item "I think I am a good example of being a man.” Perhaps men who are married and have children would be more likely to endorse these characteristics, which are more typical of the feminine gender role. For example, a previous study found that married older men were more likely to endorse a balance of both masculine and feminine traits than unmarried men (Lemaster et al., 2015a).

\section{Interdependent Strategies Not Related to Health}

Despite previous research finding that interdependent strategies were beneficial for health and longevity (Delaney et al., 2016), interdependent problem solving was not significantly related to any of the health indices in the current study. A different measure was used than in a previous study (Delaney et al., 2016), which could have contributed to different findings. In addition, it would be useful to utilize a measure that can assess the specific domain in which 
MULTIDIMENSIONAL APPROACH TO GENDER AND HEALTH

individuals seek help or advice, which could more directly relate to health outcomes. For example, it may be beneficial for someone to seek advice regarding medical decisions from their doctor or family, which in turn could relate to better health outcomes. Utilizing interdependent strategies on a daily basis, however, may not have a significant influence on health.

\section{Endorsing Gender-Typed Traits Related to Interdependent Problem Solving}

In regards to interdependent behaviors (e.g., seeking advice and help), it was expected that in accordance with the feminine gender role being characterized by nurturance and caring for others (Eagly, 1987; Eagly \& Wood, 1991), women would report more interdependent problem solving than men. Within the multidimensional model, differences between men and women in the endorsement of interdependent problem solving were not found. However, associations between interdependent problem solving and gender-typed traits were found. For men and women, endorsing more feminine traits related to greater reported interdependent problem solving, whereas endorsing more masculine traits related to reporting less interdependent problem solving. These findings seem to map onto traditional depictions of masculinity and femininity. Being interpersonally-oriented is often associated with femininity, whereas independence is associated with masculinity (Eagly, 1987; Eagly \& Wood, 1991).

Those who reported greater gender typicality also reported greater interdependent problem solving. That is, both men and women who felt a strong affiliation with their gender group were more likely to utilize people in their social network when faced with problems. Research on adolescents and young adults has found that feeling more strongly affiliated with one's own-gender group is associated with spending more time with members of the same gender (Mehta et al., 2013; Mehta \& Strough, 2010). Thus, our findings could reflect that individuals who reported greater typicality had more opportunities to seek advice from others. 
MULTIDIMENSIONAL APPROACH TO GENDER AND HEALTH

\section{Social Support Associated with Better Health}

In accordance with previous research (Berkman et al., 2000; Shumaker \& Hill, 1991;

Uchino, 2009), perceived social support was associated with better perceived health and less chronic health burden. Similar to interdependent problem solving, sex differences in social support were found. In addition, associations between gender-typed traits and social support were found, which could offer insight into how gender may indirectly influence health through social support.

\section{Gender-Typed Traits Linked to Greater Perceptions of Social Support}

In the current study, men reported less perceived social support than women. Similar to interdependent problem solving, social support is interpersonally-oriented and could be considered an outcome of the stereotypical feminine gender role. Men are less likely to seek social support and utilize fewer sources of support than women (Gurung et al., 2003; Tamres et al., 2002), which could be due to interpersonally-oriented behaviors being perceived as in opposition to the strong, masculine gender role (Courtenay, 2000; Evans et al., 2011).

Both men and women who reported greater masculine and feminine traits, gender typicality, and gender identification reported more perceived social support. The association with feminine traits would be expected given that social support is interpersonally-oriented and thus is a characteristic that the fits under stereotypical femininity. Gender typicality and gender identification may also be significantly associated with social support as people who feel close with and identify with their gender group, spend more time with those in their gender group (Mehta et al., 2013; Mehta \& Strough, 2010), and therefore have an available support system. The association between masculine traits and social support is somewhat surprising as interpersonal behaviors may be counter to stereotypical masculinity (Courtenay, 2000; Eagly, 2009), however one previous study also found a similar association between masculine traits and 
MULTIDIMENSIONAL APPROACH TO GENDER AND HEALTH

social support for men and women (Helgeson, 1990). In Helgeson’s (1990) study, socially

desirable masculine traits (e.g., independent and assertive) were positively associated with social support, but socially undesirable traits (e.g., aggression and competitiveness) were not. The Bem Sex Role Inventory (1974) was primarily developed based on whether a trait was more desirable for one sex more than the other, however, it did not necessarily distinguish between desirable and undesirable traits within each subscale (i.e. masculine and feminine traits). Future research should try to distinguish between desirable and undesirable masculine traits, which may help explain the association with social support.

In addition, although research does find differences between men and women in regards to social support, men still seek and obtain support but it is just from fewer sources (Tamres et al., 2002; Thoits, 1995). Men often seek the most support from their spouse (Antonucci \& Akiyama, 1987; Shumaker \& Hill, 1991), whom they may be more comfortable obtaining support from. Identifying associations between specific types of support (e.g., emotional, instrumental), the sex of the person who serves as the source of support (male, female), and the relationship with the source of support (e.g., family member, friend), could also help identify how gender-typed traits relate to social support. Indeed, one study found that feminine traits were related to seeking and receiving emotional support for both men and women. Men and women who endorsed masculine traits, however, reported receiving more tangible support (e.g., transportation; Reevy \& Maslach, 2001).

\section{Health-Promoting Behaviors Associated with Better Health}

Reporting greater engagement in health-promoting behaviors was also associated with better perceived health and better physical functioning, which would be expected based on prior literature (Duffy \& MacDonald, 1990; Strawbridge et al., 1993). Similar to prior research (Nassar \& Shaheen, 2014; Powell-Griner et al., 1997), women also reported engaging in more 
MULTIDIMENSIONAL APPROACH TO GENDER AND HEALTH

health-promoting behaviors than men. Endorsing gender-typed traits was also positively associated with health-promoting behaviors, suggesting the benefit of endorsing aspects of gender in relation to health.

\section{Endorsing Gender-Typed Traits Positively Related to Health Promotion}

In the present study, for men and women, endorsing greater feminine traits was associated with reporting more frequent health-promoting behaviors. This was expected as caring about health and seeking help have been characterized as feminine attributes that positively influence health (Cameron \& Bernardes, 1998; Courtenay, 2000; Evans et al., 2011) and healthpromoting behaviors (e.g., physician visits, medication adherence; Annandale \& Hunt, 1990; Ruffing-Rahal et al., 1997). For men and women, greater endorsement of masculine traits related to reporting greater health-promoting behaviors. For men, this is contrary to previous research that found that masculine traits related to fewer health-promoting behaviors for men (e.g., exercise, dietary habits; Mahalik et al., 2007). A different measure of masculinity was used in Mahalik et al. (2007) that focused on conforming to specific masculine roles, which could have influenced the different findings. However, for women, this aligns with a study that found among older women, masculine traits related to greater health-promoting behaviors (e.g., stress management, medication adherence, Ruffing-Rahal et al., 1997). Both masculine and feminine traits were positively related to health-promoting behaviors, which suggests the benefits of having both types of traits. Perhaps stereotypical masculine traits, such as being assertive and having leadership abilities, contribute to people taking charge in regards to their health behaviors (e.g., asking medical questions and seeking help) and are thus beneficial. Feminine traits, such as being compassionate and understanding, promote interpersonal relations which have been shown to positively influence health (e.g., Berkman et al., 2000; Rowe \& Kahn, 1997). 
MULTIDIMENSIONAL APPROACH TO GENDER AND HEALTH

Similar to masculine and feminine traits, reporting greater gender typicality was related to reporting greater health-promoting behaviors. These findings are also in accord with positive associations found in the current study between gender typicality with interdependent problem solving and social support. Interpersonal relations was also a subscale included in the healthpromoting behavior measure. As was noted with interdependent problem solving and social support, feeling close to one’s gender group may be related to having a support network available. This support network can potentially help with coping with stress and serve as a support system for engaging in health care responsibility.

\section{Health-Risk Behaviors Not Associated with Health}

Despite research that has connected health-risk behaviors to poorer health outcomes (Kaplan et al., 1987; Klatsky et al., 1992; Strawbridge et al., 1993), significant associations between health-risk behaviors and the three health outcomes were not found in the current study. This could be due to the measure reflecting self-reported likelihood of engaging in the behaviors, rather than measuring the actual frequency of the behavior (e.g., number of alcoholic drinks per week). Although no significant associations were found between health-risk behaviors and health in this sample, associations were found between gender-typed traits and health-risk behaviors that can add to the literature.

\section{Aspects of Gender Related to Differences in Health-Risk Behaviors}

In accordance with previous literature (Byrnes et al., 1999; Powell-Griner et al., 1997; Ratner et al., 1994), men reported that they would be more likely to engage in health-risk behaviors than women. Associations between gender-typed traits and health-risk behaviors were also found. Interestingly, for both men and women, greater endorsement of masculine traits (e.g., competitive, individualistic) were associated with reporting greater health-risk behaviors. The men and masculinities literature emphasizes that men who enact the stereotypical masculine 


\section{MULTIDIMENSIONAL APPROACH TO GENDER AND HEALTH}

gender role characterized by stoicism and invincibility may engage in more health-risk behaviors because they perceive themselves invulnerable to harm (Courtenay, 2000; Lohan, 2007;

Nicholas, 2000). Conversely, endorsing greater feminine traits (e.g., yielding, shy) was associated with fewer health-risk behaviors. These findings suggest that masculine traits may be harmful to both men and women, and that feminine traits may serve as a protective factor against health-risk behaviors. Future research can further test the extent to which feminine traits may also buffer the association between masculine traits and health-risk behaviors.

In the current study, reported gender identification for both men and women was associated with reporting fewer health-risk behaviors. Those who reported that they strongly connected to and identified as member of their gender group reported fewer health-risk behaviors. We expected that similar to masculine traits, men who felt more connected to their gender would have reported greater health-risk behaviors. However, research on financial risk behaviors has had a similar finding, where there was a negative association between gender identification and financial risk for men (Lemaster \& Strough, 2014). As Lemaster and Strough (2014) suggested, it is possible that men who feel less positive about their male identity may engage in more risk in an attempt to demonstrate socially-prescribed masculinity. In contrast to expected findings for men, for women, we expected that feeling closer with the feminine gender role, would relate to fewer health-risk behaviors. Our findings are in line with a previous study that found that women who reported greater gender identification engaged in less substance use (Mehta et al., 2013).

\section{Limitations and Future Directions}

As with all studies, there are limitations that should be noted, but can in turn offer direction for future research. First, it would be beneficial to apply the proposed multidimensional model of gender and health among a more nationally representative sample of aging adults. With 


\section{MULTIDIMENSIONAL APPROACH TO GENDER AND HEALTH}

a more representative sample, including a greater range of adults 65 years of age and older, differences between men's and women's health may be significant as functional disabilities and chronic health conditions increase in late adulthood (i.e., 65+ years old; Gerteis et al., 2014). A larger sample (> 500 participants) could also help to increase power, which may have been relatively low when divided by sex ( $<250$ in each group) in the multi-group analyses. Second, results were presented using correlational data, thus causation cannot be inferred. Directional associations cannot be formally concluded as there is potential that bidirectional processes occur among gender, behaviors, and health over time. For example, while masculine traits predicted greater health-risk behaviors, engaging in health-risk behaviors may also reinforce the stereotypical masculine gender role (i.e. sense of invisibility). In addition, due to the crosssectional nature of the data, cohort differences cannot be assessed which may be relevant for considering gender differences as historical events can shape a person’s social history and development (Stewart \& Healy, 1989). Conducting studies utilizing longitudinal or experimental design can aid with clarifying the directionality of the associations and address some of the limitations of cross-sectional research designs. Third, including other measures of gender could lead to different findings. As this is the first known study to attempt to test multiple indicators of gender, a more limited number of gender variables were used. There are other measures, such as gender role stress (i.e. stress associated with trying to conform to stereotypical gender roles; Eisler \& Skidmore, 1987; O’ Neil, 2008) and conformity to masculinity (i.e. extent to which a person conforms to stereotypical masculinity; Mahalik et al., 2003) that have been connected to health outcomes in previous studies. Fourth, the internal consistency was relatively low for gender identification $(\alpha=.60)$ and high for composite measures (e.g., health-promoting behaviors, $\alpha=.95$ ), suggesting some issues with the reliability of the measures (i.e., too low among gender identification, but potential redundancy among health-promoting behaviors; 


\section{MULTIDIMENSIONAL APPROACH TO GENDER AND HEALTH}

Tavakol \& Dennick, 2011). For the purposes of the current study, composite scales were used to first get a broad understanding of associations between gender-typed traits and behaviors, but utilizing subscales instead could offer more descriptive findings and reduce redundancy in the measure. Future research, for instance, should test whether the association for stereotypical masculine and feminine traits is significant for all of the health-promoting subscales (e.g., health responsibility, stress management), or just some. Targeting specific behaviors can also offer more utility for developing interventions if significant findings arise.

\section{Conclusion}

To our knowledge, this is the first study to apply a comprehensive multidimensional model to better understand how gender relates to health. Although there were no significant differences in health for men and women, nor associations between gender-typed traits and health in the full model, findings suggested that there is potential for gender-typed traits to indirectly influence health through various behaviors. That is, gender-typed traits, such as stereotypical masculine (e.g., self-reliant, assertive) and feminine traits (e.g., understanding, affectionate), were significantly associated with health-promoting and health-risk behaviors. In addition, the current study added to the literature by testing other indicators of gender (i.e., gender typicality and identification), which were also associated with some of the health behaviors. Identifying these associations can be useful for further research and intervention development to determine if certain gender-typed traits are risk factors for poor health behaviors and health. Developing interventions to reduce and prevent specific health-risk factors can then serve to reduce healthcare expenditures over time. Connecting specific gender-typed traits and health behaviors (e.g., stress management and substance use) can also be useful for identifying ways to reduce health disparities between men and women. Such research can facilitate a better understanding of how to improve longevity for men and women. 
MULTIDIMENSIONAL APPROACH TO GENDER AND HEALTH

\section{References}

Addis, M. E., \& Mahalik, J. R. (2003). Men, masculinity, and the contexts of help seeking. American Psychologist, 58(1), 5-14. doi: 10.1037/0003-066X.58.1.5

Annandale, E., \& Hunt, K. (1990). Masculinity, femininity and sex: An exploration of their relative contribution to explaining gender differences in health. Sociology of Health and Illness, 12(1), 24-46. doi:10.1111/1467-9566.ep10844865

Annandale, E., \& Hunt, K. (2000). Gender inequalities in health. Buckingham: Open University Press.

Antonucci, T. C., \& Akiyama, H. (1987). An examination of sex differences in social support among older men and women. Sex Roles, 17(11-12), 737-749. doi: 10.1007/BF00287685

Ashmore, R. D. (1990). Sex, gender, and the individual. In L. A. Pervin (Ed.), Handbook of personality: Theory and research (pp. 486-526). New York, NY: Guilford Press.

Baker, P., Dworkin, S. L., Sengfah, T., Banks, I., Shand, T., \& Yamey, G. (2014). The men’s health gap: Men must be included in the global health equity agenda. Bulletin of the World Health Organization, 92(8), 618-620. doi:10.2471/BLT.13.132795

Baltes, P. B. (1987). Theoretical propositions of life-span developmental psychology: On the dynamics between growth and decline. Developmental Psychology, 23(5), 611-626. 10.1037/0012-1649.23.5.611

Bem, S. L. (1974). The measurement of psychological androgyny. Journal of Consulting and Clinical Psychology, 42, 155-162. doi: 10.1037/h0036215

Bem, S. L. (1981). A manual for the Bem sex role inventory. Palo Alto, CA: Mind Garden. Bentler, P. M., \& Chou, C. P. (1987). Practical issues in structural modeling. Sociological Methods \& Research, 16(1), 78-117. doi: 0.1177/0049124187016001004 
MULTIDIMENSIONAL APPROACH TO GENDER AND HEALTH

Benyamini, Y. (2008). Self-ratings of health and longevity: A health psychologist's viewpoint on epidemiological findings. The European Health Psychologist, 10, 10-13. Retrieved from http://www.ehps.net/ehp/index.php/contents/article/viewFile/ehp.v10.i1.p10/34

Berinsky, A. J., Huber, G. A., \& Lenz, G. S. (2012). Evaluating online labor markets for experimental research: Amazon.com's Mechanical Turk. Political Analysis, 20(3), 351368. doi: 10.1093/pan/mpr057

Berger, J. L., Addis, M. E., Green, J. D., Mackowiak, C., \& Goldberg, V. (2013). Men’s reactions to mental health labels, forms of help-seeking, and sources of help-seeking advice. Psychology of Men \& Masculinity, 14(4), 433-443. doi: 10.1037/a0030175

Berkman, L. F., Glass, T., Brissette, I., \& Seeman, T. E. (2000). From social integration to health: Durkheim in the new millennium. Social Science \& Medicine, 51(6), 843-857. doi:10.1016/S0277-9536(00)00065-4

Blais, A. R., \& Weber, E. U. (2006). A domain-specific risk-taking (DOSPERT) scale for adult populations. Judgment \& Decision Making, 1(1), 33-47.

Branch, L. G., \& Jette, A. M. (1982). A prospective study of long-term care institutionalization among the aged. American Journal of Public Health, 72(12), 1373-1379. doi: 10.2105/AJPH.72.12.1373

Branch, L., Jette, A., Evashwick, C., Polansky, M., Rowe, G., \& Diehr, P. (1981). Toward understanding elders' health service utilization. Journal of Community Health, 7(2), 8092. doi: 10.1007/BF01323227

Byrnes, J. P., Miller, D. C., \& Schafer, W. D. (1999). Gender differences in risk taking: A metaanalysis. Psychological Bulletin, 125, 367- 383. doi: 10.1037/0033-2909.125.3.367 
MULTIDIMENSIONAL APPROACH TO GENDER AND HEALTH

Buhrmester, M., Kwang, T., \& Gosling, S. D. (2011). Amazon’s Mechanical Turk: A new source of inexpensive, yet high-quality data? Perspectives on Psychological Science, 6, 3-5. doi: $10.1177 / 1745691610393980$

Cameron, E., \& Bernardes, J. (1998). Gender and disadvantage in health: Men’s health for a change. Sociology of Health \& Illness, 20(5), 673-693. 10.1111/1467-9566.00124

Centers for Disease Control and Prevention (2013). The state of aging and health in America 2013. Retrieved from https://www.cdc.gov/aging/pdf/State-Aging-Health-in-America2013.pdf

Centers for Disease Control and Prevention (2009). The power of prevention. Chronic disease...the public health challenge of the $21^{\text {st }}$ century. Retrieved from http://www.cdc.gov/chronicdisease/pdf/2009-Power-of-Prevention.pdf

Centers for Disease Control and Prevention (2013). CDC health disparities and inequality reportUnited States, 2011. Retrieved from https://www.cdc.gov/mmwr/pdf/other/su6203.pdf

Centers for Medicare and Medicaid Services (2012). Chronic conditions among Medicare beneficiaries. Baltimore, MD. Retrieved from https://www.cms.gov/research-statisticsdata-and-systems/statistics-trends-and-reports/chronicconditions/downloads/2012chartbook.pdf

Charlson, M. E., Pompei, P., Ales, K. L., \& MacKenzie, C. R. (1987). A new method of classifying prognostic comorbidity in longitudinal studies: Development and validation. Journal of Chronic Diseases, 40(5), 373-383. doi: 10.1016/0021-9681(87)90171-8

Chen, H., Cohen, P., \& Kasen, S. (2007). Cohort differences in self-rated health: Evidence from a three-decade, community-based, longitudinal study of women. American Journal of Epidemiology, 166(4), 439-446. doi :10.1093/aje/kwm100 
MULTIDIMENSIONAL APPROACH TO GENDER AND HEALTH

Christensen, K., Doblhammer, G., Rau, R., \& Vaupel, J. W. (2009). Ageing populations: The challenges ahead. The Lancet, 374(9696), 1196-1208. doi: 10.1016/S01406736(09)61460-4

Clayton, J. A. \& Tannenbaum, C. (2016). Reporting sex, gender, or both in clinical research? JAMA, 316(18), 1863-1864. doi: 10.1001/jama.2016.16405

Cleary, P. D., Greenfield, S., Mulley, A. G., Pauker, S. G., Schroeder, S. A., Wexler, L., \& McNeil, B. J. (1991). Variations in length of stay and outcomes for six medical and surgical conditions in Massachusetts and California. JAMA, 266(1), 73-79. doi: 10.1001/jama.1991.03470010077034

Collins, P. H. (1990). Black feminist thought: Knowledge, consciousness, and the politics of empowerment. New York: Routledge.

Collins, P. H. (2000). Gender, black feminism, and black political economy. The Annals of the American Academy of Political and Social Science, 568(1), 41-53. doi: $10.1177 / 000271620056800105$

Concato, J., Horwitz, R. I., Feinstein, A. R., Elmore, J. G., \& Schiff, S. F. (1992). Problems of comorbidity in mortality after prostatectomy. JAMA, 267(8), 1077-1082. doi: 10.1001/jama.1992.03480080047025

Constantinople, A. (1973). Masculinity-femininity: An exception to a famous dictum? Psychological Bulletin, 80, 389-407. doi: 10.1037/h0035334

Corney, R. H. (1990). Sex differences in general practice attendance and help seeking for minor illness. Journal of Psychosomatic Research, 34(5), 525-534. doi:10.1016/00223999(90)90027-2

Courtenay, W. H. (1998). College men's health: an overview and a call to action. Journal of American College Health, 46(6), 279-290. doi: 10.1080/07448489809596004 
MULTIDIMENSIONAL APPROACH TO GENDER AND HEALTH

Courtenay, W. H. (2000). Constructions of masculinity and their influence on men's well-being: a theory of gender and health. Social Science \& Medicine, 50(10), 1385-1401. doi:10.1016/S0277-9536(99)00390-1

Crimmins, E. M., Kim, J. K., \& Solé-Auró, A. (2010). Gender differences in health: Results from SHARE, ELSA and HRS. The European Journal of Public Health, 21(1), 81-91. doi: 10.1093/eurpub/ckq022

Delaney, R., Strough, J., Parker, A. M., \& de Bruin, W. B. (2015). Variations in decision-making profiles by age and gender: A cluster-analytic approach. Personality and Individual Differences, 85, 19-24. doi:10.1016/j.paid.2015.04.034

Delaney, R., Turiano, N. A., \& Strough, J. (2016). Living longer with help from others: Seeking advice lowers mortality risk. Journal of Health Psychology, 1-8. doi: 10.1177/1359105316664133

Deyo, R. A., Cherkin, D. C., \& Ciol, M. A. (1992). Adapting a clinical comorbidity index for use with ICD-9-CM administrative databases. Journal of Clinical Epidemiology, 45(6), 613619. doi: 10.1016/0895-4356(92)90133-8

Duffy, M. E., \& MacDonald, E. (1990). Determinants of functional health of older persons. The Gerontologist, 30(4), 503-509. doi: 10.1093/geront/30.4.503

Eagly, A. H. (1987). Sex differences in social behavior: A social-role interpretation. Hillsdale, NJ: Lawrence Erlbaum Associates.

Eagly, A. H., Eaton, A., Rose, S. M., Riger, S., \& McHugh, M. C. (2012). Feminism and psychology: Analysis of a half-century of research on women and gender. American Psychologist, 67(3), 211-230. doi:10.1037/a0027260 
MULTIDIMENSIONAL APPROACH TO GENDER AND HEALTH

Eagly, A. H., \& Wood, W. (1991). Explaining sex differences in social behavior: A metaanalytic perspective. Personality and Social Psychology Bulletin, 17(3), 306-315. doi: $10.1177 / 0146167291173011$

Eagly, A. H., \& Wood, W. (1999). The origins of sex differences in human behavior: Evolved dispositions versus social roles. American Psychologist, 54(6), 408-423. doi:10.1037/0003-066X.54.6.408

Eagly, A. H., Wood, W., \& Diekman, A. B. (2000). Social role theory of sex differences and similarities: A current appraisal. In T. Eckes \& H. Martin Trautner (Eds.), The Developmental Social Psychology of Gender, (pp. 123-174). New York, NY: Psychology Press.

Egan, S. K., \& Perry, D. G. (2001). Gender identity: A multidimensional analysis with implications for psychosocial adjustment. Developmental Psychology, 37(4), 451-463. doi: 10.1037/0012-1649.37.4.451

Eisler, R. M., \& Skidmore, J. R. (1987). Masculine gender role stress: Scale development and component factors in the appraisal of stressful situations. Behavior Modification, 11(2), 123-136. doi: 10.1177/01454455870112001

Erikson, E. H. (1980). Identity and the life cycle. New York, NY: W. W. Norton.

Eriksson, T., Maclure, M., \& Kragstrup, J. (2004). Consultation with the general practitioner triggered by advice from social network members. Scandinavian Journal of Primary Health Care, 22(1), 54-59. doi: 10.1080/02813430310003192

Evans, J., Frank, B., Oliffe, J. L., \& Gregory, D. (2011). Health, illness, men and masculinities (HIMM): A theoretical framework for understanding men and their health. Journal of Men's Health, 8(1), 7-15. doi:10.1016/j.jomh.2010.09.227 
MULTIDIMENSIONAL APPROACH TO GENDER AND HEALTH

Fillenbaum, G. (1987). Activities of daily living. In G. L. Maddox (Ed.), The Encyclopedia of Aging. New York: Springer.

Fischer, E. H., \& Turner, J. I. (1970). Orientations to seeking professional help: Development and research utility of an attitude scale. Journal of Consulting and Clinical Psychology, 35(1), 79-90. doi: 10.1037/h0029636

Foti, D., \& Koketsu, L. (2008). Activities of daily living, in H. M. Pendleton, W. Schultz-Krohn, (Eds.) Pedretti’s Occupational Therapy: Practice Skills for Dysfunction, (pp. 146-192). St. Louis, MI: Elsevier, Inc.

Freedman, V. A., \& Martin, L. G. (1998). Understanding trends in functional limitations among older Americans. American Journal of Public Health, 88(10), 1457-1462. doi: 10.2105/AJPH.88.10.1457

Fylkesnes, K., \& Førde, O. H. (1991). The Tromsø study: Predictors of self-evaluated health— Has society adopted the expanded health concept? Social Science \& Medicine, 32(2), 141-146. doi: 10.1016/0277-9536(91)90053-F

Galdas, P. M., Cheater, F., \& Marshall, P. (2005). Men and health help-seeking behaviour: Literature review. Journal of Advanced Nursing, 49(6), 616-623. doi: 10.1111/j.13652648.2004.03331.x

Garber, A. M. (1989). Long-term care, wealth, and health of the disabled elderly living in the community. In D. A. Wise (Eds.), The Economics of Aging (pp. 255-278). Chicago, IL: University of Chicago Press.

Gaugler, J. E., Duval, S., Anderson, K. A., \& Kane, R. L. (2007). Predicting nursing home admission in the US: A meta-analysis. BMC geriatrics, 7(1), 13. doi:10.1186/1471-23187-13 
MULTIDIMENSIONAL APPROACH TO GENDER AND HEALTH

Gerteis, J., Izrael, D., Deitz, D., LeRoy, L., Ricciardi, R., Miller, T., \& Basu, J. (2014). Multiple chronic conditions chartbook. Rockville, MD: Agency for Healthcare Research and Quality.

Goodman, J. K., Cryder, C. E., \& Cheema, A. (2013). Data collection in a flat world: The strengths and weaknesses of Mechanical Turk samples. Journal of Behavioral Decision Making, 26(3), 213-224. doi: 10.1002/bdm.1753

Gurung, R. A., Taylor, S. E., \& Seeman, T. E. (2003). Accounting for changes in social support among married older adults: insights from the MacArthur Studies of Successful Aging. Psychology and Aging, 18(3), 487-497. doi: 10.1037/0882-7974.18.3.487

Hacıhasanoğlu, R., Yıldırım, A., Karakurt, P., \& Sağlam, R. (2011). Healthy lifestyle behaviour in university students and influential factors in eastern Turkey. International Journal of Nursing Practice, 17(1), 43-51. doi: 10.1111/j.1440-172X.2010.01905.x

Helgeson, V. S. (1990). The role of masculinity in a prognostic predictor of heart attack severity. Sex Roles, 22(11-12), 755-774. doi: 10.1007/BF00292059

Heidrich, S. M. (1998). Health promotion in old age. Annual Review of Nursing Research, 16(1), 173-195.

Hibbard, J. H., \& Pope, C. R. (1983). Gender roles, illness orientation and use of medical services. Social Science \& Medicine, 17(3), 129-137. doi:10.1016/0277-9536(83)90246-0

Hoffman, R. M., \& Borders, L. D. (2001). Twenty-five years after the Bem Sex-Role Inventory: A reassessment and new issues regarding classification variability. Measurement and Evaluation in Counseling and Development, 34(1), 39-55. Retrieved from http://libres.uncg.edu/ir/uncg/f/__borders_twenty_2001.pdf

Holt, C. L., \& Ellis, J. B. (1998). Assessing the current validity of the Bem Sex-Role Inventory. Sex Roles, 39(11-12), 929-941. doi: 10.1023/A:1018836923919 
MULTIDIMENSIONAL APPROACH TO GENDER AND HEALTH

Hooper, D., Coughlan, J., \& Mullen, M. (2008). Structural equation modelling: Guidelines for determining model fit. Electronic Journal of Business Research Methods, 6(1), 53-60.

Hu, L. T., \& Bentler, P. M. (1999). Cutoff criteria for fit indexes in covariance structure analysis: Conventional criteria versus new alternatives. Structural Equation Modeling: A Multidisciplinary Journal, 6(1), 1-55. doi: 10.1080/10705519909540118

Huston, A. C. (1983). Sex-typing. In E. M. Hetherington (Ed.), Handbook of child psychology Vol. 4: Socialization, personality and social development (pp. 387-467). New York, NY: Wiley.

Hunt, K. (2002). A generation apart? Gender-related experiences and health in women in early and late mid-life. Social Science \& Medicine, 54(5), 663-676. doi:10.1016/S02779536(01)00116-2

Hunt, K., Lewars, H., Emslie, C., \& Batty, G. D. (2007). Decreased risk of death from coronary heart disease amongst men with higher 'femininity' scores: A general population cohort study. International Journal of Epidemiology, 36(3), 612-620. doi: 10.1093/ije/dym022

Husaini, B. A., Moore, S. T., \& Cain, V. A. (1994). Psychiatric symptoms and help-seeking behavior among the elderly: An analysis of racial and gender differences. Journal of Gerontological Social Work, 21(3-4), 177-196. doi: 10.1300/J083V21N03_12

Hyde, J. S. (2005). The gender similarities hypothesis. American Psychologist, 60(6), 581-592. doi: 10.1037/0003-066X.60.6.581

Hyde, J. S. (2007). New directions in the study of gender similarities and differences. Current Directions in Psychological Science, 16(5), 259-263. doi: 10.1111/j.14678721.2007.00516.x

Hyde, J. S., \& Phillis, D. E. (1979). Androgyny across the lifespan. Developmental Psychology, 15(3), 334-336. doi: 10.1037/0012-1649.15.3.334 
MULTIDIMENSIONAL APPROACH TO GENDER AND HEALTH

Idler, E. L., \& Benyamini, Y. (1997). Self-rated health and mortality: A review of twenty-seven community studies. Journal of Health and Social Behavior, 21-37. doi: 10.2307/2955359

Jagger, C., Gillies, C., Moscone, F., Cambois, E., Van Oyen, H., Nusselder, W., \& Robine, J. M. (2009). Inequalities in healthy life years in the 25 countries of the European Union in 2005: A cross-national meta-regression analysis. The Lancet, 372(9656), 2124-2131. doi:10.1016/S0140-6736(08)61594-9

Jette, A. (1996). Disability trends and transitions. In R. Binstock, L. K. George, (Eds.), Handbook of Aging and the Social Sciences (pp. 94-117). San Diego, CA: Academic Press.

Jylhä, M. (2009). What is self-rated health and why does it predict mortality? Towards a unified conceptual model. Social Science \& Medicine, 69(3), 307-316. doi: 10.1016/j.socscimed.2009.05.013

Kaplan, M. S., \& Marks, G. (1995). Appraisal of health risks: The roles of masculinity, femininity, and sex. Sociology of Health \& Illness, 17(2), 206-221. 10.1111/14679566.ep10933391

Kaplan, G. A., Seeman, T. E., Cohen, R. D., Knudsen, L. P., \& Guralnik, J. (1987). Mortality among the elderly in the Alameda County Study: behavioral and demographic risk factors. American Journal of Public Health, 77(3), 307-312. doi: 10.2105/AJPH.77.3.307

Kasen, S., Chen, H., Sneed, J., Crawford, T., \& Cohen, P. (2006). Social role and birth cohort influences on gender-linked personality traits in women: A 20-year longitudinal analysis. Journal of Personality and Social Psychology, 91(5), 944-958. 10.1037/0022-

3514.91.5.944 


\section{MULTIDIMENSIONAL APPROACH TO GENDER AND HEALTH}

Katz, S. (1983). Assessing self-maintenance: activities of daily living, mobility, and instrumental activities of daily living. Journal of the American Geriatrics Society, 31(12), 721-727. doi: 10.1111/j.1532-5415.1983.tb03391.x

Katz, J. N., Chang, L. C., Sangha, O., Fossel, A. H., \& Bates, D. W. (1996). Can comorbidity be measured by questionnaire rather than medical record review? Medical Care, 34(1), 7384. doi: 10.1097/00005650-199601000-00006

Kessler, R. C., \& McRae Jr, J. A. (1981). Trends in the relationship between sex and psychological distress: 1957-1976. American Sociological Review, 443-452. Retrieved from http://www.jstor.org/stable/2095263

Klatsky, A. L., Armstrong, M. A., \& Friedman, G. D. (1992). Alcohol and Mortality. Annals of Internal Medicine, 117(8), 646-654.

Kozak, L. J., Hall, M. J., \& Owings, M. F. (2001). Trends in avoidable hospitalizations, 19801998. Health Affairs, 20(2), 225-232. doi: 10.1377/hlthaff.20.2.225

Kramarow, E., Lentzner, H., Rooks, R., Weeks, J., \& Saydah, S. (1999). Health, United States, 1999. Health and Aging Chartbook. Hyattsville, MD: National Center for Health Statistics.

Kulis, S., Marsiglia, F. F., \& Hecht, M. L. (2002). Gender labels and gender identity as predictors of drug use among ethnically diverse middle school students. Youth \& Society, 33(3), 442-475. doi: 10.1177/0044118X02033003005

Lawton, M. P., Moss, M., Fulcomer, M., \& Kleban, M. H. (1982). A research and service oriented multilevel assessment instrument. Journal of Gerontology, 37(1), 91-99. doi: doi: 10.1093/geronj/37.1.91 
MULTIDIMENSIONAL APPROACH TO GENDER AND HEALTH

Lemaster, P., Delaney, R. \& Strough, J. (2015a). Crossover, degendering, or...? A

multidimensional approach to life-span gender development. Sex Roles, 1-13. doi: 10.1007/s11199-015-0563-0

Lemaster, P., \& Strough, J. (2014). Beyond Mars and Venus: Understanding gender differences in financial risk tolerance. Journal of Economic Psychology, 42, 148-160. doi:10.1016/j.joep.2013.11.001

Lemaster, P., Strough, J., Stoiko, R., \& DiDonato, L. (2015b). To have and to do: Masculine facets of gender predict men's and women's attitudes about gender equality among college students. Psychology of Men \& Masculinity, 16(2), 195-205. doi: $10.1037 / \mathrm{a} 0036429$

Lee, Y. (2000). The predictive value of self assessed general, physical, and mental health on functional decline and mortality in older adults. Journal of Epidemiology and Community Health, 54(2), 123-129. doi: 10.1136/jech.54.2.123

Levant, R. F., Wimer, D. J., Williams, C., Smalley, K. B., \& Noronha, D. (2009). The relationships between masculinity variables, health risk behaviors and attitudes toward seeking psychological help. International Journal of Men’s Health, 8, 3-21. doi: 10.3149/jmh.0801.3

Lochner K. A., Cox C. S. (2010) Prevalence of multiple chronic conditions among Medicare beneficiaries, United States. doi: 10.5888/pcd10.120137

Lohan, M. (2007). How might we understand men's health better? Integrating explanations from critical studies on men and inequalities in health. Social Science \& Medicine, 65(3), 493504. doi: 10.1016/j.socscimed.2007.04.020 


\section{MULTIDIMENSIONAL APPROACH TO GENDER AND HEALTH}

Mahalik, J. R., Burns, S. M., \& Syzdek, M. (2007). Masculinity and perceived normative health behaviors as predictors of men's health behaviors. Social Science \& Medicine, 64(11), 2201-2209. doi: 10.1016/j.socscimed.2007.02.035

Mahalik, J. R., Locke, B. D., Ludlow, L. H., Diemer, M. A., Scott, R. P., Gottfried, M., \& Freitas, G. (2003). Development of the Conformity to Masculine Norms Inventory. Psychology of Men \& Masculinity, 4(1), 3-25. doi: 10.1037/1524-9220.4.1.3

Manton, K. G. (1988). A longitudinal study of functional change and mortality in the United States. Journal of Gerontology, 43(5), 153-161. doi: 10.1093/geronj/43.5.S153

Mason, W., \& Suri, S. (2012). Conducting behavioral research on Amazon’s Mechanical Turk. Behavior Research Methods, 44, 1-23. doi: 10.3758/s13428-011-0124-6

Matthews, K. A., \& Haynes, S. C. (1986). Type A behavior pattern and coronary disease risk update and critical evaluation. American Journal of Epidemiology, 123(6), 923-960.

McCormick, C. M., Kuo, S. I., \& Masten, A. S. (2011). Developmental tasks across the life span. In K. L. Fingerman, C. A. Berg, J. Smith, \& T. C. Antonucci (Eds.), Handbook of lifespan development (pp. 117-139). New York, NY: Springer.

McKay, J. R., Rutherford, M. J., Cacciola, J. S., Kabasakalian-McKay, R., \& Alterman, A. I. (1996). Gender differences in the relapse experiences of cocaine patients. The Journal of Nervous and Mental Disease, 184(10), 616-622. 10.1097/00005053-199610000-00006

Mehta, C. M., Alfonso-Barry, J., Delaney, R., \& Ayotte, B. J. (2014). Associations between mixed-gender friendships, gender reference group identity and substance use in college students. Sex Roles, 70(3-4), 98-109. doi: 10.1007/s11199-013-0334-8

Mehta, C. M. \& Strough, J. (2010). Gender segregation and gender-typing in adolescence. Sex Roles, 63(3-4), 251-263. doi: 10.1007/s11199-010-9780-8 


\section{MULTIDIMENSIONAL APPROACH TO GENDER AND HEALTH}

Michaelieu, Q. (1997). Female identity, reports of parenting, and adolescent women's self esteem (Unpublished doctoral dissertation). Arizona State University, Tempe, AZ.

Millán-Calenti, J. C., Tubío, J., Pita-Fernández, S., González-Abraldes, I., Lorenzo, T., Fernández-Arruty, T., \& Maseda, A. (2010). Prevalence of functional disability in activities of daily living (ADL), instrumental activities of daily living (IADL) and associated factors, as predictors of morbidity and mortality. Archives of Gerontology and Geriatrics, 50(3), 306-310. doi:10.1016/j.archger.2009.04.017

Miller, V. M. (2014). Why are sex and gender important to basic physiology and translational and individualized medicine? American Journal of Physiology-Heart and Circulatory Physiology, 306(6), 781-788. doi: 10.1152/ajpheart.00994.2013

Minino, A. M., Heron, M. P., Murphy, S. L., \& Kocharek, K. D. (2007). Deaths: Final data for 2004. National Vital Statistics Reports, 55, 1-120.

Nagi, S. Z. (1991). Disability concepts revisited: Implications for prevention. In A. Pope \& A. Tarlov (Eds.), Disability in America: Toward a national agenda for prevention. Washington, DC: National Academy Press.

Nassar, O. S., \& Shaheen, A. M. (2014). Health-promoting behaviours of university nursing students in Jordan. Health, 6(19), 2756. doi: 10.4236/health.2014.619315

National Academy on Aging Society (1999). Chronic conditions: A challenge for the $21^{\text {st }}$ century. Retrieved from http://www.agingsociety.org/agingsociety/pdf/chronic.pdf

National Institutes of Health (2015). Consideration of sex as a biological variable in NIH-funded research (NIH NOT-OD-15-102). Retrieved from https://orwh.od.nih.gov/resources/pdf/NOT-OD-15-102_Guidance.pdf 
MULTIDIMENSIONAL APPROACH TO GENDER AND HEALTH

Nicholas, D. R. (2000). Men, masculinity, and cancer: Risk-factor behaviors, early detection, and psychosocial adaptation. Journal of American College Health, 49(1), 27-33. doi: $10.1080 / 07448480009596279$

Oliver, M. I., Pearson, N., Coe, N., \& Gunnell, D. (2005). Help-seeking behaviour in men and women with common mental health problems: Cross-sectional study. The British Journal of Psychiatry, 186(4), 297-301. doi: 10.1192/bjp.186.4.297

Olomu, A. B., Corser, W. D., Stommel, M., Xie, Y., \& Holmes-Rovner, M. (2012). Do selfreport and medical record comorbidity data predict longitudinal functional capacity and quality of life health outcomes similarly?. BMC Health Services Research, 12(1), 398. doi: 10.1186/1472-6963-12-398

O'Neil, J. M. (2008). Summarizing 25 years of research on men's gender role conflict using the gender role conflict scale new research paradigms and clinical implications. The Counseling Psychologist, 36(3), 358-445. doi: 10.1177/0011000008317057

Oppenheimer, D. M., Meyvis, T., \& Davidenko, N. (2009). Instructional manipulation checks: Detecting satisficing to increase statistical power. Journal of Experimental Social Psychology, 45(4), 867-872. doi: 10.1016/j.jesp.2009.03.009

Padesky, C. A., \& Hammen, C. L. (1981). Sex differences in depressive symptom expression and help-seeking among college students. Sex Roles, 7(3), 309-320. doi: 10.1007/BF00287545

Palmore, E. (1970). Health practices and illness among the aged. The Gerontologist, 10(4 Part 1), 313-316. doi: 10.1093/geront/10.4_Part_1.313

Paolacci, G., Chandler, J., \& Ipeirotis, P. G. (2010). Running experiments on Amazon mechanical turk. Judgment and Decision Making, 5(5), 411-419. 
MULTIDIMENSIONAL APPROACH TO GENDER AND HEALTH

Philips, S. P. (1974). Including gender in public research. Public Health Reports, 1(Supplement

3), 16-21. Retrieved from www.jstor.org/stable/41639299

Phillips, S. D., Pazienza, N. J., \& Ferrin, H. H. (1984). Decision-making styles and problemsolving appraisal. Journal of Counseling Psychology, 31(4), 497 -502. doi:10.1037/00220167.31.4.497

Pinquart, M. (2001). Correlates of subjective health in older adults: A meta-analysis. Psychology and Aging, 16(3), 414-426. doi: 10.1037//0882-7974.16.3.414

Powell-Griner, E., Anderson, J. E., \& Murphy, W. (1997). State-and sex-specific prevalence of selected characteristics--behavioral risk factor surveillance system, 1994 and 1995. MMWR. CDC surveillance summaries: Morbidity and Mortality Weekly Report, 46(3), 131.

Quan, H., Li, B., Couris, C. M., Fushimi, K., Graham, P., Hider, P., ... \& Sundararajan, V. (2011). Updating and validating the Charlson comorbidity index and score for risk adjustment in hospital discharge abstracts using data from 6 countries. American Journal of Epidemiology, 173(6), 676-682. doi: 10.1093/aje/kwq433

Ratner, P. A., Bottorff, J. L., Johnson, J. L., \& Hayduk, L. A. (1994). The interaction effects of gender within the health promotion model. Research in Nursing \& Health, 17(5), 341350. doi: 10.1002/nur.4770170505

Read, J., \& Gorman, B. (2010). Gender and health revisited. In B. Pescosolido, J. Martin, J. McLeod, \& A. Rogers (Eds.), Handbook of Health, Illness \& Healing: Blueprint for the 21st century (pp. 411-430). New York: Springer.

Reevy, G. M., \& Maslach, C. (2001). Use of social support: Gender and personality differences. Sex Roles, 44(7-8), 437-459. doi: 10.1023/A:1011930128829 
MULTIDIMENSIONAL APPROACH TO GENDER AND HEALTH

Rieker, P. P., \& Bird, C. E. (2000). Sociological explanations of gender differences in mental and physical health. New Jersey: Prentice Hall.

Risman, B. J. (2004). Gender as a social structure theory wrestling with activism. Gender \& Society, 18(4), 429-450. doi: 10.1177/0891243204265349

Rosenthal, M. J., Fajardo, M., Gilmore, S., Morley, J. E., \& Naliboff, B. D. (1998). Hospitalization and mortality of diabetes in older adults: a 3-year prospective study. Diabetes Care, 21(2), 231-235. doi: 10.2337/diacare.21.2.231

Rowe, J. W., \& Kahn, R. L. (1997). Successful aging. The Gerontologist, 37(4), 433-440. doi: 10.1093/geront/37.4.433

Rubin, M., Watt, S. E., \& Ramelli, M. (2012). Immigrants’ social integration as a function of approach-avoidance orientation and problem-solving style. International Journal of Intercultural Relations, 36(4), 498-505. doi:10.1016/j.ijintrel.2011.12.009

Ruffing-Rahal, M. A., Barin, L. J., \& Combs, C. J. (1997). Gender role orientation as a correlate of perceived health, health behavior, and qualitative well-being in older women. Journal of Women \& Aging, 10(1), 3-19. doi: 10.1300/J074v10n01_02

Schön, P., \& Parker, M. G. (2008). Sex differences in health in 1992 and 2002 among very old Swedes. Journal of Population Ageing, 1(2-4), 107-123. doi: 10.1007/s12062-009-90091

Sherbourne, C. D., \& Stewart, A. L. (1991). The MOS social support survey. Social Science \& Medicine, 32(6), 705-714. doi:10.1016/0277-9536(91)90150-B

Shooshtari, S., Menec, V., \& Tate, R. (2007). Comparing predictors of positive and negative self-rated health between younger (25-54) and older (55+) Canadian adults: A longitudinal study of well-being. Research on Aging, 29(6), 512-554. doi: $10.1177 / 0164027507305729$ 


\section{MULTIDIMENSIONAL APPROACH TO GENDER AND HEALTH}

Shumaker, S. A., \& Hill, D. R. (1991). Gender differences in social support and physical health. Health Psychology, 10(2), 102-111. doi:10.1037/0278-6133.10.2.102

Soldo, B. J., \& Manton, K. G. (1985). Changes in the health status and service needs of the oldest old: Current patterns and future trends. The Milbank Memorial Fund Quarterly. Health and Society, 286-319. doi: 10.2307/3349882

Spence, J. T., \& Helmreich, R. L. (2014). Masculinity and femininity: Their psychological dimensions, correlates, and antecedents. Austin, Texas: University of Texas Press.

Stewart, A., \& Healy, J. M. (1989). Linking individual development and social changes. American Psychologist, 44, 30-42. doi:10.1037/0003-066X.44.1.30.

Strawbridge, W. J., Camacho, T. C., Cohen, R. D., \& Kaplan, G. A. (1993). Gender differences in factors associated with change in physical functioning in old age: A 6-year longitudinal study. The Gerontologist, 33(5), 603-609. doi: 10.1093/geront/33.5.603

Strough, J., Leszczynski, J. P., Neely, T. L., Flinn, J. A., \& Margrett, J. (2007). From adolescence to later adulthood: Femininity, masculinity, and androgyny in six age groups. Sex Roles, 57, 385-396.

Tamres, L. K., Janicki, D., \& Helgeson, V. S. (2002). Sex differences in coping behavior: A meta-analytic review and an examination of relative coping. Personality and Social Psychology Review, 6(1), 2-30. Retrieved from http://search.ebscohost.com/login.aspx?direct=true\&db=a9h\&AN=6009031\&site=ehostlive

Tavakol, M., \& Dennick, R. (2011). Making sense of Cronbach's alpha. International Journal of Medical Education, 2, 53-55. doi: 10.5116/ijme.4dfb.8dfd 


\section{MULTIDIMENSIONAL APPROACH TO GENDER AND HEALTH}

Thacker, S. B., Stroup, D. F., Carande-Kulis, V., Marks, J. S., Roy, K., \& Gerberding, J. L. (2006). Measuring the public’s health. Public Health Reports, 121(1), 14-22. Retrieved from http:/www.ncbi.nlm.nih.gov/pmc/articles/PMC1497799/

Thoits, P. A. (1995). Stress, coping, and social support processes: Where are we? What next?. Journal of Health and Social Behavior, 35(1), 53-79. Retrieved from http://www.jstor.org/stable/2626957

Tirodimos, I., Georgouvia, I., Savvala, T. N., Karanika, E., \& Noukari, D. (2009). Healthy lifestyle habits among Greek university students: Differences by sex and faculty of study. Eastern Mediterranean Health Journal, 15, 722- 728. Retrieved from http://apps.who.int/iris/bitstream/10665/117691/1/15_3_2009_0722_0728.pdf

Twenge, J. M. (1997). Changes in masculine and feminine traits over time: A meta-analysis. Sex Roles, 36(5-6), 305-325. doi: 10.1007/BF02766650

Twenge, J. M. (1999). Mapping gender: The multifactorial approach and the organization of gender-related attributes. Psychology of Women Quarterly, 23, 485-502. doi: 10.1111/j.1471-6402.1999.tb00377.x

Unger, R. K. (1979). Toward a redefinition of sex and gender. American Psychologist, 34(11), 1085-1094. doi: 10.1037/0003-066X.34.11.1085

Verbrugge, L. M. (1985). Gender and health: An update on hypotheses and evidence. Journal of Health and Social Behavior, 156-182. Retrieved from http://www.jstor.org/stable/2136750

Verbrugge, L. M., \& Jette, A. M. (1994). The disablement process. Social Science \& Medicine, 38(1), 1-14. doi: 10.1016/0277-9536(94)90294-1

Walker, S., Sechrist, K., \& Pender, N. (1995). The health-promoting lifestyle profile II. 
MULTIDIMENSIONAL APPROACH TO GENDER AND HEALTH

Ware Jr, J. E., \& Sherbourne, C. D. (1992). The MOS 36-item short-form health survey (SF-36):

I. Conceptual framework and item selection. Medical Care, 473-483. doi: 10.1097/00005650-199206000-00002

West, C., \& Zimmerman, D. H. (1987). Doing gender. Gender \& Society, 1, 125-151. doi: $10.1177 / 0891243287001002002$

Wolff, J. L., Starfield, B., \& Anderson, G. (2002). Prevalence, expenditures, and complications of multiple chronic conditions in the elderly. Archives of Internal Medicine, 162(20), 2269-2276. doi: 10.1001/archinte.162.20.2269 
Table 1

Bivariate Correlations for Full Sample

\begin{tabular}{|c|c|c|c|c|c|c|c|c|c|c|c|c|c|c|c|}
\hline Variable & 1 & 2 & 3 & 4 & 5 & 6 & 7 & 8 & 9 & 10 & 11 & 12 & 13 & 14 & 15 \\
\hline 1. Sex $(0=$ male, $1=$ female $)$ & -- & & & & & & & & & & & & & & \\
\hline 2. Age & -.04 & -- & & & & & & & & & & & & & \\
\hline 3. Masculine traits & $-.22_{c}$ & .07 & -- & & & & & & & & & & & & \\
\hline 4. Feminine traits & $.32_{c}$ & .02 & -.04 & -- & & & & & & & & & & & \\
\hline 5. Gender typicality & -.08 & $.15_{\mathrm{c}}$ & $.19_{c}$ & $.27_{\mathrm{c}}$ & -- & & & & & & & & & & \\
\hline 6. Gender identification & .04 & -.00 & $.19_{c}$ & $.24_{\mathrm{c}}$ & $.43_{c}$ & -- & & & & & & & & & \\
\hline 7. Interdependent problem solving & .03 & .01 & $-.11_{b}$ & $.40_{c}$ & $.28_{c}$ & $.15_{c}$ & -- & & & & & & & & \\
\hline 8. Social support & $.14 \mathrm{~b}$ & -.01 & $.22_{\mathrm{c}}$ & $.38_{\mathrm{c}}$ & $.33_{c}$ & $.34_{c}$ & $.26_{c}$ & $=-$ & & & & & & & \\
\hline 9. Health-promoting behaviors & $.11_{\mathrm{a}}$ & $.12 \mathrm{~b}$ & $.36_{c}$ & $.47_{\mathrm{c}}$ & $.36_{c}$ & $.26_{c}$ & $.28_{c}$ & $.54_{c}$ & -- & & & & & & \\
\hline 10. Health-risk behaviors & $-.33_{c}$ & $-.13_{b}$ & $.12 \mathrm{~b}$ & $-.24_{c}$ & $-.14_{b}$ & $-.21_{c}$ & -.07 & $-.25_{c}$ & $-.26_{c}$ & -- & & & & & \\
\hline 11. Perceived health & -.07 & -.01 & $.26_{c}$ & $.10_{\mathrm{a}}$ & $.16_{c}$ & $.13_{b}$ & .03 & $.29_{c}$ & $.42_{\mathrm{c}}$ & -.02 & -- & & & & \\
\hline 12. Chronic health burden & .05 & $.20_{c}$ & -.04 & .00 & -.02 & -.04 & .03 & $-.12 \mathrm{~b}$ & -.04 & $-.02-$. & $28_{c}$ & -- & & & \\
\hline 13. Physical functioning & $-.12 \mathrm{a}$ & $-.21_{\mathrm{C}}$ & $.18_{\mathrm{c}}$ & .02 & $.10_{\mathrm{a}}$ & $.12_{b}$ & -.02 & $.29_{c}$ & $.22_{\mathrm{c}}$ & -.00 & $.62_{c}-$. & $.34_{c}$ & -- & & \\
\hline 14. Education & -.02 & $.12_{b}$ & $.18_{c}$ & .00 & -.07 & -.04 & .05 & -.01 & $.14_{b}$ & -.07 . & $.14 \mathrm{~b}$. & .01 & .01 & -- & \\
\hline 15. Income & $-.20_{c}$ & .02 & $.27_{c}$ & .01 & $.10_{a}$ & .05 & .01 & $.22_{c}$ & $.19_{\mathrm{c}}$ & .04. & $.33_{c}-$. & $10_{a}$ & $.25 c$ & $32_{c}--$ & \\
\hline
\end{tabular}

Note. $\mathrm{N}=486 ;{ }^{a} p<.05,{ }^{b} p \leq .01,{ }^{c} p \leq .001$. For perceived health and physical functioning, high scores indicate better health and functioning. 
Table 2

Bivariate Correlations for Men and Women Separately

\begin{tabular}{|c|c|c|c|c|c|c|c|c|c|c|c|c|c|c|}
\hline Variable & 1 & 2 & 3 & 4 & 5 & 6 & 7 & 8 & 9 & 10 & 11 & 12 & 13 & 14 \\
\hline 1. Age (continuous) & -- & -.01 & .10 & $.17_{\mathrm{b}}$ & -.04 & .02 & .00 & $.16 \mathrm{~b}$ & $-.14_{\mathrm{a}}$ & -.07 & $.22 \mathrm{~b}$ & $-.21_{c}$ & -.05 & -.02 \\
\hline 2. Masculine traits & $.15 \mathrm{a}$ & -- & -.11 & -.03 & .07 & $-.25_{c}$ & $.13_{a}$ & $.31_{\mathrm{C}}$ & $.14_{\mathrm{a}}$ & $.22_{\mathrm{c}}$ & -.07 & $.18_{b}$ & $.20_{c}$ & $.28_{c}$ \\
\hline 3. Feminine traits & -.04 & $.21_{b}$ & -- & $.40_{c}$ & .39 c & $.38_{c}$ & $.37 \mathrm{c}$ & $.43_{\mathrm{c}}$ & $-.20_{c}$ & .09 & .00 & .05 & -.07 & .00 \\
\hline 4. Gender typicality & .12 & $.44_{c}$ & $.19_{b}$ & -- & $.44_{\mathrm{c}}$ & $.32_{c}$ & $.28_{c}$ & $.29_{c}$ & $-.24_{c}$ & .06 & .02 & .05 & $-.15 a$ & .04 \\
\hline 5. Gender identification & .04 & $.35_{c}$ & .06 & $.43_{c}$ & -- & $.21_{c}$ & $.36 \mathrm{c}$ & $.27_{\mathrm{c}}$ & $-.22_{c}$ & .11 & -.04 & .08 & -.08 & .02 \\
\hline 6. Interdependent problem solving & .01 & .09 & $.45_{\mathrm{c}}$ & $.23_{\mathrm{c}}$ & .08 & -- & $.27 \mathrm{c}$ & $.22_{\mathrm{c}}$ & -.05 & .02 & .02 & .01 & .03 & -.06 \\
\hline 7. Social support & -.01 & $.40_{c}$ & $.34_{c}$ & $.43_{\mathrm{c}}$ & $.33_{c}$ & $.25_{c}$ & -- & $.52_{c}$ & $-.23_{c}$ & $.30_{c}$ & -.12 & $.35_{c}$ & -.07 & $.17_{b}$ \\
\hline 8. Health-promoting behaviors & .09 & $.49_{\mathrm{c}}$ & $.49_{c}$ & $.47_{\mathrm{c}}$ & $.25_{c}$ & $.35 \mathrm{c}$ & $.55_{c}$ & -- & $-.21_{c}$ & $.37 \mathrm{c}$ & -.01 & $.26_{c}$ & .09 & $.18 b$ \\
\hline 9. Health/safety risk behaviors & $-.17 \mathrm{~b}$ & -.04 & -.09 & -.12 & $-.20_{b}$ & -.08 & $-.22_{c}$ & $-.27_{\mathrm{c}}$ & -- & .03 & -.05 & -.02 & .07 & .02 \\
\hline 10. Perceived health & .06 & $.30_{c}$ & $.18 \mathrm{~b}$ & $.30_{c}$ & $.15 \mathrm{a}$ & .05 & $.31_{c}$ & $.50_{c}$ & -.12 & -- & $-.31_{c}$ & $.67 \mathrm{c}$ & .11 & $.37 \mathrm{c}$ \\
\hline 11. Chronic health burden & $.18_{\mathrm{c}}$ & .04 & -.04 & -.06 & -.04 & .05 & $-.15 \mathrm{a}$ & -.09 & .05 & $-.23_{c}$ & -- & $-.35_{c}$ & -.07 & -.10 \\
\hline 12. Physical functioning & $-.21_{c}$ & $.15_{a}$ & .06 & $.17_{\mathrm{b}}$ & $.19_{b}$ & -.06 & $.26_{\mathrm{c}}$ & $.21_{\mathrm{C}}$ & -.06 & $.54_{\mathrm{C}}$ & $-.38_{c}$ & -- & .03 & $.28_{c}$ \\
\hline 13. Education & $.30_{\mathrm{c}}$ & $.17_{\mathrm{b}}$ & .09 & .03 & .01 & .07 & .05 & $.20_{b}$ & $-.21_{c}$ & $.18_{b}$ & .12 & .01 & -- & $.28_{c}$ \\
\hline 14. Income & .05 & $.19_{\mathrm{b}}$ & $.18_{b}$ & $.14_{a}$ & .10 & .11 & $.35_{c}$ & $.27_{\mathrm{c}}$ & -.07 & $.27_{\mathrm{c}}$ & -.09 & $.17_{\mathrm{b}}$ & $.37_{c}$ & -- \\
\hline
\end{tabular}

Note. ${ }^{a} p<.05,{ }^{b} p \leq .01,{ }^{c} p \leq .001$. Correlations below the diagonal are for men $(n=221)$ and above the diagonal are for women $(n=265)$. 
MULTIDIMENSIONAL APPROACH TO GENDER AND HEALTH

Table 3

MANOVA: Multivariate Effects for Gender-Typed Traits and Behaviors

\begin{tabular}{lccccc}
\hline & Wilks' $\lambda$ & $F$ & $\mathrm{df}$ & $p$ & $\eta_{\mathrm{p}}{ }^{2}$ \\
\hline Sex & & & & & \\
\hline Age group & 0.94 & 19.18 & 8,475 & $<.001$ & 0.24 \\
Sex x age group & 0.99 & 1.57 & 8,475 & 0.13 & 0.03 \\
\hline
\end{tabular}

Note. Dependent variables included: stereotypical masculine traits, stereotypical feminine traits, gender typicality, gender identification, interdependent problem-solving, social support, healthpromoting behaviors, and health-risk behaviors. 
MULTIDIMENSIONAL APPROACH TO GENDER AND HEALTH

Table 4

Main Effects of Self-Reported Sex on Variables of Interest (Univariate ANOVA)

\begin{tabular}{llllllll}
\hline & Overall & Men & Women & & & \\
& $(N=486)$ & $(n=221)$ & $(n=265)$ & $\mathrm{F}$ & $\eta_{\mathrm{p}}{ }^{2}$ & \\
\hline Masculine traits & $4.61(.84)$ & $4.82(.82)$ & $4.44(.83)$ & $24.80_{\mathrm{c}}$ & .05 & $\mathrm{M}>\mathrm{F}$ \\
Feminine traits & $4.54(.81)$ & $4.26(.77)$ & $4.77(.77)$ & $56.68_{\mathrm{c}}$ & .11 & $\mathrm{M}<\mathrm{F}$ \\
Gender typicality & $2.86(.64)$ & $2.91(.62)$ & $2.81(.65)$ & 1.97 & .00 & $\mathrm{M}=\mathrm{F}$ \\
Gender identification & $3.52(.45)$ & $3.51(.46)$ & $3.54(.44)$ & 0.60 & .00 & $\mathrm{M}=\mathrm{F}$ \\
Interdependent problem solving & $3.70(1.11)$ & $3.66(1.08)$ & $3.74(1.14)$ & 0.64 & .00 & $\mathrm{M}=\mathrm{F}$ \\
Social support & $3.71(1.06)$ & $3.55(1.09)$ & $3.84(1.01)$ & $9.71_{\mathrm{b}}$ & .02 & $\mathrm{M}<\mathrm{F}$ \\
Health-promoting behaviors & $2.56(.50)$ & $2.50(.50)$ & $2.61(.49)$ & $7.42_{\mathrm{b}}$ & .02 & $\mathrm{M}<\mathrm{F}$ \\
Health-risk behaviors & $1.96(.75)$ & $2.23(.78)$ & $1.72(.65)$ & $65.73_{\mathrm{c}}$ & .12 & $\mathrm{M}>\mathrm{F}$
\end{tabular}

Note. $\mathrm{df}(1,482) ;{ }^{a} p<.05,{ }^{b} p \leq .01,{ }^{c} p \leq .001$. Means are presented with standard deviations in parentheses. 
MULTIDIMENSIONAL APPROACH TO GENDER AND HEALTH

Table 5

Main Effects of Age Group on Variables of Interest (Univariate ANOVA)

\begin{tabular}{lllllll}
\hline & Overall & MA & OA & & & \\
& $(N=486)$ & $(n=250)$ & $(n=236)$ & $\mathrm{F}$ & $\eta_{\mathrm{p}}{ }^{2}$ & \\
\hline Masculine traits & $4.61(.84)$ & $4.54(.81)$ & $4.68(.87)$ & 2.86 & .01 & MA $=$ OA \\
Feminine traits & $4.54(.81)$ & $4.50(.81)$ & $4.58(.81)$ & 3.29 & .01 & MA $=$ OA \\
Gender typicality & $2.86(.64)$ & $2.75(.66)$ & $2.97(.60)$ & $12.95_{c}$ & .03 & MA $<$ OA \\
Gender identification & $3.52(.45)$ & $3.52(.46)$ & $3.53(.44)$ & 0.11 & .00 & MA $=$ OA \\
Interdependent problem solving & $3.70(1.11)$ & $3.67(1.07)$ & $3.74(1.16)$ & 0.69 & .00 & MA $=$ OA \\
Social support & $3.71(1.06)$ & $3.66(1.08)$ & $3.76(1.02)$ & 1.95 & .00 & MA $=$ OA \\
Health-promoting behaviors & $2.56(.50)$ & $2.50(.49)$ & $2.63(.51)$ & $10.11_{b}$ & .02 & MA $<$ OA \\
Health-risk behaviors & $1.96(.75)$ & $2.04(.78)$ & $1.87(.71)$ & $10.86_{c}$ & .02 & MA $>$ OA
\end{tabular}

Note. $\mathrm{df}(1,482) ;{ }^{a} p<.05,{ }^{b} p \leq .01,{ }^{c} p \leq .001 . \mathrm{MA}=$ Middle-aged adults and $\mathrm{OA}=$ Older adults.

Means are presented with standard deviations in parentheses. 
MULTIDIMENSIONAL APPROACH TO GENDER AND HEALTH

Table 6

MANCOVA: Multivariate Effects for Health Outcomes

\begin{tabular}{lccccc}
\hline & Wilks' $\lambda$ & $F$ & $\mathrm{df}$ & $p$ & $\eta_{\mathrm{p}}{ }^{2}$ \\
\hline Sex & 0.99 & 1.22 & 3,478 & 0.30 & 0.01 \\
Age group & 0.92 & 13.29 & 3,478 & $<.001$ & 0.08 \\
Sex x age group & 0.99 & 0.44 & 3,478 & 0.72 & 0.00 \\
Income & 0.91 & 16.43 & 3,478 & $<.001$ & 0.09 \\
Education & 0.99 & 1.25 & 3,478 & 0.29 & 0.01
\end{tabular}

Note. Dependent variables included: perceived health, physical functioning, and chronic health burden. 
MULTIDIMENSIONAL APPROACH TO GENDER AND HEALTH

Table 7

Main Effects of Self-Reported Sex on Health Outcomes (Univariate ANCOVA)

\begin{tabular}{llllllll}
\hline & Overall & Men & Women & & & \\
& $(N=486)$ & $(n=221)$ & $(n=265)$ & $\mathrm{F}$ & $\eta_{\mathrm{p}}{ }^{2}$ & \\
\hline Perceived health & $9.48(.09)$ & $9.50(.13)$ & $9.47(.12)$ & 0.02 & .00 & $\mathrm{M}=\mathrm{F}$ \\
Physical functioning & $80.16(1.07)$ & $81.83(1.60)$ & $78.49(1.46)$ & 2.32 & .01 & $\mathrm{M}=\mathrm{F}$ \\
Chronic health burden & $0.80(.07)$ & $0.73(.11)$ & $0.88(.10)$ & 0.91 & .00 & $\mathrm{M}=\mathrm{F}$
\end{tabular}

Note. df $(1,482) ;{ }^{a} p<.05,{ }^{b} p \leq .01,{ }^{c} p \leq .001$. Means are presented with standard errors in parentheses. These are the estimated marginal means, adjusted for the covariates (education and income). For perceived health and physical functioning, high scores indicate better health and functioning. 
MULTIDIMENSIONAL APPROACH TO GENDER AND HEALTH

Table 8

Main Effects of Age Group on Health Outcomes (Univariate ANCOVA)

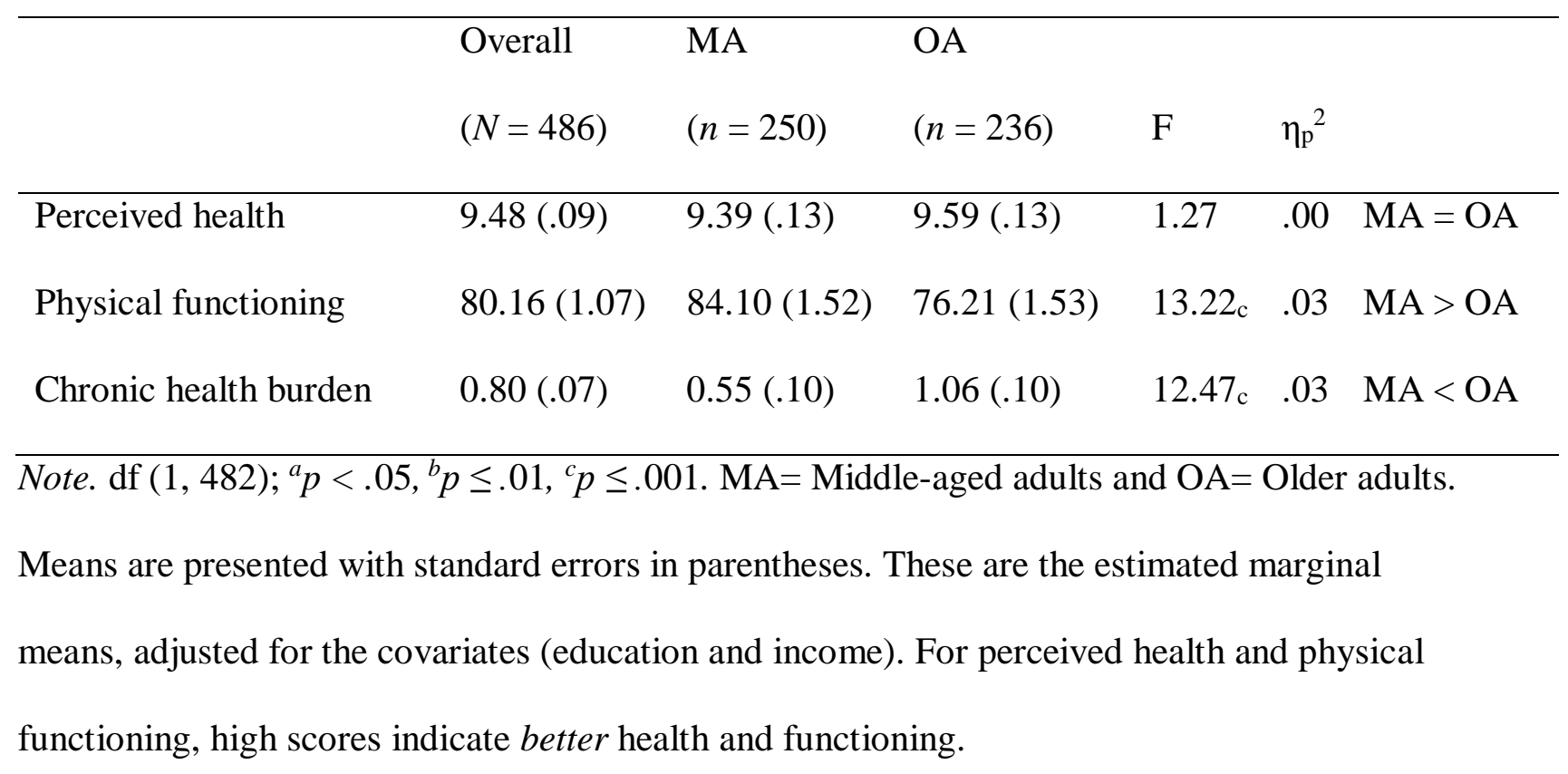


MULTIDIMENSIONAL APPROACH TO GENDER AND HEALTH

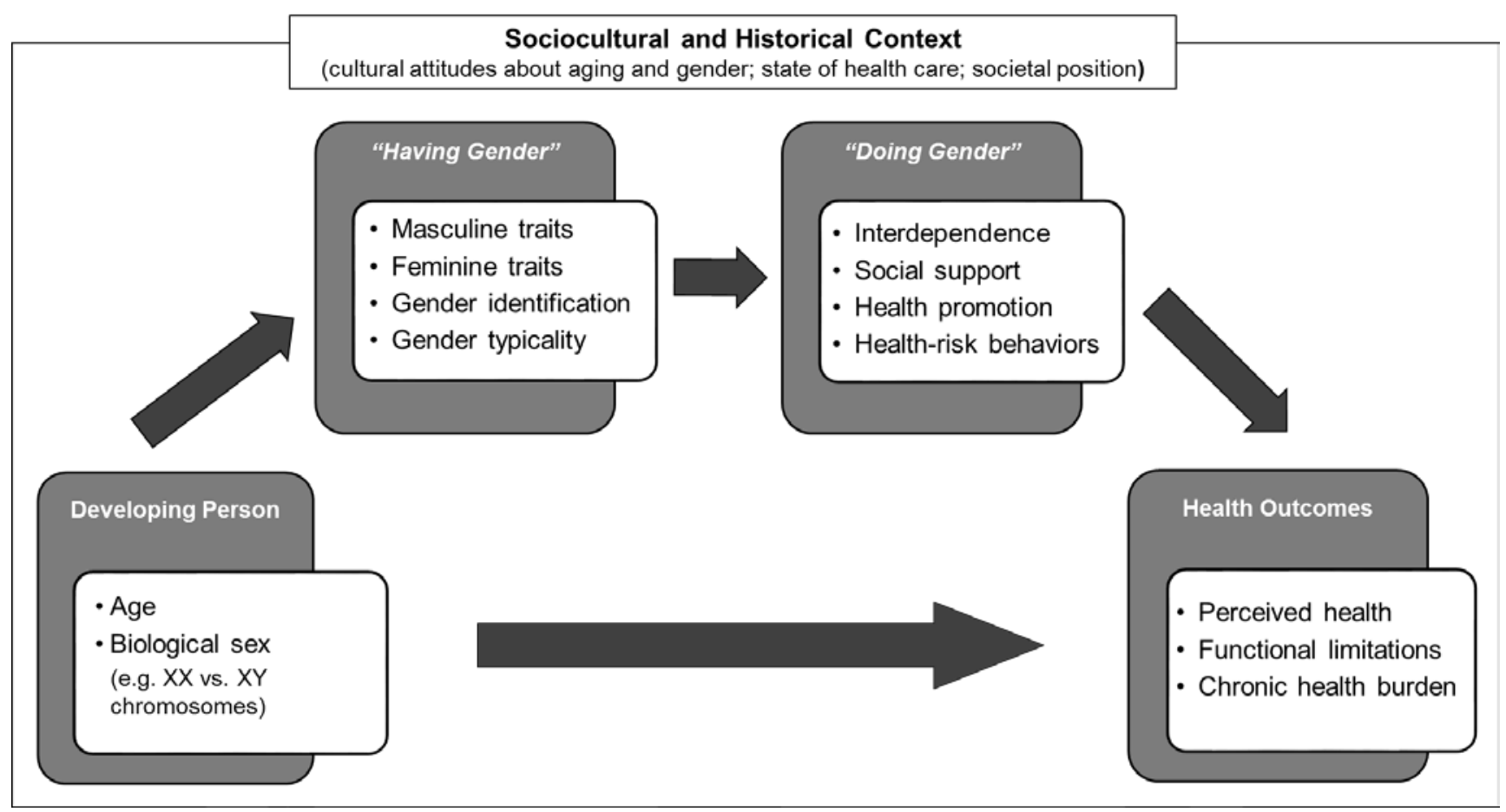

Figure 1. Conceptual model depicting the framework for the multidimensional model of gender and health proposed for the study. 




Figure 2. The originally proposed conceptual model testing aspects of "having gender" and "doing gender" in relation to health outcomes. Note, three separate path analysis models were performed for each health outcome rather than the full model shown. 




Figure 3. Conceptual model showing interdependent strategies (i.e. interdependent problem solving, social support) and health behaviors (i.e. health promotion and health risk) as mediators between gender-typed traits and health. Sex and age group were also tested as moderators of the model. Note, each health outcome was tested in a separate model. 


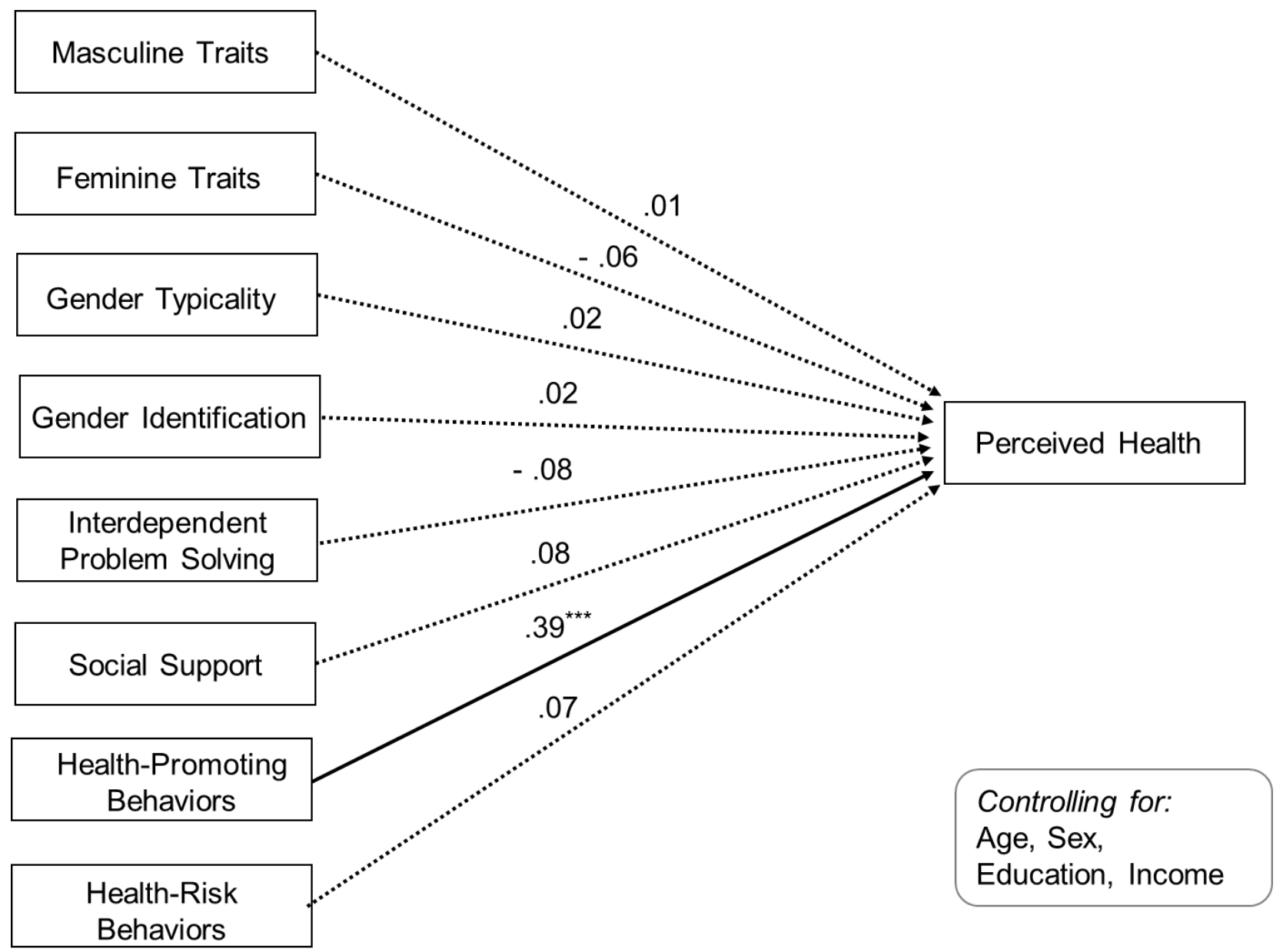

Figure 4. Path analysis with gender-typed traits and behaviors predicting perceived health. All gender-typed traits and behaviors were covaried. Standardized estimates are reported. Higher perceived health scores indicated better health. Note. ${ }^{*} p<.05,{ }^{* *} p \leq .01,{ }^{* * *} p \leq .001$ 
MULTIDIMENSIONAL APPROACH TO GENDER AND HEALTH

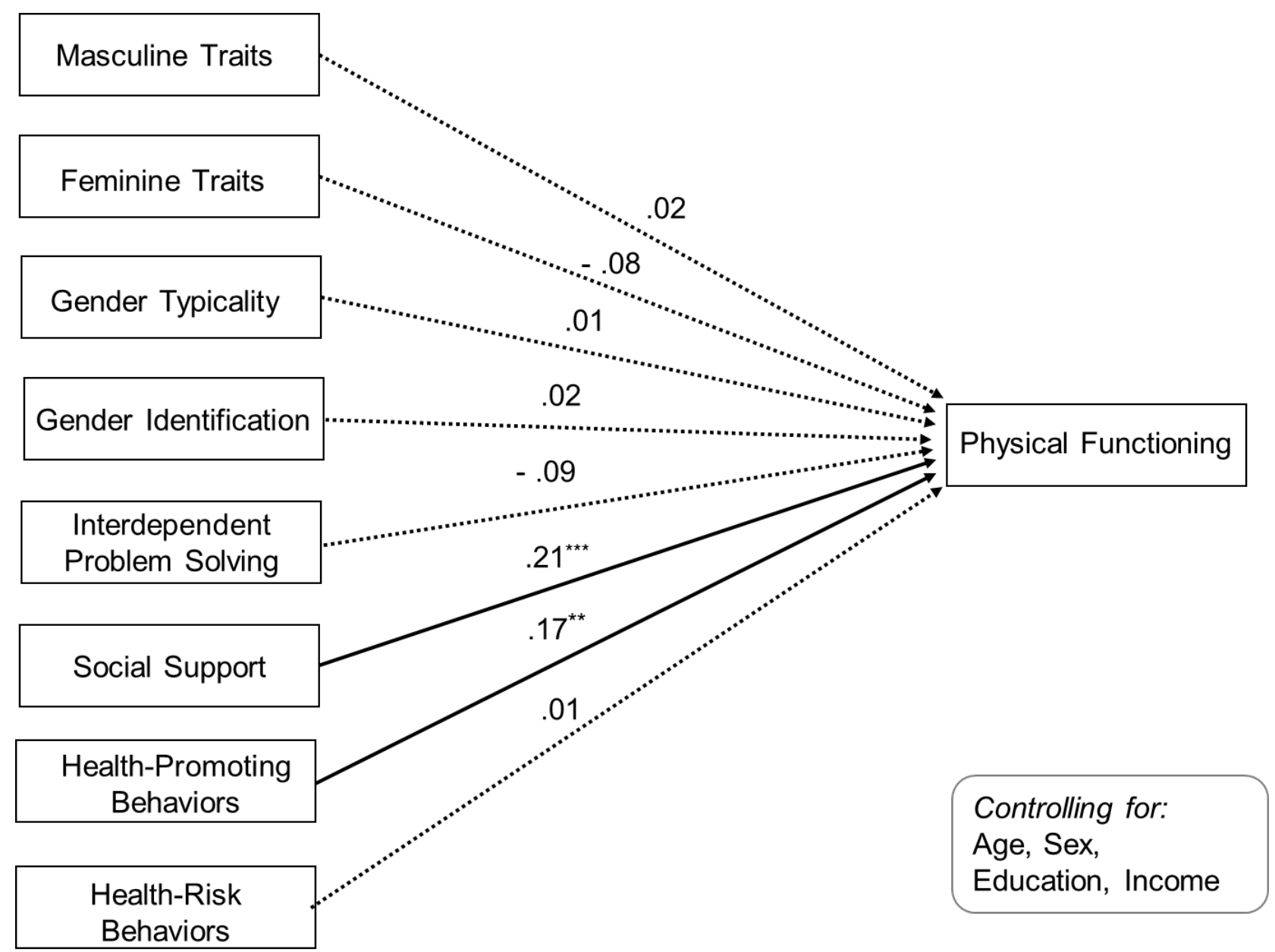

Figure 5. Path analysis with gender-typed traits and behaviors predicting physical functioning. All gender-typed traits and behaviors were covaried. Standardized estimates are reported. Higher physical functioning scores indicated better health. Note. ${ }^{*} p<.05,{ }^{* *} p \leq .01,{ }^{* * *} p \leq .001$ 
MULTIDIMENSIONAL APPROACH TO GENDER AND HEALTH



Figure 6. Path analysis with gender-typed traits and behaviors predicting chronic burden. All gender-typed traits and behaviors were covaried. Standardized estimates are reported. Higher chronic burden scores indicated poorer health. Note. ${ }^{*} p<.05,{ }^{* *} p \leq .01,{ }^{* * *} p \leq .001$ 


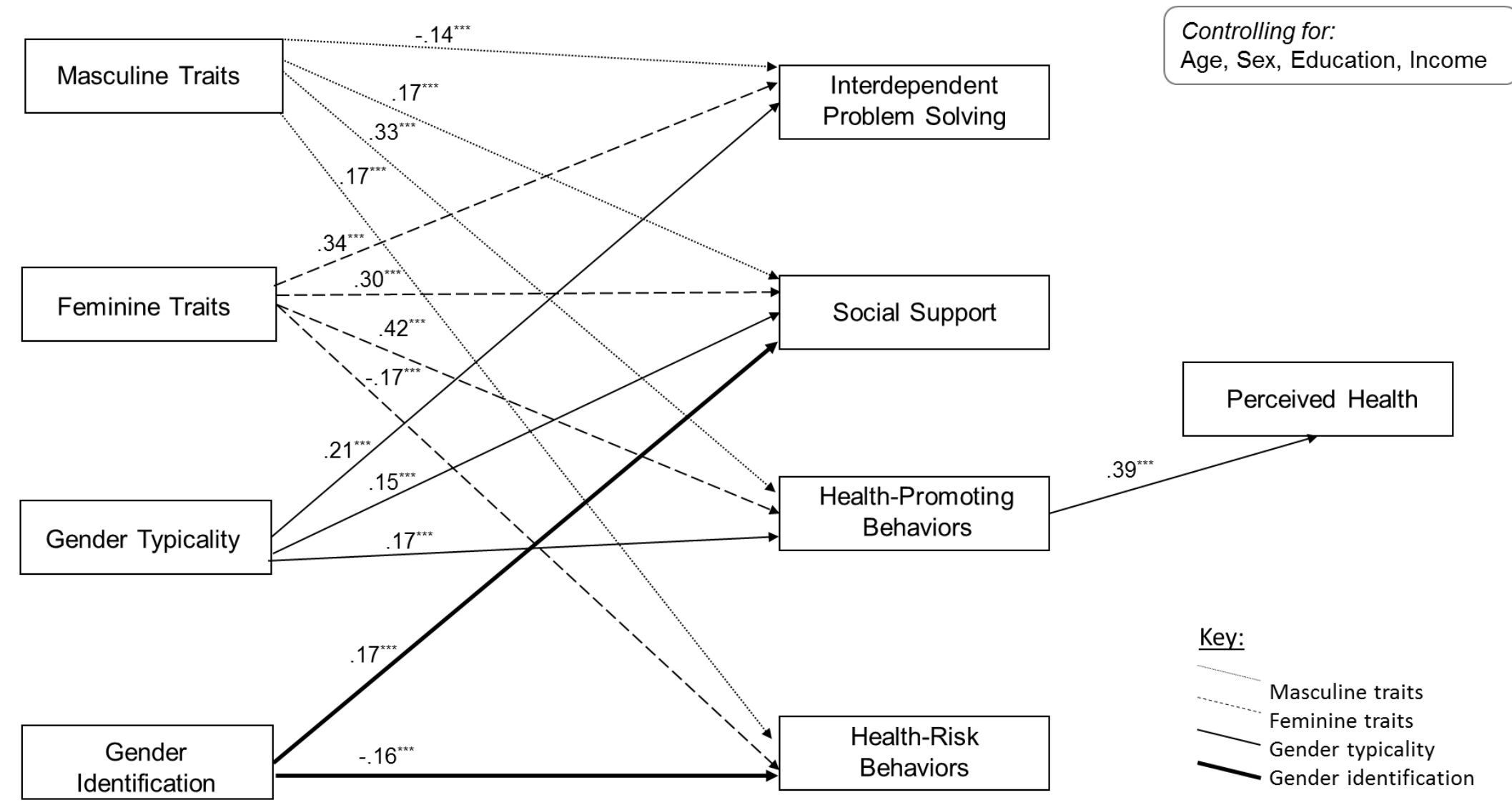

Figure 7. Final model with perceived health as outcome variable. Only significant associations shown ( $p$ s $<.06)$. Pathways for each predictor (i.e., masculine and feminine traits, gender typicality and identification) are represented by different marked lines (see Key). Standardized estimates are included. Note. ${ }^{*} p<.05,{ }^{* *} p \leq .01,{ }^{* * *} p \leq .001$ 


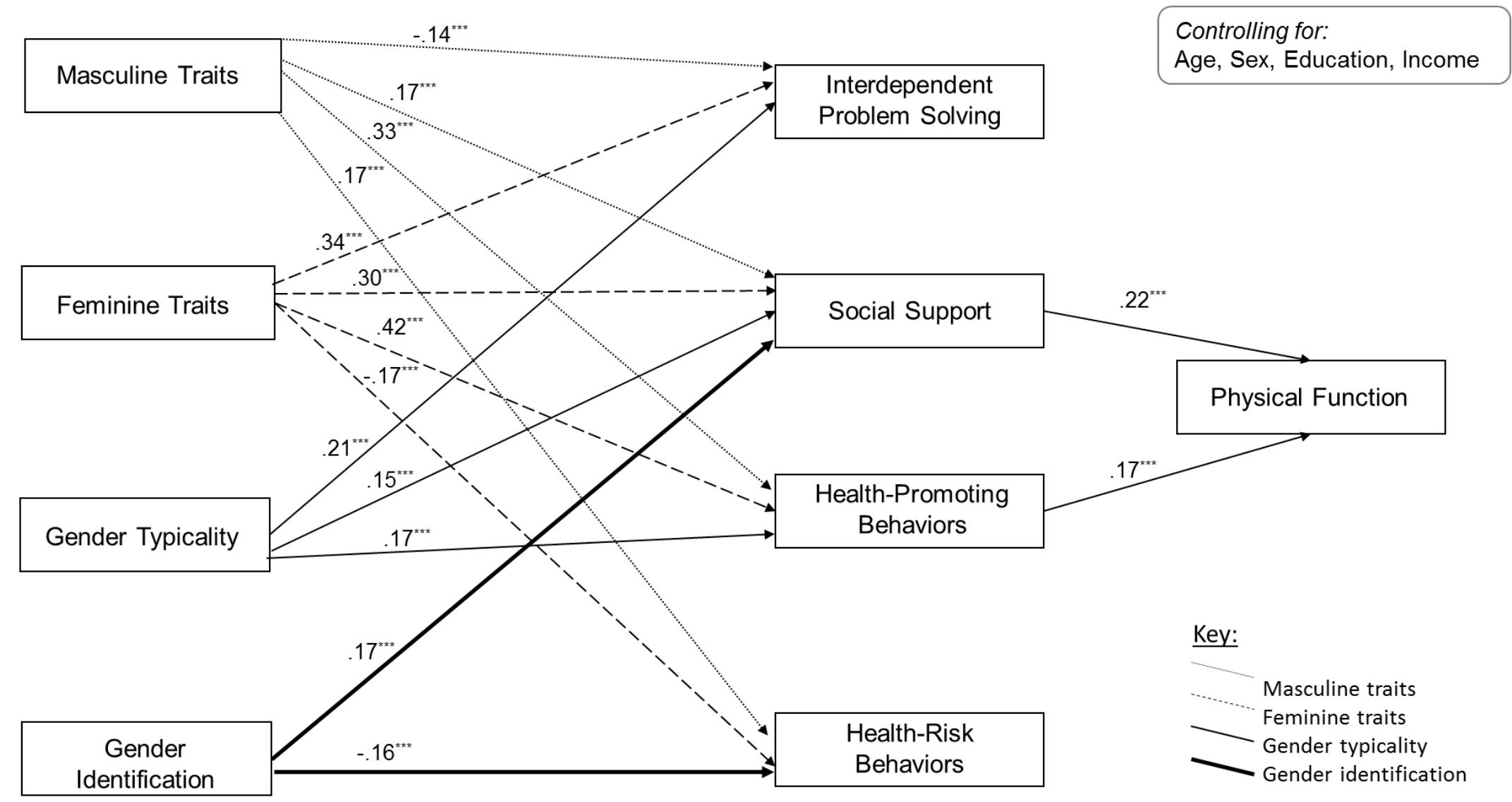

Figure 8. Final model with physical functioning as outcome variable. Only significant associations shown $(p s<.06)$. Pathways for each predictor (i.e., masculine and feminine traits, gender typicality and identification) are represented by different marked lines (see Key). Standardized estimates are included. Note. ${ }^{+} p=.06,{ }^{*} p<.05,{ }^{* *} p \leq .01,{ }^{* * *} p \leq .001$ 




Figure 9. Final model with chronic burden as outcome variable. Only significant associations shown ( $p s<.05)$. Pathways for each predictor (i.e., masculine and feminine traits, gender typicality and identification) are represented by different marked lines (see Key).

Standardized estimates are included. Note. ${ }^{*} p<.05,{ }^{* *} p \leq .01,{ }^{* * *} p \leq .001$ 
Appendix A

\section{How SEX and GENDER Influence Health and Disease}

Sex and gender can influence health in important ways. While sex and gender are distinct concepts, their influence is often inextricably linked. The scientific studies that generate the most complete data consider sex and/or gender influences in study design, data collection and analysis, and reporting of findings.

SeX is a biological classification, encoded in our DNA. Males have XY chromosomes, and females have XX chromosomes. Sex makes us male or female. Every cell in your body has a sex-making up tissues and organs, like your skin, brain, heart, and stomach. Each cell is either male or female depending on whether you are a man or a woman.

Gender refers to the socially constructed roles, behaviors, expressions, and identities of girls, women, boys, men, and gender diverse people. It influences how people perceive themselves and each other, and how they act and interact. Gender is usually conceptualized as binary (girl/woman and boy/man), yet there is considerable diversity in how individuals and groups understand, experience, and express it.

Visit NIH.gov/women to learn how studying sex and gender strengthens science.

\section{Examples of SEX $\underset{X Y}{X Y}$ and GENDER @o influences}

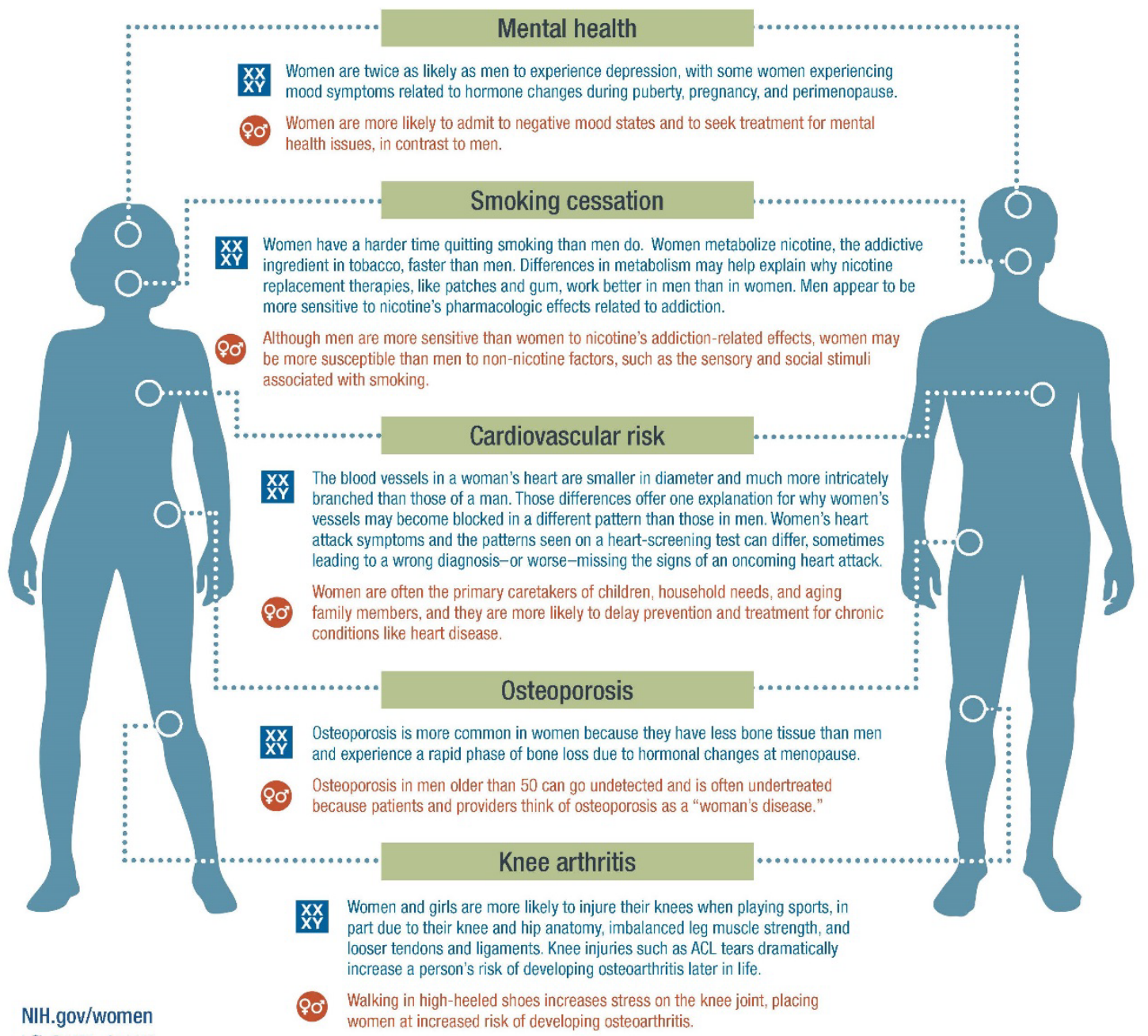

1. @NIH_ORWH

\#SexinScience

Sources: Institute of Medicine. Canadian Institutes of Health Research. World Heatth Organization. National Instithte on Drug Abuse. NH Osteoporossis and Related Bone Diseases National Resource Center. Nattional Instiftute of Arthitits and Musculoskeletal and Skin Diseases. Kerrigan, D. C., Johansson, J.L., Bryant, M. G., Boxer, J.A. Della Croce, U., \& Rilley, P. . . (2005). Moderate- heeled shoes and knee joint torques relevant to the developine, and progression of knee osteoart thritis. Archives of Physical Medicine and Rehabilitation, 86(5), 871-875. 
MULTIDIMENSIONAL APPROACH TO GENDER AND HEALTH

\section{Appendix B}

\section{Demographic Questions}

1. What sex were you assigned at birth on your original birth certificate? Male Female

2. What is your current gender identity?

Male

Female

Male to female transgender

Female to male transgender

Not sure

Other (please specify):

3. Which of the following do you identify most closely with?

_ Straight or heterosexual

Lesbian, gay, or homosexual

Bisexual

Self Identify:

Don't know

Prefer not to answer

4. Please indicate your marital status:

never married

married

not married, but living together

widowed/widower, married

divorced other (please specify

5. Please indicate your age (in years; e.g. "22")

6. Please indicate the year you were born (YYYY)

7. Are you of Hispanic, Latino, or Spanish origin?

No, not of Hispanic, Latino, or Spanish origin

Yes, Mexican, Mexican American, Chicano

Yes, Puerto Rican

Yes, Cuban

Yes, another origin. Please indicate:

Prefer not to answer

8. What is your race?

White or Caucasian

Black or African-American

American Indian or Alaska Native 


\section{MULTIDIMENSIONAL APPROACH TO GENDER AND HEALTH}

Asian

Native Hawaiian or Other Pacific Islander Biracial or Multi-racial.

Please indicate each one:

Other; print race:

Prefer not to answer

9. Please indicate your highest level of education:

Did not graduate high school

High school diploma or GED

Some college

Associate's degree

Bachelor's degree

Master's degree (e.g., MA, MS, MSW, MBA)

Professional degree beyond bachelor's degree (e.g., MD, DDS, JD)

Doctoral degree (e.g., PhD, EdD)

10. Employment Status: Are you currently...?

Employed full time

Employed part time

Partially retired (retired, but working part-time)

Fully retired (no longer working)

Unemployed

A student

Unable to work

Other (please specify

11. Do you currently volunteer (unpaid help)? Yes or No

If YES to \#11: How often do you volunteer?

a. Once a week or more

b. Once a month

c. A few times a year

d. Once a

If YES to \#11: Which of the following types of organizations, clubs or groups do you give unpaid help to? Please indicate all that apply.

a) Non-profit, voluntary, charity, community, church, religious organization (e.g., local sports club, environmental group)

b) Public (e.g., local councils, schools)

c) Private (profit making) (e.g., private nursery, private museum, private health organization)

d) Other-please specify:

12. Please estimate your gross income from the past 12 months (including wages, social security earnings, tips, etc.). 
Less than $\$ 10,000$

$\$ 10,000-19,000$

$\$ 20,000-29,000$

$\$ 30,000-39,000$

$\$ 40,000-49,000$

$\$ 50,000-59,000$

$\$ 60,000-69,000$

$\$ 70,000$ or more

Prefer to not answer

13. If you are working, please indicate your current or former occupation. If you are a full-time student, please write student.

14. Are you currently covered by any of the following types of health insurance or health coverage plans? Mark “yes” or "no” for EACH type (a-h)

a. Insurance through a current or former employer or union (including yourself or family member's)

b. Insurance purchased directly from an insurance company (including yourself or family member's)

c. Medicare, for people 65 and older, or people with certain disabilities

d. Medicaid, Medical Assistance, or any kind of government-assistance plan for those with low incomes or a disability

e. TRICARE or other military health care

f. VA (including those who have ever used or enrolled)

g. Indian Health Service

h. Any other type: please specify-

15. Have you ever served on active duty in the U.S. Armed Forces, Reserves, or National Guard?

a. Never served in the military

b. Only on active duty for training in the Reserves or National Guard

c. Yes, now on active duty

d. Yes, on active duty in the past, but not now

16. During the past month, did you provide unpaid care or assistance to a family member or friend who has a health condition, long-term illness or disability? Time can range from a few hours to intensive care. Tasks include activities such as shopping, cleaning, cooking, giving medications, etc.
a. Yes
b. No

If YES to \#16: How often have you actually provided care in the past 6 month?

c. Less than once a month

d. 1 to 2 times per month

e. At least 3 times per month

If YES to \#16: How many people do you provide unpaid care or assistance for? 
MULTIDIMENSIONAL APPROACH TO GENDER AND HEALTH
f. 1
g. 2
h. 3 or more

If YES to \#16: What is your relationship to the person for whom you provide care? I am the persons':
i. Spouse or partner
j. Adult child
k. Parent
1. Family member
m. Friend
n. Other: 
MULTIDIMENSIONAL APPROACH TO GENDER AND HEALTH

\author{
Appendix C \\ Gender Typicality Scale \\ (adapted from Egan \& Perry, 2001)
}

This questionnaire contains some statements that describe things about people, such as who they are and how they feel about various things. We are interested in what kind of person you are like. This is a survey, not a test. There are no right or wrong answers. Some people are very different from one another, and every person will select something different.

Read each statement below and rate how much like you it is.

$1=\underline{\text { Very untrue for me }}$

2 Sort of untrue for me

$3=\underline{\text { Sort of true for me }}$

4 = $\underline{\text { Very true for me }}$

1. I feel like I'm just like all the other men/women* my age.

2. I feel like I fit in with other men/women.

3. I think I am a good example of being a man/woman.

4. I feel that the things I like to do in my spare time are similar to what most other men/women like to do in their spare time.

5. I feel that the kinds of things I'm good at are similar to what most men/women are good at.

6. I feel that my personality is similar to most men's/women's personalities.

*Items are sex specific. Men and women will receive separate versions of the same items. 
MULTIDIMENSIONAL APPROACH TO GENDER AND HEALTH

\section{Appendix D}

Independent-Interdependent Problem Solving Scale

(Rubin, Watt, \& Ramelli, 2012)

Please indicate how much you agree or disagree with each of the following statements:



1. When faced with a difficult personal problem, it is better to decide yourself rather than to follow the advice of others.*

2. I value other people's help and advice when making important decisions.

3. In general, I do not like to ask other people to help me to solve problems.*

4. I prefer to make decisions on my own, rather than with other people.

5. I like to get advice from my friends and family when deciding how to solve my personal problems.

6. I prefer to consult with others before making important decisions.

7. I usually find other people's advice to be the most helpful source of information for solving my problems.

8. I would rather struggle through a personal problem by myself than discuss it with a friend.*

9. I do not like to depend on other people to help me to solve my problems.*

10. I usually prefer to ask other people for help rather than to try to solve problems on my own.

*Reversed coded 


\section{Appendix E}

Perceived Health

(Lawton et al., 1982)

\section{INSTRUCTIONS}

Please circle the one that BEST describes you:

1.) How would you rate your overall health at the present time?

_ Excellent

_ Good

- Fair

_ Poor

2.) Is your health now better, about the same, or not as good as it was 3 years ago?

- Better

_ Same

_ Not as good

3.) Do your health problems stand in the way of your doing the things you want to do?

Not at all

_ A little

_ A great deal

4.) Compared with most other people your age, would you say your health is:
- Better
_ The same, or
Not as good 


\section{Appendix F}

Bem Sex Role Inventory

(Bem, 1974)

This survey consists of several adjectives. For each, you must indicate on a scale of 1 to 7 how much like you the word is $(1=\underline{\text { never like me }}, 2=$ rarely like me, $3=$ sometimes like me, $4=$ equally like and unlike me, $5=\underline{\text { like me }}, 6=$ frequently like me, $7=\underline{\text { always like me }}$.

1. Self reliant ${ }^{\mathrm{M}}$

2. Yielding $^{\mathrm{F}}$

3. Helpful

4. Defends own beliefs ${ }^{\mathrm{M}}$

5. Cheerful $^{\mathrm{F}}$

6. Moody

7. Independent ${ }^{\mathrm{M}}$

8. Shy $^{\mathrm{F}}$

9. Conscientious

10. Athletic ${ }^{\mathrm{M}}$

11. Affectionate ${ }^{\mathrm{F}}$

12. Theatrical

13. Assertive ${ }^{\mathrm{M}}$

14. Flatterable ${ }^{\mathrm{F}}$

15. Happy

16. Strong personality ${ }^{\mathrm{M}}$

17. Loyal ${ }^{\mathrm{F}}$

18. Unpredictable

19. Forceful ${ }^{\mathrm{M}}$

20. Feminine $^{\mathrm{F}}$

21. Reliable

22. Analytical ${ }^{\mathrm{M}}$

23. Sympathetic ${ }^{\mathrm{F}}$

24. Jealous

25. Has leadership abilities ${ }^{\mathrm{M}}$

26. Sensitive to other's needs ${ }^{\mathrm{F}}$

27. Truthful

28. Willing to take risks ${ }^{\mathrm{M}}$

29. Understanding ${ }^{\mathrm{F}}$

30. Secretive

31. Makes decisions easily ${ }^{\mathrm{M}}$

32. Compassionate ${ }^{\mathrm{F}}$

33. Sincere

34. Self-sufficient ${ }^{\mathrm{M}}$

35. Eager to soothe hurt feelings ${ }^{F}$

36. Conceited

37. Dominant ${ }^{\mathrm{M}}$ 
MULTIDIMENSIONAL APPROACH TO GENDER AND HEALTH

38. Soft spoken ${ }^{\mathrm{F}}$

39. Likable

40. Masculine ${ }^{\mathrm{M}}$

41. Warm ${ }^{\mathrm{F}}$

42. Solemn

43. Willing to take a stand ${ }^{\mathrm{M}}$

44. Tender ${ }^{\mathrm{F}}$

45. Friendly

46. Aggressive ${ }^{\mathrm{M}}$

47. Gullible ${ }^{\mathrm{F}}$

48. Inefficient

49. Acts as a leader ${ }^{\mathrm{M}}$

50. Childlike ${ }^{\mathrm{F}}$

51. Adaptable

52. Individualistic ${ }^{\mathrm{M}}$

53. Does not use harsh language ${ }^{\mathrm{F}}$

54. Unsystematic

55. Competitive ${ }^{\mathrm{M}}$

56. Loves children ${ }^{\mathrm{F}}$

57. Tactful

58. Ambitious ${ }^{\mathrm{M}}$

59. Gentle ${ }^{\mathrm{F}}$

60. Conventional

Scoring

$\mathrm{M}=$ Masculine trait

$\mathrm{F}=$ Feminine trait 


\author{
Appendix G \\ Health-Promoting Life Style Profile \\ (Walker, Sechrist, \& Pender, 1995)
}

DIRECTIONS: This questionnaire contains statements about you present way of life or personal habits. Please respond to each item as accurately as possible, and try not to skip any item. Indicate the frequency with which you engage in each behavior by circling:

\title{
$1=$ Never \\ $2=$ Sometimes \\ $3=$ Often \\ 4=Routinely
}

1. Discuss my problems and concerns with people close to me.

2. Choose a diet low in fat, saturate fat, and cholesterol.

3. Report any unusual signs or symptoms to a physician or other health professional.

4. Follow a planned exercise program.

5. Get enough sleep.

6. Feel I am growing and changing in positive ways.

7. Praise other people easily for their achievements.

8. Limit use of sugars and food containing sugar (sweets).

9. Read or watch TV programs about improving health.

10. Exercise vigorously for 20 or more minutes at least three times a week (such as brisk walking, bicycling, aerobic dancing, using a stair climber).

11. Take some time for relaxation each day.

12. Believe that my life has purpose.

13. Maintain meaningful and fulfilling relationships with others.

14. Eat 6-11 servings of bread, cereal, rice and pasta each day.

15. Question health professionals in order to understand their instructions.

16. Take part in light to moderate physical activity (such as sustained walking 30-40 minutes 5 or more times a week).

17. Accept those things in my life which I cannot change.

18. Look forward to the future.

19. Spend time with close friends.

20. Eat 2-4 servings of fruit each day.

21. Get a second opinion when I question my health care provider's advice.

22. Take part in leisure-time (recreational) physical activities (such as swimming, dancing, bicycling).

23. Concentrate on pleasant thoughts at bedtime.

24. Feel content and at peace with myself.

25. Find it easy to show concern, love and warmth to others.

26. Eat 3-5 servings of vegetables each day.

27. Discuss my health concerns with health professionals.

28. Do stretching exercises at least 3 times per week.

29. Use specific methods to control my stress. 


\section{MULTIDIMENSIONAL APPROACH TO GENDER AND HEALTH}

30. Work toward long-term goals in my life.

31. Touch and am touched by people I care about.

32. Eat 2-3 servings of milk, yogurt or cheese each day.

33. Inspect my body at least monthly for physical changes/danger signs.

34. Get exercise during usual daily activities (such as walking during lunch, using stairs instead of elevators, parting car away from destination and walking).

35. Balance time between work and play.

36. Find each day interesting and challenging.

37. Find ways to meet my needs for intimacy.

38. Eat only 2-3 servings from the meat, poultry, fish, dried beans, eggs, and nuts group each day.

39. Ask for information from health professionals about how to take good care of myself.

40. Check my pulse rate when exercising.

41. Practice relaxation or mediation for 15-20 minutes daily.

42. Am aware of what is important to me in life.

43. Get support from a network of caring people.

44. Read labels to identify nutrients, fats, sodium content in packaged food.

45. Attend educational programs on personal health care.

46. Reach my target heart rate when exercising.

47. Pace myself to prevent tiredness.

48. Feel connected with some force greater than myself.

49. Settle conflicts with other through discussion and compromise.

50. Eat breakfast.

51. Seek guidance or counseling when necessary.

52. Expose myself to new experiences and challenges.

\section{Items scored for each subscale:}

Health-Promoting Lifestyle 1 to 52

Health Responsibility 3, 9, 15, 21, 27, 33, 39, 45, 51

Physical Activity 4, 10, 16, 22, 28, 34, 40, 46

Nutrition 2, 8, 14, 20, 26, 32, 38, 44, 50

Spiritual Growth 6, 12, 18, 24, 30, 36, 42, 48, 52

Interpersonal Relations 1, 7, 13, 19, 25, 31, 37, 43, 49

Stress Management 5, 11, 17, 23, 29, 35, 41, 47

\section{Reliability (Alphas):}

Composite $=.95$

Health Responsibility $=.87$

Physical Activity $=.88$

Nutrition $=.77$

Spiritual Growth $=.88$

Interpersonal Relations $=.87$

Stress Management $=.80$ 


\section{Appendix $\mathrm{H}$}

Gender Identification

(Michaelieu, 1997)

The following statements refer to your sense of self and the group that you feel you most identify with as a female. These statements are not intended to find out about who you are physically attracted to or romantically interested in. The questions are aimed at finding out about your views of your identity as a person. Please rate the following statements. Click the number that best describes how true the statement is for you. Remember, there are no right or wrong answers! Your answers are confidential so please be honest!

$1=\underline{\text { Strongly disagree }}$

2 = Somewhat disaqree

$3=\underline{\text { Neither agree nor disagree }}$

$4=\underline{\text { Somewhat aqree }}$

$5=\underline{\text { Strongly agree }}$

1. Being a male/female* is an important part of my identity.

2. Being a male/female is an important part of who I am.

3. Being a male/female is unimportant to my sense of what kind of person I am. ${ }^{\mathrm{R}}$

4. Overall, being a male/female has very little to do with how I feel about myself. ${ }^{R}$

5. Overall, I'm glad to be a male/female.

6. In general, other people respect males/females.

7. Most people consider males/females to be more ineffective than females/males. ${ }^{\mathrm{R}}$

8. Overall, males/females as a group are considered to be good by other people.

9. In general, people think that males/females as a group are unworthy. ${ }^{\mathrm{R}}$

10. I think of myself as having more in common with females/males than with males/females. ${ }^{R}$ 11. I think of myself as different than most other males/females. ${ }^{\mathrm{R}}$

12. Usually I identify with males/females more than females/males.

13. I think of myself as having more in common with males/females than with females/males. *Items are sex specific. Men and women will receive separate versions of the same items.

Scoring

$\mathrm{R}=$ reverse scored 
Appendix I

RAND 36-Item Health Survey

(Ware \& Sherbourne, 1992)

INSTRUCTIONS: Please complete the following questions.

1. In general, would you say your health is:

(1) Excellent, (2) Very good, (3) Good, (4) Fair, (5) Poor

2. Compared to one year ago, how would you rate your health in general now?

(1) Much better now than one year ago, (2) Somewhat better now than one year ago, (3) About the same, (4) Somewhat worse now than one year ago, (5) Much worse now than one year ago

The following items are about activities you might do during a typical day. Does your health now limit you in these activities? If so, how much? (Circle One Number on Each Line)

[1] Yes, Limited a Lot,

[2] Yes, Limited a Little

[3]No, Not limited at All

3. Vigorous activities, such as running, lifting heavy objects, participating in strenuous sports 4. Moderate activities, such as moving a table, pushing a vacuum cleaner, bowling, or playing golf

5. Lifting or carrying groceries

6. Climbing several flights of stairs

7. Climbing one flight of stairs

8. Bending, kneeling, or stooping

9. Walking more than a mile

10. Walking several blocks

11. Walking one block

12. Bathing or dressing yourself

During the past 4 weeks, have you had any of the following problems with your work or other regular daily activities as a result of your physical health? (Circle One Number on Each Line)

[1] Yes

[2] No

13. Cut down the amount of time you spent on work or other activities

14. Accomplished less than you would like

15. Were limited in the kind of work or other activities

16. Had difficulty performing the work or other activities (for example, it took extra effort)

During the past 4 weeks, have you had any of the following problems with your work or other regular daily activities as a result of any emotional problems (such as feeling depressed or anxious)?

[1] Yes

[2] No 


\section{MULTIDIMENSIONAL APPROACH TO GENDER AND HEALTH}

17. Cut down the amount of time you spent on work or other activities

18. Accomplished less than you would like

19. Didn't do work or other activities as carefully as usual

20. During the past 4 weeks, to what extent has your physical health or emotional problems interfered with your normal social activities with family, friends, neighbors, or groups? (Circle One Number)

[Not at all 1] [Slightly 2] [Moderately 3] [Quite a bit 4] [Extremely 5]

21. How much bodily pain have you had during the past 4 weeks? (Circle One Number) [None 1] [Very mild 2] [Mild 3] [Moderate 4] [5 Severe] [Very severe 6]

22. During the past 4 weeks, how much did pain interfere with your normal work (including both work outside the home and housework)? (Circle One Number)

[Not at all 1] [A little bit 2] [Moderately 3] [Quite a bit 4] [Extremely 5]

These questions are about how you feel and how things have been with you during the past 4 weeks. For each question, please give the one answer that comes closest to the way you have been feeling.

How much of the time during the past 4 weeks ...

[1] All of the Time

[2] Most of the Time

[3] A Good Bit of the Time

[4] Some of the Time

[5] A Little of the Time

[6]None of the Time

23. Did you feel full of pep?

24. Have you been a very nervous person?

25. Have you felt so down in the dumps that nothing could cheer you up?

26. Have you felt calm and peaceful?

27. Did you have a lot of energy?

28. Have you felt downhearted and blue?

29. Did you feel worn out?

30. Have you been a happy person?

31. Did you feel tired?

32. During the past 4 weeks, how much of the time has your physical health or emotional problems interfered with your social activities (like visiting with friends, relatives, etc.)? (Circle One Number)

[All of the time 1] [Most of the time 2] [Some of the time 3]

[A little of the time 4] [None of the time 5] 
How TRUE or FALSE is each of the following statements for you. (Circle One Number on Each Line)

$$
\begin{aligned}
& \text { [1] Definitely True [2] Mostly True [3] Don't Know } \\
& \text { [4] Mostly False [5] Definitely False }
\end{aligned}
$$

33. I seem to get sick a little easier than other people

34. I am as healthy as anybody I know

35. I expect my health to get worse

36. My health is excellent

\section{Scoring:}

Items Averaged for the following items:

Physical functioning: 3, 4. 5, 6, 7, 8, 9, 10, 11, 12

Role limitations due to physical health: 13, 14, 15, 16

Role limitations due to emotional problems: 17, 18, 19

Energy/fatigue: 23, 27, 29, 31

Emotional well-being: 24, 25, 26, 28, 30

Social functioning: 20, 32

Pain: 21, 22

General health: 1 33, 34, 35, 36

\section{Reliability (Alphas):}

Physical functioning $=.93$

Role limitations due to physical health $=.88$

Role limitations due to emotional problems $=.82$

Energy/Fatigue $=.87$

Emotional well-being $=.87$

Social functioning $=.79$

Pain $=.83$

General Health $=.85$ 
MULTIDIMENSIONAL APPROACH TO GENDER AND HEALTH

Appendix J

Social Support Survey

(Sherbourne \& Stewart, 1991)

INSTRUCTIONS: People sometimes look to others for companionship, assistance, or other types of support. How often is each of the following kinds of support available to you if you need it? Circle one number on each line.

\section{$1=$ none of the time \\ $2=$ a little of the time \\ $3=$ some of the time \\ $4=$ most of the time \\ $5=$ all of the time}

Emotional/informational support

1. Someone you can count on to listen to you when you need to talk.

2. Someone to give you information to help you understand a situation.

3. Someone to give you good advice about a crisis.

4. Someone to confide in or talk to about yourself or your problems.

5. Someone whose advice you really want.

6. Someone to share your most private worries and fears with.

7. Someone to turn to for suggestions about how to deal with a personal problem.

8. Someone who understands your problems.

Tangible support

9. Someone to help you if you were confined to bed.

10. Someone to take you to the doctor if you needed it.

11. Someone to prepare your meals if you were unable to do it yourself.

12. Someone to help with daily chores if you were sick.

Affectionate support

13. Someone who shows you love and affection.

14. Someone to love and make you feel wanted.

15. Someone who hugs you.

Positive social interaction

16. Someone to have a good time with.

17. Someone to get together with for relaxation.

18. Someone to do something enjoyable with.

Additional Item

19. Someone to do things with to help you get your mind off things. 
Appendix K

\section{Chronic Health Burden/Comorbidities}

(Katz et al., 1996)

Please answer the following questions according to health conditions that have been diagnosed by your physician.

If YES: To what extent does this health problem limit your daily activities?

a) Not at all

b) Some

c) A lot

\section{Myocardial infarction:}

1. Have you ever had a heart attack?

\section{Congestive heart failure:}

2. Have you ever been treated for heart failure? (You may have been short of breath and the doctor may have told you that you had fluid in your lungs or that your heart was not pumping well.)

\section{Peripheral vascular disease:}

3. Have you had an operation to unclog or bypass the arteries in your legs?

\section{Cerebrovascular accident:}

4. Have you had a stroke, cerebrovascular accident, blood clot or bleeding in the brain, or transient ischemic attack (TIA)?

\section{Hemiplegia:}

4a. Do you have difficulty moving an arm or leg as a result of the stroke or cerebrovascular accident?

\section{Chronic obstructive pulmonary disease:}

5. Do you have asthma? If yes, do you take medicines for your asthma?

a. No

b. Yes, only with flare-ups of my asthma

c. Yes, I take medicines regularly, even when I'm not having a flare-up.

6. Do you have emphysema, chronic bronchitis, or chronic obstructive lung disease? If yes, do you take medicines for your lung disease?

\section{Ulcer Disease:}

7. Do you have stomach ulcers, or peptic ulcer disease?

If yes, has this condition been diagnosed by endoscopy (where a doctor looks into your stomach through a scope) or an upper GI or barium swallow study (where you swallow chalky dye and then X-rays are taken)?

\section{Diabetes:}

8. Do you have diabetes (high blood sugar)?
a. No
b. Yes, treated by modifying my diet
c. Yes, treated by medications taken by mouth
d. Yes, treated by insulin injections

8a. Has the diabetes caused any of the following problems? 
a. Problems with your kidneys

Renal:

b. Problems with your eyes, treated by an ophthalmologist

9. Have you ever had the following problems with your kidneys?

a. Poor kidney function (blood tests show high creatinine)

b. Have used hemodialysis or peritoneal dialysis

c. Have received kidney transplantation

Connective tissue disease:

10. Do you have rheumatoid arthritis? Do you take medications for it regularly?

Do you have:

a. Lupus (systemic lupus erythematosus)

b. Polymalgia rheumatica

Dementia, liver disease, leukemia, lymphoma, tumor, metastases, AIDS:

11. Do you have any of the following conditions?

a. Alzheimer's Disease, or another form of dementia

b. Cirrhosis, or serious liver damage

c. Leukemia or polycythemia vera

d. Lymphoma

e. Cancer, other than skin cancer, leukemia or lymphoma? If yes, has the cancer spread, or metastasized to other parts of your body?

f. AIDS

Assigned Weights by Health Conditions

\begin{tabular}{|c|c|}
\hline Weight & Disease Condition \\
\hline \multirow{10}{*}{1} & Myocardial infarct \\
\hline & Congestive heart failure \\
\hline & Peripheral vascular disease \\
\hline & Cerebrovascular disease \\
\hline & Dementia \\
\hline & Chronic pulmonary disease \\
\hline & Connective tissue disease \\
\hline & Ulcer disease \\
\hline & Mild liver disease \\
\hline & Diabetes \\
\hline \multirow{7}{*}{2} & Hemiplegia \\
\hline & Moderate or severe renal disease \\
\hline & Diabetes with end organ damage \\
\hline & Any tumor \\
\hline & Leukemia \\
\hline & Lymphoma \\
\hline & Liver disease \\
\hline 3 & Moderate or severe liver disease \\
\hline \multirow{2}{*}{6} & Metastatic solid tumor \\
\hline & AIDS \\
\hline
\end{tabular}

Note. We did not distinguish between mild and serious liver disease, instead we assigned two points to patients who endorsed liver disease (Katz et al., 1996). 


\section{Appendix L}

\section{Domain-Specific Risk Behaviors}

\section{Instructions:}

(Blais \& Weber, 2006)

For each of the following statements, please indicate your likelihood of engaging in each activity or behavior. Provide a rating from 1 to 5, using the following scale:
unlikely
Unlikely
Not sure
45
Likely Very

1. Admitting that your tastes are different from those of a friend. (S)

2. Going camping in the wilderness. (R)

3. Betting a day's income at the horse races. (F)

4. Investing $10 \%$ of your annual income in a moderate growth mutual fund. (F)

5. Drinking heavily at a social function. (H/S)

6. Taking some questionable deductions on your income tax return. (E)

7. Disagreeing with an authority figure on a major issue. (S)

8. Betting a day's income at a high-stake poker game. (F)

9. Having an affair with a married man/woman. (E)

10. Passing off somebody else's work as your own. (E)

11. Going down a ski run that is beyond your ability. (R)

12. Investing 5\% of your annual income in a very speculative stock. (F)

13. Going whitewater rafting at high water in the spring. (R)

14. Betting a day's income on the outcome of a sporting event (F)

15. Engaging in unprotected sex. (H/S)

16. Revealing a friend's secret to someone else. (E)

17. Driving a car without wearing a seat belt. (H/S)

18. Investing $10 \%$ of your annual income in a new business venture. (F)

19. Taking a skydiving class. (R)

20. Riding a motorcycle without a helmet. (H/S)

21. Choosing a career that you truly enjoy over a more secure one. (S)

22. Speaking your mind about an unpopular issue in a meeting at work. (S)

23. Sunbathing without sunscreen. (H/S)

24. Bungee jumping off a tall bridge. (R)

25. Piloting a small plane. (R)

26. Walking home alone at night in an unsafe area of town. (H/S)

27. Moving to a city far away from your extended family. (S)

28. Starting a new career in your mid-thirties. (S)

29. Leaving your young children alone at home while running an errand. (E)

30. Not returning a wallet you found that contains \$200. (E)

Note E $=$ Ethical, $\mathrm{F}=$ Financial, $\mathbf{H} / \mathbf{S}=$ Health/Safety, $\mathrm{R}=$ Recreational, and $\mathrm{S}=$ Social . 